\title{
Die Beziehungen der Habsburger zum litauischen Hochadel im Zeitalter der Jagellonen.
}

\author{
Von \\ Oskar Ritter v. Halecki,
}

Zur Einführung.

Die österreichisch-polnischen Beziehungen haben leider noch keine Gesamtdarstellung gefunden, wie wir sie für die österreichisch-russischen — vorläufig bis 1605 - im grundlegenden Werke H. Uebersbergers: Österreich und Rußland seit dem Ende des 15. Jahrhunderts, I (Wien und Leipzig 1906), besitzen. Utd doch waren die letzteren, wenigstens in jener Zeit, stets nur eine Folge der ersteren, die daher auch für die damalige Geschichte Österreichs und seines Herrscherhauses eine unmittelbarere Bedeutung haben, was besonders bei Gelegenheit der ersten polnischen Interregna nach dem Aussterben der Jagellonen deutlich zu. Tage trat. Eröffnete sich doch hiebei jedesmal den österreichischen Habsburgern eine so viel versprechende Möglichkeit der Machterweiterung, dab sie sich im Falle eines erfolgreichen Ausganges ihrer Bestrebungen um den polnisch-litauischen Thron der Jagellonen nur mit der Erwerbung des böhmisch-ungarischen Erbes derselben Dynastie hätte vergleichen lassen. Dementsprechend hat auch in der reichen, vielsprachigen Literatur der drei ersten polnischen Königswahlen nach dem Tode Sigismund Augusts die habsburgische Kandidatur stets eine eingehende Berücksichtigung gefunden; um aber hiebei ihre Aussichten, ebenso wie die Ursachen ihres endgültigen Mißerfolges zu verstehen, ist es unumgänglich nötig, ihre Vorgeschichte im weitesten Sinne des Wortes zu 
erforschen, und zwar nicht so sehr das im allgemeinen schon ziemlich bekannte Verhältnis des Hauses Habsburg zur polnischen Dynastie, die ja nach ihrem Erlöschen nur mehr durch ihre Traditionen wirken konnte, als vielmehr seine Beziehungen zum Adel des verwaisten Königreiches, dem ja doch bei jedem Interregnum die entscheidende Rolle zutiel, zu seinen verschiedenen Parteien und Gruppen, wie auch zu den einzelnen führenden Geschlechtern. Und gerade zur Aufhellung dieser letzteren Beziehungen, die 1572 eine schon ungefähr hundertjährige Geschichte hatten, ist bisher noch sehr wenig geschehen.

Eines dieser Probleme zu lösen, ist die Aufgabe der folgenden Abhandlung. Es fällt nämlich besonders bei der Betrachtung der zwei ersten Interregna in oft überraschender Weise auf, wie einerseits gerade in der fernen litauischen Reichshälfte, unter den einflußreichsten Vertretern der mächtigen litauischen Adelsfamilien, die österreichische Partei am stärksten und zurerlässigsten schien, andererseits aber die Unterstützung von litauischer Seite, die für die Kandidatur des kaiserlichen Hauses eine sichere Grundlage zu bilden versprach, zu keinem Erfolge verhelfen konnte. Dies zı erklären, ist umso interessanter und notwendiger, als es mit der drei Jahre vor dem Aussterben der Jagellonen zu Lublin abgeschlossenen endgültigen polnisch-litauischen Union in einem unzweifelhaften, aber noch nicht erschöpfend untersuchten Zusammenhange steht. Die hiebei auftauchenden, bisher ungelösten Fragen zu beantworten, ist nur möglich, wenn man die Entstehung und Zusammensetzung jener habsburgischen Partei in Litauen im Lichte der schon viele Jahrzehnte zurückreichenden Beziehungen der betreffenden Maguatengeschlechter zum kaiserlichen Hause zu verstehen sucht. Mühsame Detailforschung auf bisher wenig bekanntem Gebiete, auf Grund teils ungedruckter, teils in den verschiedensten Publikationen verstreuter Quellen, muß ein genaues Bild dieser Beziehungen während der Jagellonenzeit liefern, bevor Litauens Rolle bei den darauffolgenden Königswahlen und diese Seite der österreichischen Politik richtig gewürdigt und beurteilt werden kann.

Neben dieser politischen hat aber das behandelte Thema auch eine gewisse kulturgeschichtliche Bedeutung. Es ist nämlich nicht uninteressant zu sehen, wie jenes in der Übergangszone zwischen der westeuropäischen und der osteuropäischen Welt gelegene Litauen, das am Ende des XIV. Jahrhunderts noch in letzter Stunde durch Polen für die erstere gewonnen wurde, kaum seiner heidnischen Frühzeit entwachsen, in den Personen seiner vornehmsten Vertreter mit dem traditionellen Zentrum der westeuropäischen Staatengruppe, dem kaiserlichen 
Hofe, in unmittelbare Verbindung tritt. Das anziehende kulturelle Problem in der Geschichte der polnisch-litauischen Union erfährt hiedurch, wenn auch nur in einer Einzelfrage, eine genauere Würdigung.

\section{Die Vorbereitungszeit; bis zur Mitte des XVI. Jahr- hunderts.}

Als der berühmte Freiherr von Herberstein auf seinen beiden Gesandtschaftsreisen nach Moskau nicht nur Polen, sondern auch ganz Litauen durchquerte ${ }^{1}$, , schien ihm, im Gegensatze zum wohlbekannten Polen, das Stammland der Jagellonen, in nicht minderem Maße als das moskowitische Reich, eine ,terra incognita" zu sein, die dem gebildeten Westeuropäer erst näher geschildert werden mußte, so daß er in seinem epochemachenden Reisewerke über Moskau der benachbarten "Lithuania" ein besonderes Kapitel widmete ${ }^{2}$ ). Waren doch in früherer Zeit die dieses Land betreffenden Kenntnisse des Westens so unzulänglich, daß selbst ein Aeneas Sylvins ${ }^{3}$ ) kaum mehr darüber wußte, als daß sich dort, in bitter kaltem Klima, weite, nur spärlich besiedelte Wälder und Sümpfe ausdehnten, und mit Ausnahme der Nachrichten, die ihm Meister Hieronymus von Prag über seine apostolische Tätigkeit unter den dortigen Heiden mitgeteilt hatte, mehr Dichtung als Wahrheit über Litauen verbreitete.

Und doch war es gerade der habsburgische Hof, der sich früher als irgend ein anderer im mittleren Europa mit jenem fernen litauischen Reiche unmittelbar beschäftigen mußte. Noch kurz vorher hatten Mitglieder des österreichischen Hauses, dem Beispiele aller vornehmen Geschlechter des christlichen Europa folgend, an den ständigen Kriegszügen des Deutschen Ordens gegen das heidnische Litauen teilgenommen, als eines von ihnen, Herzog Wilhelm der Schöne, auf geradezu demütigende Art die sichere Aussicht auf den polnischen Thron einbüßte (1385)4),

1) AuBer auf seinen beiden Reisen nach Moskau 1517 und 1526 war Herberstein auch noch 1529 und 1540 als österreichischer Gesandter bei König Sigismund I. in Litauen; vgl. seine Selbstbiographie in Fontes rer. austr. Ss. I. 286/7, $325 / 6$.

^) Rerum Moscoviticarum commentarii, Basileae 1551, pag. 109-117: „De Lithuania .

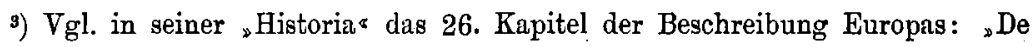
Lituania ", herausg. z. B. Ss. rer. Pruss. IV 237/9; hierüber in der neuesten polnischen Literatur J. Fijałek: Uchrześcijanienie Litwy przez Polskę, Krak6w 1914, S. 11-15.

S. $124 / 7$.

4) Eine kritische Analyse der Quellen bei S. Smolka: Rok 1386, 2. Aut. 
um den litauischen Großfürsten Jagiełło beide Nachbarreiche in seiner Hand vereinigen zu sehen. Allerdings ist dieses für die weitere Geschichte Osteuropas entscheidende Ereignis in der Folgezeit für die gegenseitigen Beziehungen beider Herrscherhäuser obne Bedeutung geblieben; die begreifliche anfängliche Verstimmung wurde ja schon wenige Jahre nach Wilhelms Tode durch die verwandtschaftliche und diplomatische Annäherung seiner Brüder, der jüngeren Leopoldiner, an den neuen Herrscher Polens und Litauens beseitigt $\left.{ }^{1}\right)$. Und zur Zeit seines Sohnes und Nachfolgers, König Wladislaw's IIl., schien gerade die damalige Sonderstellung Litauens im jagellonischen Doppelstaate dem Haupte des Hauses Habsburg, König Albrecht II., eine günstige Gelegenheit zu bieten, um Polen bei der Rivalität um die böhmische Krone in Schach zu halten. Bekanntlich ${ }^{2}$ ) sollte dies durch ein Bündnis Albrechts mit dem dem polnischen Könige lehenspflichtigen litauischen Großfürsten Sigismund, einem Sohne des berühmten Kiejstut, geschehen. Von den verschiedenen Umständen, die das Zustandekommen des Vertrages verhinderten, ist für uns eine von besonderem Interesse, daß sich nämlich unter dem Adel des Großfürstentums zwei Parteien bildeten, von denen nur eine die separatistische Politik Sigismunds begünstigte, während die andere zu Polen hielt ${ }^{3}$ ). Es zeigte sich eben schon damals, daß die litauischen Bojaren, die vor der Union mit Polen sich unbedingt der großfürstlichen Gewalt beugen mußten, allmählich auch in der äußeren Politik ihren Einfluß geltend machen konnten, wozu die kurz vorher das Land zerrüttenden inneren Wirren nicht wenig beigetragen hatten. Da ferner im weiteren Verlaufe der Jagellonenzeit Litauen nur mehr vorübergehend, innmer nur durch wenige Jahre (1440 -1447, 1492-1501, 1544_1548), einen eigenen Herrscher batte, der übrigens, so verschieden auch jedesmal seine staatsrechtliche Stellung war, immer der gemeinsamen Dynastie entstammte und bald auch den polnischen Thron bestieg, so ist es einleuchtend, daß wenn von den Beziehungen Österreichs zur litauischen Reichshälfte gesondert die Rede sein soll, nur die zu ihren politisch bedeutenden Adelsgeschlechtern in Frage kommen können.

1) Über diese Annäherung 1411/2 und ihre Bedeutung vgl. z. B. A. Prochaska: Król Władysław Jagiełło, Kraków 1908, I 333, sowie L. Bąkowski im Warschauer Przegląd histor. 1913, XVI S. 10.

2) Hierüber A. Lewicki: Przymierze Zygmunta w. ks. lit. z królem rzymskim Albrechtem, im 37. Bande der histor. Abhandlungen der Krakauer Akademie der Wissensch.

8) Vgl. daselbst Beilage VIII, Bericht an den Hochmeister vom 22. November 1439. 
Die Adelsklasse des hochbegabten litauischen Volkes hatte sich durch die Vereinigung mit Polen sowohl rechtlich wie auch kulturell durch eine fortschreitende Rezeption polnischer Einrichtungen und Einflüsse ungemein rasch entwickelt ${ }^{1}$ ). Soziale, wirtschaftliche und politische Rechte, um die der Adel in anderen Ländern durch lange historische Perioden hindurch mit der Herrschergewalt rang, fielen ihm hier auf einer viel früheren Entwicklungsstufe fast mühelos in den SchoB, in einer langen Reihe von Privilegien zusammengefaßt (1387, 1413, 1434, 1447, 1492 u. s. w.), die Schritt für Schritt die Grundsätze der freiheitlichen polnischen Verfassung auch auf die andere Reichshälfte übertrugen. Zugleich nahmen die höheren Stände Litauens, nachdem sie sich vorher immer mehr dem Einflusse der reußisch-byzantinischen Kultur hingegeben hatten, unter dem Einflusse Polens nicht minder rasch die lateinische Kultur des katholischen Abendlandes an. Ja überraschend bald empfanden sie das Bedürfnis, zu dieser neuen Kulturwelt, deren Wirkungssphäre mit dem Lichte des katholischen Glaubens in Litauens Wälder gedrungen war, in unmittelbare Beziehung zu treten. Die Unternehmendsten unter den litauischen Herren begnügten sich nicht damit, zusammen mit den polnischen bei diplomatischen Unterhandlungen oder z. B. auf dem Konzil zu Konstanz den Vertretern der verschiedensten europäischen Staaten zu begegnen, sondern begannen auf weiten Reisen jene Länder, ihre Fürstenböfe, ja sogar ihre Universitäten 2), selbst aufzusuchen.

Es handelte sich hiebei nicht bloß um Einzelfälle, wie etwa jenen Georg Butrym, der sich schon am Anfange des XV. Jabrhunderts durch langjährigen Aufenthalt in verschiedenen "katholischen Reichen" seine geistvolle Bildung erwarb ${ }^{\text {s) }}$ und vielleicht an der Entstehung der charakteristischen Sagen vom vornehmen römischen Ursprunge der Litauer und ihrer Adelsgeschlechter beteiligt war ${ }^{4}$ ). Es mußte dies vielmehr eine häufige Erscheinung sein, wenn sogar das Reichsprivileg von 1447 die Bestimmung enthielt, daß alle litauischen Fürsten und Edelleute das Recht haben, sich in fremde Länder zu begeben, um dort ihr Glück zu machen oder sich in der Kriegskunst auszubilden, wenn es nur

1) Näher besprochen im Zusammenhange mit Litauens verfassungsgesch. Entwicklung bei S. Kutrzeba: Historya ustroju Polski II Litwa, Iwów 1914, S. 33 u. a.

2) Schon 1409 studiert z. B, ein "Gregorius de Litwania“ an der Universität Leipzig (Metrica ... nationis Polon. univers. Lipsiensis, im Archiwum do dziejów. dit. $\mathrm{i}$ oświaty w Polsce II).

3) Joh. Dlugossii Hist. Pol. IV 482 (1432).

4) A. Brückner: Starożytna Litwa, Warszawa 1904, S. 64/5. 
keine ihrem Vaterlande feindliche Staaten waren 1 ). Das bekannteste. Beispiel eines solchen litauischen Magnaten, der, wie es ausdrücklich in den Quellen heißt, um das Ausland mit seinen fremden Bräuchen und Einrichtungen kennen zu lernen, die Welt durchwanderte, ist der Hofedelmann König Kasimirs des Jagellonen Alexander Soltan, der in den Jahren 1467 bis 1469 ganz Westeuropa und das Heilige Land bereiste und bei Kaiser und Papst, sowie an den Höfen von Sizilien, Mailand, Kastilien, Portugal, Burgund und England gleich ehrenvoll empfangen, als Ritter des Goldenen Vließjes und Kämmerer Karls des Kühnen heimkehrte ${ }^{2}$ ). Es ist hiebei besonders bemerkenswert, daß dieser später recht bedeutende Würdenträger und Diplomat des Großfürstentums keineswegs einer ethnographisch litauischen, unmittelbar vom Heidentum zum römischen Katholizismus bekehrten Familie entstammte, sondern ruthenischer Herkunft war und, wenn auch Anhänger der religiösen Union mit Rom, der griechischen Kirche angehörte, was deutlich beweist, wie die abendländische Kultur auch auf die Oberschicht der ruthenischen Bevölkerung des Großfürstentumes überzugreifen begann, was wir im Folgenden noch oft bestätigt finden werden.

Es war kein Zufall und nicht allein durch die geographische Lage bedingt, daß dieser „splendidus dominus e Lithuania“, wie ihn Galeazzo Maria Sforza nennt, seine Europareise am habsburgischen Hofe, bei Kaiser Friedrich III. begann, der ihn dann auch an die übrigen Herrscher weiterempfahl. Neben dem traditionellen Nimbus, der gerade in fernen Landen das weltliche Oberhaupt der Christenheit umgab, war gewiß auch der Umstand dafür entscheidend, daß Friedrich III. nicht nur mit Kasimir dem Jagellonen noch vor dessen Erhebung auf den polnischen Thron, als Großfürsten von Litauen, in diplomatischem Verkehr gestanden war ${ }^{3}$ ), sondern ihm auch Elisabeth, König Albrechts II. Tochter, zur Frau gegeben hatte. Schon auf der Zusammenkunft zu Breslau im August 1453, wo diese Ehe endgültig festgesetzt wurde, waren außer den polnischen Vertretern König Kasimirs auch zwei litauische Herren, der einflußreiche Starost von Polock Andreas Sakowicz und Johann Niemirowicz, anwesend gewesen ${ }^{4}$ ), und als erste Habsburgerin, die sich mit einem Jagellonen verband, war Königin Elisabeth auch

1) Codex epistol. saeculi XV, Band III nr. $7 \S 5$; vgl. auch hiezu bei J. Jakubowski: Studya nad stosunkami narodow. na Litwie, Warsz. 1912, S. 32.

2) Vgl. seine interessante, auf ungedruckte Urkunden gestützte Biographie von Ad. Sołtan in der Zeitschrift Litwa i Ruś 1913, Heft 10/2.

s) Codex epistol. saeculi XV, Band I/2 nr. 9.

4) Długosz, V 147; Dogiel: Codex dipl. Regni Poloniae, I S. 155, 157. 
die erste ihres Hauses, die sich in Begleitung ihres Gemahls öfter in Litauen aufhielt. Nichts Näheres wissen wir leider von ihrem Verhältnisse zu ibren dortigen Untertanen und es wäre höchstens zu erwähnen, dab, als 1475 eine von ihren nach Deutschland beiratenden Töchtern, Prinzessin Hedwig, nach Landshut reiste, um Herzog Georg yon Bayern zu ehelichen, auch einer der vornehmsten litauischen Magnaten, Adalbert Moniwidowicz, sie begleitete ${ }^{1}$ ). Im allgemeinen hatte natürlich Kasimir nur als König von Polen unmittelbare Beziehungen zum kaiserlichen Oheim seiner Gattin, einmal aber wenigstens wandte sich dieser auch als litauischen Herrscher an ihn, als er ihn nämlich im Aprił 1481 aufforderte ${ }^{2}$ ), dem mit Litanen benachbarten Ordensmeister in Livland gegen die "Reußen " und anderen Ungläubigen, als gemeinsame Feinde der Christenheit, Hilfe zu leisten; da aber schon damals, besonders wegen der durch die Personalunion mit Polen bedingten öfteren Abwesenheit des Landesherren, in Litauen der großfürstliche Rat einen immer größeren Einfluß gewann, ja manchmal so gut wie selbständig diplomatische Verhandlungen führte, richtete Friedrich III. gleichzeitig auch ein gleichlautendes Schreiben „an prelaten, ritterschafft und reten des Großfurstentumbs zu Litthaw“, das gleichsam das älteste Denkmal politischer Beziehungen der Habsburger zum dortigen Adel bildet.

Von größerer Bedeutung konnten diese aber erst dann werden, als. litauische Magnaten nicht nur vorübergehend, z. B. auf einer Reise, sondern für längere Zeit den Hof des österreichischen Herrscherhauses aufzusuchen begannen, indem sie zeitweise in seine Dienste traten, wie dies schon zur Zeit Maximilians I. mehr als einmal geschah. Einer der ersten und zugleich bedeutendsten unter ihnen war der berühmite Fürst. Michael Gliński, „Pan Michael“, wie ihn die Deutschen nannten, die sich in böhmischer Sprache mit ihm verständigten ${ }^{3}$ ). Obwohl er seiner Abstammung nach, als Sproß eines ursprünglich tatariscben Geschlechtes der westlichen Kultur besonders fern zu stehen schien, war er doch durch langjäbrigen Aufenthalt in Italien, wo er studierte und den katholischen Glauben annahm, und in Deutschland von ihrem Einflusse stark durchdrungen worden; er hielt sich, eifrig Kriegsdienste leistend, während seiner Wanderjahre bei verschiedenen Fürsten auf, - so nahm er 1498 unter Herzog Albrecht von Sachsen an dessen Kämpfen in Friesland teil -, und war auch in Hofdienste Kaiser Maximilians ge-

1) Ibidem, V 634; über das Autsehen, das er durch seine Tracht erregte, vgl. F. Papée: Studya i szkice, S. $291,295$.

2) Haus-, Hof- und Staatsarchiv zu Wien, Russica, fasc. 1 a.

s) Herberstein : Rerum Moscov. commentarii, S. 112/4 ein längerer Abschnitt: über Gliński. 
standen: unterschreibt er sich doch noch 1509 in dem interessanten Briefe, den er aus Moskau an den Kaiser sandte ${ }^{1}$, als dessen „humilis familiaris". Bekanntlich war nämlich Fürst Gliński, nachdem er nach längeren Fehden mit einer ihm feindlichen Partei in Litauen daselbst einen Aufstand entfesselt hatte, zum gefährlichsten Feinde dieses Landes, dem Großfürsten von Moskau übergegangen, dem er in den darauffolgenden Kämpfen seinen Einfluß und seine Kriegskunst zur Verfügung stellte. Wenn er sich auch im moskowitischen Reiche, das zu dem Westen, wo er aufgewachsen war, in so vollkommenem Gegensatze stand, nicht heimisch fühlen konnte und daher eben in dem erwähnten Schreiben den Kaiser bat, ihm bei König Sigismund I. von Polen eine vollkommene Amnestie zu erwirken, waren doch gerade seine Beziehungen zu Maximilian für seinen neuen Herren von besonderer Bedeutung, indem sie bei der österreichisch-moskauischen Annäherung in den Jahren 1508 bis 1514, als der Kaiser durch Erneuerung des schon von seinem Vorgänger abgeschlossenen Bündnisses mit Moskau die Jagellonen in. Schach zu halten suchte, eine nicht unwichtige Rolle spielten ${ }^{2}$ ). So wurde Litauen, das an dem habsburgisch-jagellonischen Gegensatze im Westen naturgemäß unbeteiligt war, in den Folgen dennoch gefährlich davon betroffen und ist es daher begreiflich, daß, wie wir gleich sehen werden, auch seine Vertreter an jenen Verhandlungen beteiligt waren, die 1515 einen vollständigen politischen Umschwung brachten.

So kommt es, daß der Wiener Kongreß dieses bedeutungsvollen Jahres auch für die Verbindungen der Habsburger mit Litauens hervorragenden Magnaten von besonderer Wichtigkeit wurde, und zwar vor allem auch deshalb, weil sie damals zum ersten Male mit jenem litauischen Geschlechte in Verbindung traten, das ihnen von nun an immer am nächsten stand und später so oft an der Spitze der österreichischen Partei seines Heimatlandes erschien, nämlich mit den Radziwiłł.

Wenn auch einer der Rivalen dieser Familie, den wir noch näher kennen lernen werden, in starker Übertreibung auf die bescheidenen Anfänge der Radziwiłł vor hundert Jahren hinwies und nicht ohne

1) Veröffentl. bei L. Finkel : Elekcya Zygmunta I, Kraków 1910, Beilage VII. Vgl. daselbst über Gliński S. $90 \mathrm{ff}$.

2) Ibidem, S. 229, 230, 232; vgl. auch Uẻbersberger: Österreich und Rußland, I $71 \mathrm{ff}$., 128/9. Als Gliński 1514 entgültig von Mloskau abfallen wollte, wurde er bekanntlich ins Gefängnis geworfen, aus dem ihn Maximilian I. vergeblich durch Herberstein zu befreien suchte, indem er ihn eventuell zu seinem Enkel Karl zu :senden versprach. 
Unrecht behaupten konnte, daß erst ihre Verschwägerung mit den Herzogen ron Masowien (1496/97) und die ungemein freigebigen Güterverleihungen (angeblich im Werte von 100.000 Dukaten), die sie ron König Sigismund I. erhielten, die Grundlage zu ihrer Macht und ibrem Ansehen gelegt hatten ${ }^{1}$, so ist es doch unzweifelhaft, daß sie schon seit mehreren Generationen zu den ersten Geschlechtern Litauens gehörten. Schon der Großvater der zu Sigismunds Zeit auftretenden Geschwister wurde einst von wohl unterrichteter Seite als Kandidat für die großfürstliche Würde genannt 2) und das nunmehrige Oberhaupt der Familie, Nikolaus Radziwiłł, war schon seit 1510, ebenso wie einst sein Vater, Palatin von Wilna und Großkanzler, somit der höchste weltliche Würdenträger des Reiches. Daher ist es begreiflich, daß gerade er an der Spitze jener zahlreichen Litauer erschien, die neben den Polen und den Vertretern des polnischen Preußens König Sigismund im März 1515 nach PreBburg und hierauf nach Wien begleiteten ${ }^{3}$ ).

Wie schon mit Recht hervorgehoben wurde ${ }^{4}$ ), sind die Einzelheiten der dortigen Verhandlungen nur wenig bekannt, da die meisten gleichzeitigen Schilderungen hauptsächlich nur von den imposanten Äußerlichkeiten des Kongresses, die offiziellen Urkunden nur von den Endergebnissen berichten. Von Radziwiłl, der als Vertreter Litauens jedenfalls die Aufgabe hatte, den Anschluß Österreichs an Moskau rückgängig zu machen und Maximilians Beziehungen zum moskauischen Großfürsten in einem für die Jagellonen und vor allem für Litauen günstigen Sinne zu beeinflussen, wissen wir leider nur so viel, daß er schon anfangs, am 2. April, beim Beginne der engeren Verhandlungen der Könige von Polen und Ungarn mit dem Kardinal von Gurk, dem Vertreter Österreichs, den acht Beiräten Sigismunds zugezählt wurde und

1) Acta Tomician?, VII/2 nr. 36, S. 259. Trotz der großen histor. Bedeutung der Radziwiłł gibt es über sie noch keine größere Familiengeschichte auf wissenschaftl. Busis; E. Kotlubaj's Galerja Nieświeżska portretów Radziw., Wilno 1857, bringt manche Nachricht aus dem Familienarchiv, ist aber nur mit größter Vorsicht zu benützen und für die ältere Zeit sehr mangelhaft. Zur Genealogie vgl. die Artikel in Żychliński's Złota księga XI, und Boniecki's Poczet rodów W, Ks. lit.

2) Lir-, Est- und Kurländ. Urkundenbuch XI nr. 296 (1453).

9) Seine Anwesenheit ist außer in den unten zitierten Quellen auch bei Bartholinus (Hodoeporicon Mathiae Gurcensis Episcopi, Freher: Rerum Germ. Ss. IF 655), Gorski (Acta Tomiciana, III nr. 433 S. 310, vgl. auch nr. 512) und Decius (De Sigismundi Regis temporibus, Bibl. pisarzów polskich Nr. 39, S. 98) erwähnt.

4) Vgl. X. Liske: Der Kongreß zu Wien i. J. 1515 (Forschungen zur deutschen Gesch. VII; polnische Neuauflage in Studya z dziejów wieku XVI). Zur Ergänzung können die von ihm 1878 in Ss. rerum Polon. IV publizierten zwei neuen Diarien. des Kongresses dienen. 
mit den polnischen Kanzlern Szydłowiecki und Tomicki die wichtigste Rolle unter ihnen spielte ${ }^{1}$ ). Hiebei scheint er nicht nur, wie ja die Ergebnisse des Kongresses beweisen, seine Aufgabe erfüllt, sondern auch überhaupt zum Erfolge der Unterhandlungen beigetragen zu haben, da er sich, wie wir sehen werden, in hervorragendem Maße die Gunst des Kaisers erwarb. Auf die Augenzeugen, auf Maximilians deutsches und italienisehes Gefolge und die Wiener Bevölkerung, denen die Litauer gröBtenteils als ein unbekanntes Barbarenvolk galten, machte aber vor allem Radziwitł's prunkvolles Auftreten, die Gefangenen aus den letzten Kämpfen mit den Tataren und Moskau, die er dem Kaiser übergab, einen mächtigen Eindruck und ganz besonders erstaunt war man über die 100 kunstfertigen Musikanten, die er und ein zweiter litauischer Magnat, Stanislaus Gasztołd, mitgebracht batten und die beim Gottesdienste selbst dem Kaiser vorspielten ${ }^{2}$ ).

Es ist selbstverständlich, daß Maximilian beim Abschiede die vornehmsten Räte seiner königlichen Gäste zum Danke für ibre erfolgreichen Benühungen reich beschenkte, was uns auch übereinstimmend alle Beschreibungen des Kongresses berichten. Aber Geschenke allein, die überdies die stets geldbedürftige kaiserliche Kasse stark in Anspruch nahmen, konnten kaum den Zweck erfüllen, jene ohnehin reichen und vor allem ehrgeizigen Herren dauernd für das Haus Habsburg zu gewinnen. Dies zu erreichen, faßte Maximilian einen andern Plan, der anch mit seiner hohen Auffassung der kaiserlichen Würde wohl übereinstimmte: er beschloß die herrorragendsten der mit Sigismund erschienenen Magnaten kraft seiner kaiserlichen Machtvolikommenheit zu Reichsfürsten, beziehungsweise Reichsgrafen zu machen, wobei für den Fürstentitel neben dem polnischen Großkanzler Szydłowiecki auch sein litauischer Amtskollege Radziwiłł ausersehen war; hatte er doch, wie es drei Jahre später im Fürstendiplome ausdrücklich hervorgehoben wurde, auf dem Kongresse seine edle Gesinnung und Klugheit deutlich bewiesen, sich große Verdienste um die gesamte "res publica Christiana" erworben und den Kaiser außerordentlich für sich eingenommen ${ }^{3}$ ).

1) Ss. rer. Polon. IV 116; im „Diarium de congressu Maximiliani“ etc. Cuspinian's (Freher: Rerum Germ. Ss. II 598) sind nur Tomicki, Szydłowiecki und Radziwiłł hiebei genannt, in dessen Tagebuche (ed. H. Ankwicz in den Mitteilungen des Instit. XXX 313) findet sich 2./IV nur die Eintragung: "factum principium tractatus cum duobus regibus" ohne Angabe weiterer Namen.

2) M. Stryjkowski: Kronika litewska, Buch 24, 3. Kapitel; vgl. auch A. W. Kojałowicz: Compendium (Herold polski 1897, s. 196/7).

9) Das Diplom von 1518 (wie alle folgenden) nach dem Original im Radziw. Archiv zu Nieśwież publiziert bei K. Eichhorn: Das Verhältnis des hochfürstl. Radziwill'schen Hauses zu den Fürstenhäusern Deutschlands, o. J. (verbesserte poln. UUbersetzung, Warsz. 1843), Beilage I. 
Diese anscheinend so verlockenden Standeserhöhungen begegneten aber unvermuteten Schwierigkeiten. Als des Kaisers Absicht bekannt wurde, versammelten sich die polnisch-litauischen Herren und beschlossen, die ihnen zugedachte Auszeichnung dankend abzulehnen, um - wie sie sagten - keine Neuerungen einzuführen, die mit dem bestehenden Rechte und der Gleichheit innerhalb des Adelsstandes in Widerspruch stünden ${ }^{1}$ ). Diese Antwort ist leicht zu verstehen, wenn man bedenkt, da $B$ es in Polen bekanntlich keine einheimischen Fürsten- und Grafentitel gab, sondern der gesamte Adel, dessen rechtliche Gleichheit schon damals als Dogma galt, in große Wappenstämme zerfiel, deren jeder sowohl reiche Magnatengeschlechter, wie auch ganz unbedeutende, unwermögende Familien zu seinen agnatischen Mitgliedern zählte; und wenn auch in der litauischen Reichshälfte zahlreiche einheimische Fürstengeschlechter blühten, so waren dies eben wirkliche Dynastensprossen, größtenteils Nachkommen Gedymins und Ruryk's, in deren Kreis keine Standeserhöhung Einlaß gewähren konnte. Umso bedenkJicher, nicht nur in sozialer sondern auch in politischer Beziehung, mußten erst solche Verleihungen von seiten eines fremden Staates, wie des hl. römischen Reiches erscheinen, da sie einen solchen Reichsfürsten in eine gewisse Abhängigkeit vom Kaiser bringen mußten, so sehr dieser auch in solchen Diplomen betonte, daß sie den Hoheitsrechten des polnischen Königs in keinerlei Weise präjudizieren sollten. Andererseits aber schienen diese ausländischen Titel und Würden, deren Annahme später sogar gesetzlich verboten werden mußte, einzelnen ehrgeizigen Magnaten außerordentlich begehrenswert und daher meinten es auch 1515 nicht alle ganz ernst und ehrlich mit ihrer solidarischen Ablehnung, wenn sie auch momentan dem Drucke der öffentlichen Meinung nachgaben.

$\mathrm{Zu}$ diesen letzteren, die trotz des offiziellen Beschlusses dennoch durch private Bemühungen den ihnen in Aussicht gestellten Titel .zu erhalten suchten ${ }^{2}$ ), gehörte auch Nikolaus Radziwiłł, was insofern

1) Vgl. die Schilderung im Briefe über die fremden Adelstitel in Polen, den - der Urenkel eines der 1515 die Standeserhöhung zurückweisenden Magnaten (Nic. Firlej) an seinen Sohn schrieb, bei J. Niemcewicz: Zbiór pamiętników, IV $115 \mathrm{ff}$. (auch von Driałyriski in den "adnotationes“ zum "Liber geneseos ill. familiae Schidloviciae": herausgegeben).

2) Z. B. der Kronkanzler Szydłowiecki; öffentlich lehnte er zwar den Fürstentitel $a b$ und nahm nur eine Wappenvermehrung an, die ihm ohnehin genug spöttische Kritik eintrug (vgl. die Spottverse Krzycki's bei X. Liske: Studya z dziejów w. XVI, S. 160/1 Anm, 16); beim Abschiede, am 2. August zu WienerNeustadt, erhielt er aber dennoch vom Kaiser ein Diplom, in dem ihm für seine großen Verdienste während der Verhandlungen des Kongresses neben dieser Wappen- 
begreiflich war, als damals schon längst die litauischen Herrengeschlechter, darunter auch seine Famjlie, tatsächlich weit mächtiger waren als die alten Fürstenhäuser ${ }^{1}$ ) und ihnen nun auch äußerlich nicht nachstehen wollten. Nachweisbar ${ }^{2}$ ) begann der Palatin ron Wilna seine Schritte gleich nach dem Wiener Kongresse, welcher Mittel er sich aber hiezu bediente und wie er schließlich das scheinbar verschmähte Fürstendiplon vom Kaiser erhielt, kann man dann erst recht verstehen, wenn man sich vorher darüber klar wird, wie gerade die Litauen betreffenden Ergebnisse des Kongresses weitere Beziehungen seiner einflußreichen Magnaten zu Maximilian I. hervorrufen mußten.

Die Verpflichtung des Kaisers, den Großfürsten von Moskau niemals mehr im Kampfe gegen Sigismund I. zu unterstützen, ließ sich nämlich, wie schon treffend betont wurde ${ }^{3}$ ), nur dann mit dem jm Vorjahre mit Moskau geschlossenen Bündnisse vereinbaren, wenn es ihm gelang, zwischen den beiden Gegnern einen Frieden zu vermitteln, der auch seinen Lieblingsplan, den gemeinsamen Kampf der Christenheit. gegen die Türken, einer Verwirklichung näher zu bringen schien. Da nun der moskauische Krieg, wenn auch fast immer polnische Hilfstruppen daran teilnahmen, damals ror allem eine Litauen betreffende Angelegenheit war, so war es selbstverständlich, daß die diplomatische Intervention des Kaisers nicht ohne Verständigung mit den unmittelbar daran interessierten, sachkundigen litauischen Magnaten möglich war. Zu diesem Behufe wurde daher noch im Sommer 1515 den am kaiserlichen Hofe zurückbleibenden Vertretern Sigismunds ein im diplomatischen Verkehre mit Moskau oft verwendeter litauischer Würdenträger, der einem alten wolhynischen Adelsgeschlechte entstammende großfürstliche Marschall und Reichssekretär Michael Bohusz Bohowitynowicz beigegeben ${ }^{4}$ ). Fr kehrte zwar noch im selben Jahre zu seinem Könige zurück, da Maximilian und der von ihm nach Moskau entsendete Pantaleon von Thurn sich durch ihn mit Sigismund über die bevorstehen.

besserung und der Rotwachsfreiheit auch wenigstens der Reichsfrei- und Bannerherrnstand verliehen wurde (das von St. Krzyżanowski im Breslauer Staatsarchiv entdeckte Dokument veröffentlichte J. Kieszkowski: Kanclerz Krzysztof Szydłowiecki, Poznań 1912, Beilage II; siehe dort auch S. 200/1, 206). Im "Liber geneseos ill. familiae Schidloviciae“ v. J. 1531 (ed Działyński 1848) heißt es irrtümlich, daß er vom Kaiser den Grafenstand erhalten habe.

1) Vgl. die statistische Zusammenstellung bei L. Kolankowski: Zygmunt August, w. ks. Litwy, do r. 1548, Lwów 1913, S. 205-211.

2) Acta Tomiciana XI nr. 250.

s) H. Uebersberger, o. c., S. $97 / 8$.

4) Acta Tomiciana III nr. 559 . 
den Verhandlungen verständigen wollten ${ }^{1}$ ), scheint aber doch selbst in dieser kurzen Zeit mit dem kaiserlichen Hofe auch persönlich in nähere Beziehung getreten zu sein: wir hören nämlich, daß sein jüngerer Bruder Johann in den Dienst Maximilians trat, der ihn dann, ebenso wie später Ferdinand I. ${ }^{2}$ ), seinem heimatlichen Herrscher so warm empfahl, daß er mit Rücksicht darauf nach seiner Rückkehr nach Litauen feierlich zum Ritter geschlagen wurde ${ }^{3}$ ). Bohusz selbst aber sollte bald wieder mit der östereichischen Politik in Berührung kommen.

Es geschah dies zunächst anläßlich der ersten Gesandtschaftsreise Herbersteins nach Moskau im Jahre 1517, die ja ebenfalls, allerdings ganz ergebnislos, einen Frieden mit Litauen vermitteln sollte. Für uns ist hiebei nicht nur der Umstand interessant, daß damals zum ersten Male Österreichs und Litauens Vertreter gemeinsam in Moskau verhandelten, da sich Sigismund I. nach einigen Monaten entschloß, eben jenen Bohusz Bohowitynowicz, sowie einen zweiten Litauer Johann Szczyt dahin zu senden ${ }^{4}$ ), sondern auch der Aufenthalt Herbersteins in Litauen selbst, auf der Hin- und Rückreise, der ihm Gelegenheit gab, den dortigen Herren unmittelbar näher za treten. Schon als er im März 1517 zum ersten Male nach Wilna kam, nahmen ihn diese durch einen liebenswürdigen, ehrenvollen Empfang außerordentlich für sich ein 5), was ihn allerdings nicht hinderte, den selbstsüchtigen Eigenwillen jenes Hochadels, der ihm seine übermäßige Freiheit nur zu mißbrauchen schien, und seine schädlichen Folgen für das Staatsleben wohl zu erkennen $\left.{ }^{6}\right)$. Umso mehr mußte er es allerdings für nötig halten, diese so einflußreichen Herren zu gewinnen, und begreiflicherweise waren es die Radziwiłł, deren Beziehungen zum Kaiser er aufzufrischen suchte und die ihrerseits, gewiß im Zusammenhange mit ihren Bestrebungen um das erwähnte Fürstendiplom, dem kaiserlichen Gesandten aufs herzlichste entgegenkamen. Für den Maximilian schon vom Wiener Kongresse her bekannten Palatin von Wilna Nikolaus hatte Herberstein ein kaiserliches Schreiben mitgebracht, das er ihm schon auf der Hinreise übergab, besuchte ihn aber auf dem Heimwege nochmals auf seinem Statthaltersitze in Bielsk und erhielt von ihm beim

1) Acta Tomiciana, III nr. 591, 592, 601; vgl. bei Uebersberger, S. 99, 101.

2) Acta Tomiciana XI nr. 261 (1529).

3) Vgl. die Urkunde Sigismund Augusts vom 30. August 1541 in der kais. Bibliothek zu Petersburg (Coll. aut. 205), freundlichst mitgeteilt von Prof. Dr. W. Semkowicz.

4) Acta Tomiciana IV nr. 244/8, vgl. S. 101, 187.

6) Rerum Moscov. Commentarii, pag. 144; vgl. in der Selbstbiogr. Fontes rer. Austr. I/1., S. 113.

o) Commentarii, p. 111. Mitteilungen XXXVI. 
Abschiede einige ungarische Gulden, um sich daraus, wie Radziwiłł bat, eine Kette machen zu lassen, die ihn täglich, besonders beim Kaiser, an den Spender erinnern sollte. Nicht weniger freundlich erwies sich ein mit Nikolaus stammverwandter Magnat, Gregor Ościkowicz, der als Palatin von Troki die zweithöchste Reichswürde innehatte und daselbst Herberstein auf seiner Rückreise, obwohl er unvermutet eingetroffen war, sofort zu einem Gastmahle einlud und ebenfalls reich beschenkte 1 ).

Bekanntlich hatte Herberstein auch die Aufgabe gehabt, in Wilna König Sigismund I. zur Heirat mit der vom Kaiser vorgeschlagenen Braut, Bona Sforza, zu bewegen, und dies war ihm auch besser gelungen, als seine Moskauer Mission: sandte doch der König alsbald seine Gesandten Ostroróg und Konarski nach Italien, um Bona zur Vermählung nach Krakau zu geleiten. Es ist nun bemerkenswert, daß anfangs auch Nikolaus Radziwiłł's Schwester, die verwitwete Herzogin von Masovien, beziehungsweise ihre Tochter, als Braut für Sigismund I. in Betracht kam, sich sogar deswegen um Fürsprache an den Kạiser wandte, dem es jedoch gelang, durch ein diplomatisihes Schreiben an ihren Bruder und gewiß auch durch Herbersteins Einfluß einen ernstlichen Widerstand des einfluBreichen Magnaten gegen die the mit Bona zu verhindern ${ }^{2}$ ). Gewiß hängt damit zusammen, daß Radziwiłł eben bei dieser Gelegenheit den so erwünschten Reichsfürstenstand erhielt, und zwar durch Vermittlung eines polnischen Prälaten, der nicht nur überhaupt damals eine interessante, noch nicht ganz aufgehellte politische Rolle spielte ${ }^{3}$ ), sondern auch gerade zu den litauischen Herren in nahen Beziehungen stand. Es war dies der damalige Propst zu Wilna und spätere Bischof von Kamieniec Podolski Laurentius Międzyleski.

Wie wir zufällig aus einem späteren Schreiben erfahren ${ }^{4}$ ), hatte ihn Nikolaus Radziwiłt gleich nach dem Wiener Kongresse gebeten, ihm beim Kaiser das Fürstendiplom, das er, als es ihm angeboten wurde, nicht hatte annehmen können, nachträglich zu verschaffen; es scheint aber, daß Maximilian, wohl durch die ursprüngliche Ablehnung unangenehm berührt, nun Schwierigkeiten machte, so daß Miẹdzyleski

1) Commentarii, p. 149; Fontes rer. Austr. I/1., S. 131. Bezeichnenderweise nennt ihn Herberstein Gregor Radziwiłl, was darauf hinweist, da@ beide Familien, die wirklich einen gemeinsamen Ahnherrn in der ersten Hälfte des XV. Jahrh. haben, damals noch allgemein als e in Geschlecht galten.

2) Vgl. A. Darowski: Bona Sforza, Rom 1904, S. 69/70.

3) Vgl. über ihn bei L. Kolankowski, o. c., S. 11 Anm. 9.

4) Acta Tomiciana XI nr. 250 (Tomicki an J. Chojeński 20. Juni 1529). 
sich erst die Befürwortung des kaiserlichen Sekretärs Jakob Spiegel verschaffen mußte, dem er für seine Bemühungen eine Entschädigung von 100 Gulden versprach. Es ist dies wohl ein deutlicher Beweis, dab Radziwiłł seinen Fürstenstand keineswegs, wie er später vor König Sigismund behauptete ${ }^{1}$, ohne irgendwelche eigene Bemühungen oder jemandes Fürsprache, bloß "motu proprio“ Maximilians erhalten hatte, daß vielmehr seine Gegner ganz mit Recht betonten, er habe sich selbst vom .Kaiser zum Fürsten machen lassen ${ }^{2}$ ). Trotz dieser Bestrebungen verzögerte sich aber die Erledigung fast drei Jahre lang, bis endlich bei Gelegenheit der Reise Bona's nach Polen die günstige Lösung zustande kam.

Zur selben Zeit nämlich, wo die polnischen Gesandten in Neapel die Braut ihres Königs abholten, weilte in Rom bei Papst Leo X. der damals eben von Sigismund I. zur Kurie entsendete Międzyleski, der dort gemeinsam mit den Gesandten des Kaisers, der Könige von Spanien, Frankreich, England, Portugal und anderer Fürsten an den Beratungen über einen allgemeinen Türkenkreuzzug teilgenommen hatte und nun, zur weiteren Verhandlung hierüber und als Nuntius bei Bonas Hochzeit rom Papste wieder nach Polen geschickt, zugleich mit dieser und ihren Begleitern, wenn auch auf anderem Wege, nach Norden reiste ${ }^{3}$ ). Im Februar 1518 kam er nach Augsburg und es konnte für ihn keinen günstigeren Augenblick geben, um Radziwiłts Wunsch zu erfüllen: erstens war nämlich Maximilian hochbefriedigt über das Zustandekommen der Heirat Bona's und wollte, wie wir vorhin angedeutet haben, Radziwiłł für die hiedurch vereitelten Hoffnungen seiner Verwandten entschädigen, zweitens aber hatte eben der Fürsprecher selbst den Kaiser dadurch gewonnen, $\mathrm{da} B$ er in Rom seinen Lieblingsplan förderte, indem er erklärte, daß sein König trotz der schweren Kämpfe mit Moskau und den Tataren und des ihm vom Sultan angebotenen langjährigen Waffenstillstandes an einem etwaigen gemeinsamen Türkenkriege tailzunehmen gewillt war ${ }^{4}$ ). So kam es, daß am 25. Februar die kaiser-

1) Vgl den Passus in dessen unten besprochener Bestätigungsurkunde, Eichhorn, o. c., Beilage II.

2) Acta Tomiciana VII/2 nr. 36, S. 260.

a) Acta Tomiciana IV nr. 317, 344. Ü̉ber die Verhandlungen, welche damals Leo X. mit den christlichen Staaten Europas iuber die geplante Türkenliga führte, siehe bei L. Pastor; Geschichte der Päpste, IV/1. (Freiburg i. B. 1906), S. 152 ff.; über Międzyleski's „Descriptio potentiae Turcicae“ vgl. L. Boratyński: Stefan Batory i plan ligi przeciw Turkom, Abhandl. der Krakauer Akademie, Band 44, S. 207 Anm. 1, sowie die Besprechung F. Bujak's in denselben Abhandl. B. 40, S. 287/8.

4) Ibid. nr..317. Daher betont auch der Kaiser im Diplom für Międzyleski seine verdienstvollen. Bemühungen um das Zustandekommen der Türkenexpedition. 
liche Kanzlei zwei adelsgeschichtlich hochinteressante Urkunden ausstellte: das Fürstendiplom für Radziwiłł ${ }^{1}$ ) und ein höchst merkwürdiges Privileg für Międzyleski's Geschlecht 2). Bevor wir uns dem uns ununmittelbar interessierenden ersteren zuwenden, müssen wir auch das zweite kurz berücksichtigen, da es sich u. a. auch auf litauische Familien bezieht.

Der Propst von Wilna war ein masowischer Edelmann aus dem hunderte von Familien zählenden Wappenstamme der Jastrzębiec, der in Masowien, wo damals noch die alte Piastendynastie herrschte, sowie im übrigen Polen weit verbreitet war und bei der Union mit Litauen 1413 auch ein dortiges Geschlecht adoptiert hatte. Nun verfügte der Kaiser, außer einer Wappenbesserung, daß ständig drei Mitglieder des Gesamthauses die Würde eines Ritters (miles et eques auratus) des hl. römischen Reiches bekleiden sollten; einer sollte stets ein Pole aus den Familien Myszkowski und Bielawski, einer ein Masowier aus den Familien Międzyleski und Dzierżgowski und einer schließlich ein Litauer aus den Familien Niemirowicz und Szczyt sein, jeder aber, der dieser Auszeichnung teilhaftig wurde, den Ältesten des Geschlechtes „nostro ac sacri imperii nomine" den Eid der Treue für den Kaiser und seine Nachfolger und auf Erfüllung aller Ritterpflichten leisten. Dieser Gedanke entsprach wohl der romantischen Begeisterung Maximilians für die Traditionen des Rittertums, konnte auch den Ehrgeiz einzelner Edelleute befriedigen und sie für das Kaiserhaus gewinnen, war aber eben deshalb schwer durchführbar, da ja der polnische König kaum gestatten konnte, daß stets drei Vertreter des zahlreichsten Adelsgeschlechtes seines Reiches, in seinen drei Hauptbestandteilen, einem fremden Herrscher eidlich verpflichtet sein sollten. Höchst bemerkenswert ist aber dabei, da $\beta$ der Kaiser in treffendem Verständnis für den immer engeren Zusammenhang des polnischen Adels mit dem litauischen auch zwei Familien des letzteren in seinen Plan einbezog und daß sich bei den Szczyt, deren einer, wie wir sahen, mit Herberstein in Moskau war, die ungenaue Überlieferung erhielt, daß ihr Ahnherr von Maximilian I. ein Grafendiplom und das Recht, Ritter zu schlagen, verliehen bekommen habe ${ }^{3}$ ).

Von größerer Bedeutung für die Zukunft war das Diplom für Radziwiłl, als erstes Band, das dieses mächtige Haus dauernd für die Habsburger gewinnen sollte. Als Begründung für die Verleihung des Fürstenstandes dienten erstens die Verdienste Nikolaus', die er sich,

1) Eichhorn, o. c., Beil. I.

2) Ed. bei B. Paprocki: Herby rycerstwa polskiego (Neuauf. v. 1858), S. 168.

๑) T. Zychliński: Złota księga szlachty polskiej, IV 360. 
wie erwähnt, auf dem Wiener Kongresse und in den Kämpfen gegen die Feinde der Christenheit, denen - wie der Kaiser betonte - Litauen unmittelbar ausgesetzt war, erworben hatte, und zweitens seine vornehme Abkunft und hohe soziale Stellung: war er doch der Onkel der mit den Habsburgern verwandten masowischen Herzoge und waren ihm doch nicht wenige litauisch-ruthenische Fürsten untertan oder standen in seinem Dienste! ${ }^{\text {) }}$ Da aber bekanntlich damals der Fürstenstand noch kein bloßer Adelstitel war, sondern die tatsächliche Regierung in einem fürstlichen Territorium bedingte, mußte der Umstand hervorgehoben werden, daß Nikolaus Radziwiłł als Herr der Lande Goniadz und Medele (in Podlachien), die einst ein eigenes Fürstentum bildeten, viele Adelige zu seinen Untertanen, Gerichts- und andere Beamte in seinem Dienste und eine besondere Heeresgewalt hatte ${ }^{2}$ ). Mit Rücksicht auf diese tatsächliche fürstliche Stellung wurde also der Palatin von Wilna "nicht nur zum Freiherrn und Grafen, sondern auch zum illustris Dux" erhoben, und zwar mit allen Rechten der übrigen Reichsfürsten und einer Wappenbesserung.

Diese Urkunde, durch die zum ersten Male in Litauen ein Herr nichtfürstlicher Herkunft den bisher nur Dynasten zustehenden Titel erhielt und vor allen mit ihm rivalisierenden Magnatenfamilien einen wenigstens theoretischen Vorrang gewann, brachte Międzyleski dem so Ausgezeichneten nach Litauen. Bei der Hochzeit Bona's in Krakau, wo der Propst als päpstlicher Abgesandte eine Ablaßmesse zu lesen hatte ${ }^{3}$ ), und wo die österreichischen Gäste nur mit zwei Vertretern Litauens, dem Fürsten Konstantin Ostrogski und dem Starosten von Brześć Georg Iliniez zusammentrafen ${ }^{4}$ ), war nämlich Radziwiłł nicht anwesend ge-

1) Es ist tatsächlich richtig, daß in Litauen durch die Verleihung ganzer Territorien an mächtige Magnaten auch Fürsten, die daselbst Besitzungen hatten, in eine Art von feudaler Abhängigkeit von ihnen kamen; auch geschah es wirklich, daß solche Herren, wie z. B. etwas später der Palatin von Wilna J. Hlebowicz, verarmte Fürsten zu ihren privaten "Hofmarschällen" oder "Kämmerern" machten (vgl. A. Boniecki: Herbarz polski, VII 288). Unrichtig ist nur die Behauptung des Diploms, daß diese Fürsten ihren Titel bloß usurpiert hatten.

2) Wenn man auch Goniądz und Medele kaum als einstige „ducatus singulares“ bezeichnen kann, so ist doch richtig, daß es vorher fürstliche Besitzungen gewesen waren (vgl. bei Eichhorn, Beil. VII) und daß der dortige Kleinadel zu den Radziwiłł in einem ausgesprochenen Untertanenverhältnis stand (J. Baranowski: Z dziej6w feudalizmu na Podlasiu, Przegląd histor. IV), auch erst 1529 von ihrer Gerichtsbarkeit befreit wurde (die Urkunde im Rocznik Tow. herald. we Lwowie, III nr. 324).

8) Acta Tomiciana, IV nr. 344, vgl. S. 322 .

4) Vgl. des J. Decius' Beschreibung der Hochzeitsfeier in den Acta Tomiciana IV, S. $310,319$. 
wesen. Als er nun schließlich bei sich za Hause sein Diplom in Empfang genommen hatte, wollte er, trotz der Klausel, daß es den Hoheitsrechten Sigismunds keinen Eintrag tue, seinen neuen Titel von diesem förmlich bestätigt haben. Er benützte daher dessen Anwesenheit auf dem litauischen Reichstage, der Ende 1518 zu Brześć versammelt war, und erhielt daselbst am 8. Dezember vom Könige eine die kaiserliche Standeserhöhung bestätigende Urkunde ${ }^{1}$ ), die ihm die Führung des Fürstentitels und des vermehrten Wappens gestattete. Bezeichnenderweise wurde sie aber in die Reichsmatrikel nicht eingetragen ${ }^{2}$ ) und danerte es auch noch lange, bis die Radziwiłł in öffentlichen Akten ihres Vaterlandes als Fürsten bezeichnet wurden.

Für uns ist aber noch bemerkenswerter, da 3 es auch fast 30 Jahre dauerte, bis das Diplom von 1518 für die Beziehungen dieses Geschlechts zu den Habsburgern eine politische Bedeutung gewann. Die Ursachen lassen sich leicht feststellen. Vor allem verflossen zunächst einige Jahre, in denen die österreichische Politik mit Litauen in keine unmittelbare Berührung kam. 1518 hatte allerdings noch der uns wohlbekannte litauische Marschall Bohusz Bohowitynowicz der polnischen Gesandtschaft angehört, durch die Sigismund I. auf dem Augsburger Reichstage in Vertretung seines unmündigen Neffen Ludwig für die Wahl Karls von Spanien zum römischen Könige die böhmische Kurstimme sichern ließ ${ }^{3}$ ). In den folgenden Jahren sollte aber erst die zweite Reise Herbersteins nach Moskau die kaiserliche Diplomatie wieder mit den litauischen Magnaten in Berührung bringen. Bekanntlich hatte dieser Versuch, einen Frieden zwischen Litauen und Moskau zu vermitteln einen etwas besseren Erfolg, als Maximilians Bestrebungen, indem es Ende 1526 wenigstens zu einem fünfjährigen Waffenstillstand kam ${ }^{4}$ ); wieder aber hatte Herberstein hiebei nicht nur gemeinsam mit den litauischen Gesandten (neben dem damals schon die Würde eines Reichsschatzmeisters bekleidenden Bohusz war der Palatin von Polock Peter Kiszka hiezu abgesendet worden) verhandelt 5), sondern auch, im Gegensatze zu den anderen österreichischen Diplomaten, die durch Litauen nach Moskau reisten, nochmals die Gelegenheit benützt, um mit den einflußreichsten Persönlichkeiten Litauens, so z. B. mit dem Bischofe

1) Eichhorn, Beil. II.

2) Die auf dem Reichstage ausgestellten Urkunden der Reichsmatrikel (darunter zwei Güterverleihungen für Johann Radziwiłł, Nikolaus' Bruder) zusammengestellt bei N. Maksimiejko : Sejmy litowsko-russkawo gasudarstwa, Charkow 1902, Beil. S. $46 / 7$.

3) Acta Tomiciana IV nr. 362, 364/5; Theiner: Monum. Pol. II S. 384, 394.

4) Vgl. bei Uebersberger, I 211.

5) Commentarii, pag. 140/2; Fontes rer. austr. I/1. S. 274. 
von Wilna Johann, einem natürlichen Sohne König Sigismunds 1), freundliche Beziehungen anknüpfen. Dies sollte ihm schon bald darauf wohl zu statten kommen, als er 1529 von König Ferdinand zu Sigismund selbst nach Wilna entsendet wurde, um Unterstützung gegen die Türken zu erbitten und wohl auch geheime Aufträge in der ungarischen Angelegenheit zu entrichten ${ }^{2}$ ). Bei dieser Gelegenheit wurde er nämlich vom nunmehrigen Palatin von Wilna und Großkanzler Albrecht Gasztołd aufs ehrenvollste aufgenommen und sowohl beim Könige wie auch den anderen litauischen Herren freundlichst befürwortet ${ }^{3}$ ), erhielt auch von ihm manche interessante Aufklärung über die litauischen Verhältnisse, die er in seinem Reisewerke verwertete ${ }^{4}$ ).

Es kann nun keinem Zweifel unterliegen, daß Herberstein den neuen Palatin schon auf der zweimaligen Durchreise durch Litauen 1526/7 gewonnen hatte. Bereits damals hatte er wohl bemerken müssen, daß jetzt nicht mehr, wie im vorigen Jahrzehnte, die Radziwirl, sondern eben dieser Gasztołd, der 1522 nach des Reichsfürsten Nikolaus Tode ihm in seinen beiden hohen Würden nachgefolgt war, in Litanen die leitende Rolle spielte, ja eine Art „Vizekönig“ 5) war. Einem vornehmen Herrengeschlechte entstammend, das weit ältere Machttraditionen besaß, als die Radziwiłx, und bis zu seinem Aussterben mit diesen trotz naher Verschwägerung aufs hartnäckigste rivalisierte, betrachtete Gasztołd seinen gefürsteten Vorgänger und dessen überlebende Brüder und Söhne geradezu als Emporkömmlinge und gerade, weil damals die gegenseitige Feindschaft beider Familien ihren Höhepunkt erreicht hatte ${ }^{6}$ ), wollte

1) Commentarii, pag. 155; 13. August 1528 schreibt der Bischof einen höflichen Brief an Ferdinand $I$., in dem er ihn von seiner Ergebenheit versichert (Acta Tomiciana $\mathrm{X}$ nr. 368, vgl. nr. 412).

2) Uebersberger, I 239; vgl. bes. Acta Tomic. XI nr. 81. Über das Ergebnis seiner Mission von 1529, die ihn im Sommer dieses Jahres ein zweites Mal nach Polen führte, bei J. Kieszkowski: Kanclerz Krzysztof Szydłowiecki, Poznań 1912, S. $250 / 2$.

s) Acta Tomic. XI nr. 259, s. u.!

4) Vgl, in den Commentarii, pag. 110, die (allerdings teilweise anekdotenartigen) Mitteilungen, die ihm Gasztołd über Kiew gemacht hatte, wo sein Vater Martin Gasztołd zur Zeit Kasimirs d. Jagellonen Palatin gewesen war.

5) "Regis in Lithuania vicegerens" nennt ihn 1. c. Herberstein. Vgl. auch Acta Tomiciana X nr. 292, 471. Auf demselben Reichstage von 1522, auf dem er die Würden des verstorbenen Radziwiłł erhielt, wurde ihm auch das Recht verliehen, mit rotem Wachs zu siegeln; die Urkunde (bei Maksimiejko, o. c., Beil. S. 62) wurde durch den vorerwähnten Międzyleski ausgefertigt, der, wie früher seinem Vorgänger, nun Gasztołd zur Seite stand.

a) Vgl. Gasztołds Denkschrift an Bona v. J. 1525, die ein Pamphlet gegen die Radziwiłł und Ostrogski bildet (Acta Tomiciana VII/2 nr. 36; einen charak- 
er gewiß auch in den Beziehungen zum Kaiserhause nicht hinter jenen zurückstehen 1). Schon das höfliche Dankesschreiben, das Ferdinand I. nach Herbersteins Rückkehr wohl auf dessen Rat an ihn richtete, indem er ihn zugleich dringend aufforderte, die habsburgischen Interessen in Litauen wie bisher eifrigst zu fördern ${ }^{2}$ ), mag dem stolzen Oligarchen eine gewisse Genugtuung gewäbrt haben; noch mehr mußte ihn aber Ferdinands Versprechen, sich hiefür dankbarst erkenntlich zu zeigen, in seinem Ehrgeize befriedigen, eröffnete es ihm doch die Aussicht, für seine österreich-freundliche Gesinnung ähnlich wie vorher Radziwiłł belohnt zu werden. Zwar erhielt er schon 1529 von Papst Klemens VII. den Titel eines Grafen auf Murowane Gieranony ${ }^{3}$ ), dem alten Stammsitze seines Hauses, doch schien ihm dies eine kaiserliche Standeserhöhung nicht zu ersetzen, so dab er alsbald die eifrigsten Bemühungen begann, von Karl V., wohl mit Berufung auf Ferdinands Gunst, wenn nicht ein Fürsten-, so doch ein Grafendiplom zu erbalten. Wie einst Radziwiłł durch Międzyleski, so suchte auch er durch einen geistlichen Diplomaten in polnischem Dienste, den bekannten Johann Dantiscus, damals erwählten Bischof von Kulm und polnischen Gesandten am kaiserlichen Hofe, sein Ziel zu erreichen. Schon war die Sache günstig erledigt und das Diplom, im August 1530, ausgestellt, als durch einen Irrtum statt der Urkunde, die dem Palatin von Wilna den Reichsgrafenstand verlieh, des Danticus eigenes Ritterstandsdiplom nach Polen geschickt wurde. Der Hofedelmann Nikolaus Nipschütz, der hiebei vermittelte und die freudige Nachricht schon vorher Gasztołd angekündigt hatte, war über die Verwechshung höchst bestürzt, der Palatin selbst aber erkundigte sich ungeduldig beim Bischofe, ob das Ziel denn noch immer nicht erreicht sei. Als endlich im nächsten Jahre alles erfolgreich beendet war und Gasztołd erfuhr, daß sein Diplom - wie seinerzeit das Radziwiłłs - 100 Gulden gekostet hatte, beeilte er sich, diese Summe und außerdem einen kostbaren Pelz als Belohnung an Dantiscus zu schicken 4).

Es scheint aber, daß der kluge Herberstein wohl erkannt hatte, wie stark auch die Partei der Gegner Gasztołds, zu der außer den

teristischen Komentar hiezu bilden die bei Maksimiejko, o. c., S. 50, 60, und Malinowskij: Sbornik matieriałow, Tomsk 1901, S. 385-426 edierten Akten).

1) Ebenso bemühte er sich auch, um seine politische Stellung zu festigen, um die Freundschaft Albrechts von Preußen, vgl. Acta Tomiciana XI nr. 348 S. 264.

9) Acta Tomic. XI nr. 259 (27. Juni 1529).

2) Theiner A.: Vetera monumenta Pol. II S. 466.

4) Die diesbezügliche Korrespondenz: Acta Tomiciana XII nr. 260, 270, XIII nr. 222; Jagiellonki Polskie (ed. Przezdziecki-Szujski), V S. 10. 
Radziwiłł auch die mächtigen Fürsten Ostrogski und Słucki, sowie das immer angesehenere Adelsgeschlecht der Sapieha gehörten ${ }^{1}$ ), in Litauen war. Dementsprechend sehen wir nämlich, daß die Habsburger auch diese Gruppe des litauischen Hochadels bei ibren Bemühungen, sich dort eine starke Partei zu bilden, nicht vernachlässigten. Besonders der allerdings schon 1530 verstorbene Fürst Konstantin Ostrogski, der litauische Großfeldherr und Palatin von Troki, hatte als gefeierter Kriegsheld auf Herberstein einen großen Eindruck gemacht ${ }^{2}$ ), und gewiß hängt damit zusammen, daß die beiden habsburgischen Brüder seinem Sohne, dem jugendlichen Fürsten Elias, freundlichst entgegenkamen: Karl V., dem dieser außerdem durch Dantiscus empfohlen worden war, sandte ihm nach seines Vaters Tode ein huldvolles Beileidsschreiben, das in sehr erfreute ${ }^{3}$ ), und als er 1538 durch den oben erwähnten Nipschütz König Ferdinand um einen $\mathrm{Pa}$ f für eine Pilgerfahrt nach Palästina bat, sandte ihm dieser einen liebenswürdigen Brief, worin er mit Rücksicht auf die großen Gefahren von dieser Reise abriet, aber zugleich dem religiösen Eifer des Fürsten und den Verdiensten seines Vaters hohes Lob zollte ${ }^{4}$ ). Und als 1541 der Palatin von Podlachien Jobann Sapieha, wahrscheinlich durch Intriguen seiner Gegner, soine Würden und Güter verlor, ja sogar längere Zeit gefangen gehalten wurde, war es niemand geringerer als Ferdinand I., der noch vier Jahre später für ihn, auf Bitten seines Sohnes Lukas, bei Sigismund I. Fürsprache einlegte 5). So hatten sich die Habsburger schon vor der Mitte des XVI. Jahrhunderts unter den verschiedensten Gruppen des litauischen Hochadels ergebene Anhänger zu gewinnen gewußt.

Die Radziwiłł hatten übrigens um 1537 den hartnäckigen Kampf gegen die allmächtige Stellung Gasztołds aufgegeben ${ }^{6}$ ) und war hiedurch in den kleinlichen Parteikämpfen, denen der stolze Kanzler ganz mit Unrecht ideelle Gegensätze als Ursache zuzuschreiben liebte 7), durch

1) Acta Tomiciana, VII/2 nr. 36 und X nr. 270.

2) Commentarii, pag. 112 .

s) Jagiellonki Polskie, V S. 11.

) Ibid. S. VII Anm. 1. Um einen ähnlichen $\mathrm{Paß}$ zur Reise nach Jerusalem bemühte sich bei Ferdinand im Jahre 1536 der von Moskau nach Litauen entflohene Fürst Semen Bielski (ibid. S. VI Anmo. 3); vgl. über dessen wirkliche Absichten bei L. Kolankowski: Zygmunt August, S. 178.

s) Jagiellonki V S. XIX Anm. 2; vgl. über Sapieha's Sturz: Hosii Epistolae (ed. Hippler-Zakrzewski) I nr. 90, 98, 102, 104, 107, 110, Niemcewicz: Zbiór pamiętn. IV 40, Kolankowski S. 259 Anm. 3.

B) Kolankowski, S. 222.

7) In seiner vorhin zitierten Denkschrift stellt er seinen Hader als einen Kampf der rein litauischen Geschlechter gegen die ruthenischen hin; die Unhalt- 
Annäherung der Hauptgegner eine gewisse Abschwächung eingetreten, allerdings nicht zum Vorteile des Landes selbst, auf dem hiedurch der rücksichtslose Druck der Magnatenherrschaft nur umso schwerer lastete. Die Nachgiebigkeit der Radziwiłł erwies sich alsbald als sehr zweckmäßig; Albrecht Gasztołd starb nämlich schon 1539 und drei Jahre später erlosch mit seinem einzigen Sohne, jenem Stanislaus, der in seiner Jugend auf dem Wiener Kongresse gewesen war, sein ganzes Geschlecht 1) und räumte so den Radziwiłł, die es teilweise sogar beerbten, den nunmehr unbestrittenen ersten Platz in Litauen ein. Allerdings: starb auch von ihnen jene Linie, die Fürst Nikolaus begründet. hatte, fast um dieselbe Zeit aus; aber schon waren seine Neffen herangewachsen, deren einer eben 1542 aus Italien zurückkehrte und sich auch eine Zeit lang in dem zur Eroberung Budapests bestimmten Heere König Ferdinands aufgehalten hatte ${ }^{2}$ ), und sollten bald ihre glänzende politische Laufbahn beginnen.

Diese fällt schon beinahe ganz in die Regierungszeit König Sigismund Augusts (1548-1572), der übrigens bereits 1544, zu Lebzeiten seines Vaters, das Großfürstentum Litauen zu selbständiger Verwaltung erhalten hatte. Während dieser Zeit nun sollte es sich zeigen, wie günstig es für die Habsburger war, daß sie gerade dieses Geschlecht von allem Anfange an für sich gewonnen hatten, und wie allmählich ihre Beziehungen zu den mächtigsten Magnaten Litauens hohen politischen Wert gewannen, nachdem sie in den vorhergehenden Jahrzehnten schon systematisch vorbereitet worden waren.

\section{Das Haus Habsburg und Fürst Nikolaus Radziwill der Schwarze.}

Als 1543 zu Krakau bei der Vermählung Sigismund Augusts mit Ferdinands Tochter Elisabeth unter den litauischen Gästen gerade die Radziwiłł - - aber allerdings auch ihre späteren Rivalen, die Chodkiewicz - durch besonders prunkvollen Aufwand die allgemeine Aufmerksamkeit auf sich lenkten ${ }^{3}$ ), da ahnte wohl keiner der österreichischen Be-

barkeit dieser Auffassung beweist am besten der Umstand, daß die Radziwiłł ebenfalls zur Gegenpartei gehörten und er, wie er zugeben muß, den "Ruthenus" Ostrogski anfangs selbst unterstützt hatte.

1) Die Genealogie bei A. Boniecki: Herbarz polski, V 383/4.

2) Hosii Epistolae, I nr. 118.

s) L. Kolankowski, S. 91/2, wo auch die Quellen zitiert sind; vgl. Jagiellonki polskie I 107. Der Bischof von Wilna, Fürst Paul Holszański, hatte ein kostbares Hochzeitsgeschenk nach Krakau geschickt (Fontes rer. austr. I/1. S. 360). 
gleiter der jungen Königin, daß gerade ihr baldiger Tod zu einer neuen Ankmüpfung der Beziehungen dieses Geschlechtes zu den Habsburgern einen wenigstens mittelbaren Anlaß geben würde. Es vergingen aber kaum vier Jahre, als der Marschall Nikolaus Radziwiłł, genannt „der Schwarze", als Vertreter Litauens mit der Gesandtschaft nach Österreich kam, die Sigismund August abgesendet hatte, um mit Ferdinand über eine Entschädigung für die Ausstattung seiner schon 1545 verstorbenen ersten Gattin zu verhandeln 1). Daß gerade Radziwiłł hiezu ausersehen wurde, hatte seinen besonderen Grund, der für das richtige Verständnis seiner Absichten wichtig ist.

Unmittelbar vorher hatte sich nämlich Sigismund August im geheimen wiedervermählt, und zwar mit Barbara Radziwiłł, der Witwe nach dem letzten der Gasztołd und Base Nikolaus des Schwarzen. Er mußte nun mit Recht befürchten, daß dieser Schritt nicht nur in Polen, sondern besonders auch bei seinem Schwiegervater, sobald sich die Nachricht hievon verbreiten würde, Befremden und Entrüstung hervorrufen werde, umsomehr als böse Zungen - zwar wohl mit Unrecht behaupteten, daß Barbara schon vorher die Vernachlässigung der Königin Elisabeth durch ihren Gatten verursacht habe ${ }^{2}$ ). Mag dies letztere auch auf böswilliger Erfindung beruht haben, so war es doch, wie schon die nächste Zukunft zeigte, für Sigismund August von großer Wichtigkeit, daß Ferdinand nicht allzu ungünstig über seine neue Ehe dachte, und konnte dies am leichtesten dadurch geschehen, daß sich das Haupt des Hauses Radziwiłł, noch bevor seine Verschwägerung mit seinem Könige bekannt wurde, die Gunst der Habsburger gewann; außerdem handelte es sich sowohl für ihn, wie auch für Sigismund August darum, daß der mit der Goniądz'er Linie 1546 erloschene Fürstentitel auf die jetzt. lebenden Familienmitglieder übertragen würde, um so wenigstens in einem gewissen Grade der Ehe mit Barbara den Charakter einer Mißheirat zu nehmen. So erklärt es sich, dab erstens die polnische Gesandtschaft Ferdinand das größte Entgegenkommen zeigte und sich, von seinen finanziellen Nöten wissend, bereit erklärte, für Elisabeths Ausstattung eine Entschädigung von 30.000 ung. Gulden zu gewähren ${ }^{3}$ ), und zweitens Radziwiłł schon bei seiner Abreise vorhatte, auch bei entsprechender Gelegenheit Kaiser Karl V. aufzusuchen ${ }^{4}$ ), an den man

1) Jagiellonki polskie V S. LIX.

2) Kolankowski, S. 322 .

s) Dogiel: Codex dipl. Poloniae, I, s. 211/3, nr. 48 (das Abkommen vom 26. Nov. 1547), vgl. nr. 49.

4) Vgl. sein Schreiben an Sigmund August 22. Sept. 1547 bei M. Baliński: Pisma histor., I Beil. 3. 
sich ja wegen des Fürstenstandes wenden mußte. Er benützte denn auch wirklich den Umstand, daß beide habsburgischen Brüder des Reichstags wegen zusammen in Augsburg weilten, um neben den Verhandlungen mit Ferdinand dem Kaiser, bei dem er überdies mit dem Gesandten Sigismunds I. zusammentraf ${ }^{1}$ ), auch des jüngeren Jagellonen allerdings etwas verspätete Glückwünsche zum Siege bei Mühlberg auszusprechen. Und wirklich erlangte er so ohne jede Schwierigkeit ein kaiserliches, vom 10. Dezember 1547 datiertes und vier Tage später von Ferdinand transsumiertes Diplom ${ }^{2}$ ), in dem Nikolaus der Schwarze, sein Bruder Johann und sein Vetter Nikolaus, genannt der Rote, Barbaras Bruder, also alle damals lebenden männlichen Familienmitglieder, zu Reichsfürsten auf Oxyka, Nieśwież, Dubinki und Birże erhoben wurden. Als Verdienste der so Ausgezeichneten wurden die hervorragenden Eigenschaften, die der ältere Nikolaus eben bei seiner diplomatischen Mission an den Tag gelegt hatte, und bezeichnenderweise ihr "studium et obsequium" gegen die verstorbene Königin Elisabeth angeführt; besonders das letztere war für die Radziwiłł wertvoll, da es später, als Sigismund Augusts zweite Ehe bekannt wurde, die Rolle der Familie in der ganzen heiklen Frage in ein besseres Licht stellte. Es ist selbstverständlich, daß auch wieder von der vornehmen, fürstlichen Stellung der Radziwiłl, der Verteidigung des Christentums durch die Kämpfe ihrer Ahnen mit Moskowitern und Tataren und schließlich vom Fürstenstande ihres Oheims die Rede ist, neu ist, aber die Behauptung, daß ihr Geschlecht nicht nur von altadeligem Geblüte sei, sondern von einheimischen Fürsten (indigenae duces) Litauens abstamme ${ }^{3}$ ), woron noch

1) Hosii Epistolae, I nr. 276; Sigismund I. hatte schon unmittelbar nach dem Siege von Mühlberg dem Kaiser seine Glückwünsche aussprechen lassen, vgl. die ungedruckten „Tomiciana im Archiv der Fürsten Czartoryski in Krakau Ms. 285, fol. $217 \mathrm{v}, 220$.

2) Eichhorn, Beil. III. Bekanntlich wurde Nikolaus der Schwarze Ahnherr der Füsten auf Ołyka und Nieśwież, Nikolaus der Rote Ahnherr der Fürsten auf Dubinki und Birże. Zugleich erhielten sie eine weitere Wappenvermehrung. Fast gleichzeitig, am 24. Dezember, erhielt auch eines der ersten Magnatengeschlechter Polens, die Tarnowski, vom Kaiser ein Reichsgrafendiplom (Archiwum Sanguszków $\nabla$ nr. 350).

3) Schon damals entstanden wirklich genealogische Legenden, welche die Radziwifl von einer vor den Jagellonen in Litanen herrschenden Dynastie ableiten wollten; selbstverständlich sind sie vollkommen unbaltbar, doch scheint es nach den neuesten, noch unveröffentl. Forschnngen (W. Semkowicz) nicht unwahrscheinlich, daß sie von einem,Geschlechte alter Teilfürsten oder Stammeshäuptlinge abstammen, wie es deren ursprünglich in Litauen viele gab, die natïrlich durch die Entstehung eines einheitlichen Großfürstentums im XIII. Jahrh. ihre Herrschaft einbüßten. 
Maximilians Diplom nichts wußte, was aber jetzt ebenfalls dazu dienen konnte, der Ehe Barbaras einen Schein von Ebenbürtigkeit zu verleihen.

Es ist begreiflich, daß Marschall Nikolaus von Augsburg hochbefriedigt heimkehrte 1 ), umso mehr als es ihm gelungen war, außer mit Karl und Ferdinand selbst auch mit den Söhnen des letzteren: Maximilian, dem späteren Kaiser, und Ferdinand, nähere Beziehungen anzuknüpfen 2). Erfreut über seinen Erfolg war aber auch Sigismund August, der, nachdem er 1548 infolge seines Vaters Tod auch in Polen die Regierung angetreten haite, bekanntlich gleich auf dem ersten Reichstage zu Piotrków einen wahren Sturm der Empörung über seine Heirat aushalten mußte: mit sichtlicher Befriedigung bestätigt er am Ende dieses Reichstages das kaiserliche Reichsfürstendiplom für die Angehörigen seiner Gemahlin ${ }^{3}$ ), indem er nicht nur, wie 1518 sein Vater, in kurzen Worten die Führung des Fürstentitels gestattet, sondern auch nachdrücklich betont, daß niemand das Alter ihres Geschlechtes besser kenne als er selbst und daß er sie umso herzlicher beglückwünsche, als er ja ihre Schwester zur Frau habe. Es handelte sich aber nicht nur darum, die Legitimität und Unlösbarkeit seiner zweiten Ehe zu verteidigen, die ja schließlich nicht ernst angefochten werden konnte, sondern Barbara sollte auch als Königin anerkannt und gekrönt werden, um eventuell zur Stammutter einer neuen Linie der Jagellonen werden zu können; ebenbürtig sollten ja die Nachkommen sein, die der König von ihr erhoffte und denen das unzweifelhafte Erbrecht auf das Großfürstentum Litauen zugleich auch die polnische Königswürde gesichert hätte, da man sie unter solchen Umständen, wie mehrere Präzedenzfälle bewiesen, stets auch auf den polnischen Thron gewählt hätte, um die polnisch-litauische Union aufrecht $\mathrm{zu}$ erhalten. Dies durch Barbaras Krönung zu ermöglichen, war aber umso schwieriger, als nicht nur der Widerstand in Polen, sondern auch eine starke Gegenpartei in Litauen zu bekämpfen war, der außer mehreren den Radziwiłł feindlichen Familien, wie den Hlebowicz, Chodkiewicz, Ościkowicz ${ }^{4}$ ), fectis $)$.

1) Hosii Epistolae, I nr. 277 (,rebus praeter spem suam ex sententia con-

2) Katalog der Raczyński'schen Bibliothek in Posen (ed. Sosnowski-Kurtzmann), Posen 1885, Band I. MS. nr. 86 (enthält Originalbriefe verschiedener Monarchen und Mitglieder regierender Häuser an die Radziwiłł, die sich früher in deren Familienarchiv zu Nieśwież befanden).

s) Eichhorn, Beil. IV (24. Jänner 1549).

4) Vgl. z. B. die Briefe aus den Jahren $1548-1550$ bei M. Baliński : Pisma histor. I S. 152, II S. 133, 146 etc. 
:sogar Nikolaus des Schwarzen eigener Bruder Johann Radziwiłł angehörte ${ }^{1}$ ). Da war es nun wirklich von großer Bedeutung, daß auf dem .entscheidenden Reichstage zu Piotrków im Jahre 1550 die Bemühungen des Königs durch die vermittelnde Anwesenheit der Gesandten Ferdinands eine wirksame Unterstïtzung erfuhren ${ }^{2}$ ); daß dieser, wenn er auch anfangs durch die Wiedervermählung seines Schwiegersohnes unangenehm berührt sein mußte, bei dieser Gelegenheit eine so zuvorkommende Stellung einnahm, dazu hatten außer dem im Vorjahre mit Sigismund August abgeschlossenen Freundschaftsvertrage unzweifelhaft die 1547 so geschickt erneuten Beziehungen der Radziwiłł zum Hause Habsburg beigetragen: nicht umsonst hat wohl Fürst Nikolaus, der während der Verhandlungen des polnischen Reichstages in Piotrków anwesend war $^{3}$ ), die österreichischen Gesandten, den seiner Familie längst bekannten Herberstein und Dr. Lang, in Begleitung zweier anderer litauischer Fürsten, darunter des ihm nahestehenden Holszański, im Kloster zu Witów besucht4).

Mit Recht konnte nun König Ferdinand erwarten, auch seinerseits bei seinen politischen Beziehungen zu Sigismund August von den Radziwiłł unterstützt zu werden, umso mehr als diese, besonders Nikolaus der Schwarze und teilweise auch der Rote, zu immer höheren Würden emporsteigend, trotz Barbaras baldigem Tode einen großen Einfluß auf ihren königlichen Schwager gewonnen hatten. Da aber bekanntlich gerade in den nächsten Jahren durch die ungarische Frage zwischen Ferdinand und Sigismund eine merkliche Verstimmung eintrat, mußte es für die Radziwiłł oft schwierig werden, ihre Pflichten als Würdenträger des Jagellonenreiches, als Räte ihres Königs, mit ihren traditionellen Beziehungen zum Hause Österreich zu vereinbaren. So kam es, daß 1552, als Herberstein wieder nach Polen entsendet wurde und eine überraschend kühle, ablehnende Aufnahme fand, Nikolaus Radziwiłk, trotzdem ihm Ferdinand vorher in einem eigenen Schreiben seinen Gesandten empfohlen hatte ${ }^{5}$ ), diesem auffallend auswich, ihn nicht .einmal besuchte, indem er sich wegen Zeitmangels entschuldigen ließ ${ }^{6}$ ).

1) Niemcewicz: Zbiór pamiętników I S. 421/2, 428, 438.

2) J. Szujski : Stosunki dyplom. Zygmunta Aug. z domem austryackim (Opowiadania i roztrzasania, Band I, Krak 6 w 1885), S. 365; Uebersberger, I 259. Soeben erschien hierüber eine Studie von L. Bogatyński im 59. B. d. Abhdl. d. Krak. Akademie.

s) Bericht der österr. Gesandten von 18. Juni 1550 im Wiener HHSt.-Archiv' Polonica; vgl. auch Baliński: Pisma, II 158, 164.

4) Fontes rerum austr. I/1. S. 376.

s) 12. Jänner 1552; Katalog der Raczyński'schen Bibliothek, l. c.

-) Fontes rer. austr. I/1. S. 392. 
Trotzdem ist aber die bisherige Annahme ${ }^{1}$ ), als habe gerade Radziwill seinen König dem Hause Habsburg abwendig gemacht, vollkommen unhaltbar. Richtig ist allerdings, daß Sigismund August in seiner überaus häufigen vertraulichen Korrespondenz mit dem Fürsten seinerseits kein Hehl daraus machte, daß ihn die weltbeherrschende Macht dieses Hauses beunruhige ${ }^{2}$ ); aber gerade in diesen interessanten Briefen finden wir den deutlichsten Beweis, daß Radziwił, nachdem er eine Zeit lang in dieser Beziehung eine vorsichtig zurückhaltende Stellung reingenommen hatte, alsbald seinen entscheidenden Einfluß dazu benützte, um gerade im Augenblicke, wo der König vom tiefsten Unwillen und Mißtrauen gegen die Habsburger erfüllt war, eine neuerliche Annäherung zwischen beiden Dynastien zustandezubringen. Es geschah dies schon 1553, als die in der historischen Literatur bereits mehrmals besprochene ${ }^{3}$ ) Nachricht auftauchte, daß Karl V. beim Papste die Bestrebungen des Zaren, Iwans des Grausamen, durch eine Union mit Rom die Königskrone zu erhalten, aufs eifrigste unterstütze.

Es ist nachgewiesen worden, daß von Seiten des Zaren selbst keinerlei diesbezügliche Schritte unternommen wurden, sein angebliches Schreiben an den Kaiser eine Fälschung war und dem ganzen Plane die Mystifikation der Beteiligten durch einen kühnen Abenteurer zugrundelag. Trotzdem läßt sich aber nicht leuguen, daß die unzweifelhaften Bemühungen Karls V., die Kurie für das moskowitische Reich einzunehmen und für solche Annäherungspläne günstig zu stimmen ${ }^{4}$ ), Sigismund August in berechtigte Unruhe versetzen mußten. Bewiesen sie doch, daB auch eine politische Verbindung der Habsburger mit Moskau nicht außerhalb des Bereiches der Möglichkeit lag, und da der Ausbruch eines neuen Krieges mit Iwan nur eine Frage der Zeit war, konnte, wie der König ausdrücklich in seinem Briefe an Radziwiłł betonte, wieder eine ähnliche Lage eintreten, wie zur Zeit Kaiser Maxi-

1) Vgl. z. B. bei Szujski, o. c., S. 366 .

2) Die Korrespondenz des Königs mit Nik. Radziwiłł dem Schwarzen 15491565 bei Lachowicz: Pamiętniki do dziejów Polski. Listy oryg. Zygmunta Augusta, Wilno 1842; die angeführte Stelle S. 41.

a) In der deutschen Geschichtsschreibung bei J. Fiedler: Ein Versuch der Vereinigung der russischen Kirche mit der römischen. Sitzungsber. der Wiener Akad. phil.-hist. Band 40: Uebersberger: I $282 \mathrm{ff}$.

4) Ausdrücklich erwiderte der Papst im März 1553 dem polnischen Gesandten, dab in der moskauischen Angelegenheit, multi ac illi quidem gravissimi ac permagni principes apud Stem suam vehementer instant atque urgent" (Uchańsciana, ed. T. Wierzbowski, II nr. 21). In seinem Schreiben an Ferdinand vom 11. April .glbt dies auch Karl V., wie wir sehen werden, selbst zu (Fiedler, Beil. 8). 
milians 1), im Jahre 1514, wo dessen Bündnis mit Iwans Vorgänger für Litauen so verderblich geworden war!

Das erste, was Sigismund August tat, als er jene überraschendeNachricht aus Rom erhielt, daß dort über eine Verleihung der Königswürde an den Zaren verhandelt werde, war nichts anderes, als sich in mehreren Briefen an Radziwiłł den Schwarzen um Rat zu wenden, wieeine Annäherung Moskaus an Kaiser und Papst zu verhindern sei ${ }^{2}$ ). Was Julius III. betraf, genügte es natürlich, ihn durch einen Gesandten darauf aufmerksam zu machen, welche Gefahr dem katholischen polnischlitauischen Staate von Seiten des schismatischen, es mit einer Union niemals ernst meinenden Moskau drohe ${ }^{3}$ ); wie sollte man sich aber den Habsburgern gegenüber in politischer Hinsicht sicherstellen? Hiezu gab es nur zwei Mittel: entweder die bisher schwankende Haltung zwischen ihnen und Frankreich in einen rückhaltslosen Anschluß an dieses zu verwandeln, um sie auf diese Weise von zwei Seiten zu bedrohen, wie man es von ihnen durch etwaige Beziehungen mit Moskau für Polen befürchtete, oder das in der letzten Zeit getrübte habsburgischjagellonische Einvernehmen wieder vollkommen herzustellen. Und gerade an diesem bedeutungsvollen Wendepunkte der polnischen Politik brachte Radziwiłłs Einfluß die Entscheidung zu Gunsten Österreichs.

Da Sigismund August aus politischen Rücksichten, um seinen Reichen einen Nachfolger zu hinterlassen, damals eben eine dritte the einzugehen dachte, war die Wahl seiner neuen Gemahlin gleichsam ein äußeres Zeichen, bei welchem Herrscherhause Europas er in seiner Politik einen Anschluß suchen würde, wobei natürlich nur entweder eine der österreichischen oder eine der französischen Dynastie nahestehende Prinzessin in Frage kommen konnte ${ }^{4}$ ). Dementsprechend lautete auch

1) Lachowicz, S. 38 .

8) Lachowicz, S. 35 (14. Jänner 1553), 37 (16. Jänner), 37-42 (24. Jänner). Bei P. Pierling (La Russie et le Saint-Siège, I 343, Paris 1896) wird auf den Rat, den sich der König bei Albrecht von Preußen holte, der Hauptnachdruck gelegt; ein Vergleich der Daten (siehe Ss. rer. pol. I 67/9) beweist aber, daß der König erst 11 Tage später an ihn schrieb und die Antwort (vom 14. Februar) erst eintraf, als die Sache schon durch Radziwiłłs Einfluß entschieden war.

a) Die ursprüngliche Instruktion dieses Gesandten (Albert Kryski) erwähnt diese Frage noch gar nicht, da sie vom Herbste 1552 stammt (Uchańsciana, III nr. 11, 12); seine spätere Instruktion über Moskau bei Fiedler, Beil. IV, sowie (der II. Teil) in Ss. rer. pol. I 69-71, sein von Ferdinand I. am 2. Februar 1553 ausgestellter Paß im Wiener Archiv, Polonica, die Antwort des Papstes Uchańsciana II nr. 21, s. o.! Vgl. auch Ss. rer. pol. I S. 71-75.

4) Uebersberger, S. 286; vgl. über die in Betracht kommenden Heiratspläne Dr. Langs Bericht an Erzherzog Ferdinand vom 10. März 1553 in den Wiener Polonica, sowie z. B. Hosii Epistolae II nr. 1000. 
Radziwiłłs Rat, den wir leider nur aus des Königs Antwort kennen ${ }^{1}$ ). Von einem Anschlusse an Frankreich riet er ab: die Lage des französischen Königs selbst sei zu ungünstig, um durch die Drohung, sich ihm anzuschließen, auf die Habsburger einen Druck auszuüben; hingegen schien ihm die drohende Gefahr am besten dadurch abgewendet werden zu können, daß der König sich in Ferdinands Familie eine neue Gattin suche, und zwar in der Person der Schwester seiner ersten Gemahlin. Es war dies bekanntlich die verwitwete Herzogin von Mantua Katharina. Sigismund Augusts Antwortschreiben ist vom 24. Jänner 1553 datiert, und wenn er auch gegen die Ehe mit der eigenen Schwägerin religiöse Bedenken erhob ${ }^{2}$ ) und meinte, er müsse die Sache, von der bisher nur die beiden Radziwiłł wußtan, noch mit anderen Räten besprechen, so ist es doch schon daraus vollkommen klar, daß der unmittelbare Anstoß zu Sigismunds folgenschwerer dritter Verehelichung von Nikolaus dem Schwarzen ausging und dieser Plan keineswegs, wie immer wieder in der wissenschaftlichen Literatur zu lesen ist ${ }^{3}$ ), erst während der Verhandlungen an Ferdinands Hofe auftauchte.

Allerdings konnte diese unrichtige Auffassung leicht dadurch entstehen, daß des Polenkönigs schriftliche und zuletzt auch mündliche Beratungen mit Radziwiłl, besonders was die Heiratsangelegenheit betraf, geheim gebalten wurden ${ }^{4}$ ). Schon war dieser längst nach Österreich abgereist und noch wußte niemand, weder die übrigen polnischen Herren, noch die Königin-Witwe Bona, noch der österreichische Gesandte in Polen Dr. Lang ${ }^{5}$ ), irgend etwas bestimmtes, ob und wo er für den König eine Braut suchen werde. Ja sogar später, als die Heiratsverhandlungen schon im Gange waren, herrschte in Polen die von Sigismund August geflissentlich verbreitete Meinung, daß erst in Wien Ferdiuand ganz unerwartet den Vorschlag einer neuerlichen Verschwägerung beider Dynastien durch seine Tochter gemacht habe ${ }^{6}$ ). Es lag nämlich in des Königs und des Fürsten Nikolaus offenbarem Interesse, die Sache so darzustellen, und zwar aus einem doppelten

1) Lachowicz, S. $41 / 2$.

2) Seine längeren Ausführungen über diesen Punkt beweisen, daß man keineswegs den Vorwurf erheben darf (vgl. bei Uebersberger, S. 378), es seien ihm erst nach zehnjähriger Ehe, als es sich um einen Scheidungsvorwand handelte, derlei Bedenken aufgestiegen.

s) In der nevesten polnischen Literatur richtig dargestellt bei Wł. Bogatyński: Hetman Tarnowski, Kraków 1914, S. 116.

4) Vgl. z. B. die Stelle bei Lachowicz, S. 49/50.

5) Hosii Epistolae II nr. 1000; Lachowicz, 1. c.; Langs zitierter Bericht vom 10. März.

-) Jagiellonki polskie, I S. 388/89; Hosii Epistolae, II nr. 1011. Mitteilungen XXXVI. 
Grunde: erstens gab es in Polen nicht wenige Gegner einer neuen Verbindung mit den Habsburgern, vor denen man den Heiratsplan als Vorschlag von österreichischer Seite darstellen wollte, und zweitens gab es noch zahlreichere Gegner des übermächtigen Radziwiłł, die ohnehin unzufrieden waren, da $B$ er die Verhandlungen führte ${ }^{1}$ ), und denen man vèrheimlichen mußte, daß sogar die unmittelbare Initiative von ihm stammte.

Erst die Kenntnis aller Quellen enthüllt den tatsächlichen Sachverhalt. Wie wir gesehen haben, war Sigismund August schon im Januar mit dem Heiratsplan vertraut gemacht, konnte sich aber noch nicht entschlieBen und hatte bloB vor, an Karl V. und Ferdinand I. über die moskauische Frage zu schreiben.9). Bald aber schien er sich überzengen zư lassen, daß diese Frage zugleich auch einen Vorwand bilden könnte, um einen Gesandten an Ferdinand zu senden und hiebei auch die Heiratsfrage zu berühren ${ }^{3}$ ); schon am 4. Februar teilt er Radziwiłł diesen EntschluB, außer zum Papst auch zu beiden Habsburgern einen Gesandten zu schicken, in bestimmter Form mit ${ }^{4}$ ), und schon Ende des Monats war Fürst Nikolaus in Krakau, besprach alles mündlich mit dem Könige 5), bewog diesen, nachdem er ihn offenbar für seine Pläne gewonnen hatte, ihm selbst diese Gesandtschaft anzuvertraven und erhielt wirklich am 24. Februar ein Beglaubigungsschreiben ${ }^{6}$ ) und Instruktionen, in denen allerdings nur vom „negotium Moschicum" die Rede war ").

Dementsprechend kann es nicht mehr, wie in den bisherigen Darstellungen, überraschend erscheinen, daß Sigismund August, als ihm Radziwiłl aus Österreich von der Geneigtheit Ferdinands, ihm Katharina zur Frau zu geben, schrieb, sofort dazu entschlossen war ${ }^{8}$ ); er war eben schon vorher von seinem Gesandten hiefür gewonnen worden. Es bleibt jedoch noch eine viel schwierigere Frage zu lösen, ob nämlich Radziwill selbst, aus eigenem Antriebe, mit dem Vorschlage dieser Ehe aufgetreten war oder ob ihn nicht vielleicht vorher König Ferdinand gebeten hatte, seinen Einfluß auf den König in diesem Sinne geltend

1) Hosii Epistolae, Il nr. 1012.

2) Lachowicz, S. 41.

3) Ibid., S. 81 (gehört zu einem der Briefe Anfang 1553, nicht 1554).

4) Ibid., S. 43.

s) Ibid., S. 46.

- Wiener Archiv, Polonica; außerdem erhielt er ein vom 25. Februar datiertes Empfehlungsschreiben an Erzherzog Maximilian, ibid.

7) Fiedler, Beil. III (an Ferdinand, vgl, auch Ss. rer. pol. I 75/7), V (an Karl).

3) Korespondencyja Zebrzydowskiego, nr. 807; Jagiellonki polskie, I S. 388/9; vgl. Uebersberger, S. 286. 
zu machen. Wir wissen allerdings nichts ron einem derartigen, begreiflicherweise geheimgehaltenen Schreiben Ferdinands, doch erzählt der damals so rührige und einflußreiche polnische Politiker und Schriftsteller Stanislaus Orzechowski in einer gleichzeitigen, Sigismunds dritte Hochzeit beschreibenden Druckschrift ${ }^{1}$, daß sich Ferdinand eifrig bemühte, die Verheiratung seiner verwitweten Tochter Katharina mit dem polnischen Könige durch Nikolaus Radziwiłł's Vermittlung zustandezubringen. Man muß nun zugeben, daß der Verlauf der Ereignisse eine solche Annahme insofern bestätigt, als es sonst Erstaunen erregen mïßte, wie rasch Ferdinand nicht nur auf Radziwiłłs Werbung einging, sondern auch die Hochzeit möglichst zu beschleunigen suchte ${ }^{2}$ ). Wie dies sich aber auch immer verhailten haben mag, unzweifelhaft bleibt, daß Radziwiłł damals den Habsburgern einen wichtigen Dienst leistete ond, wie uns dies auch die Einzelheiten seiner Mission beweisen werden, seine nahen Beziehungen zu ihnen, trotz manchem, was in der Folgezeit dagegen zu sprechen scheint und bisher ein richtiges Verständnis seiner Rolle verhinderte, wieder neu gefestigt wurden.

Mitte März kam Nikolaus der Schwarze, den, wie wir sehen werden, noch einige andere seinem Hause nahestehende litauische Magnaten begleiteten, zu König Ferdinand, der ihm zu Graz am 24. dieses Monats eine mehrmals konzipierte Antwort auf Sigismunds Moskau betreffende Vorstellungen erteilte ${ }^{3}$ ). Er erklärte darin, da $B$ er gar nichts davon wisse, ob sein Bruder beim Papste für den Zaren eingetreten sei, hielt es auch nicht für nötig, daß Radziwiłł gleich selbst zu Karl V. weiterreise, sondern schrieb noch am selben Tage in dieser Angelegenheit an den Kaiser ${ }^{4}$ ) and riet dem Gesandten, die Antwort in Österreich abzuwarten. Dies war aber nur die offizielle Seite der Verhandlungen, bei denen zugleich auch die Heiratsangelegenheit zur Sprache gekommen war. Leider sind uns hievon nur die Ergebnisse bekannt, und zwar

1) Panagiricus nuptiarum Sigismundi Augusti Poloniae Regis, Cracoviae 1553. Die allerdings nicht ganz deutliche Stelle lautet: ${ }_{\infty}$ Ferdinandus rex ... nihil prius habebat, quam ut eam filiam ... Sigismundo Augusto regi, Nicolao Radivilo internuncio, collocarets. Daß diese Bestrebungen Ferdinands bis ins Jahr $1552 \mathrm{zu}$ rückreichen, beweisen die Schreiben in Korespondencyja Zebrzydowskiego nr. 806, 808. Zur Vorgeschichte der Ehe vgl. auch Gornicki: Dzieje w Koronie polskiej (Jahr 1553).

2) Jagiellonki, l. c.

s) Fiedler, Beil. VI; vgl. in den Polonica die verschiedenen Konzepte und Kopien dieser Antwort.

4) Fiedler, Beil. VII. Er erinnert hiebei den Kaiser, daß der polnische Gesandte jener selbe Radziwiłł sei, „que Vre Mté a naguaires érigé en duc de Olichá et Nieswicz $\ltimes$. 
einerseits aus dem Antwortschreiben Karls an Ferdinand, in dem er Radziwiłłs Antrag, die verwitwete Katharina mit Sigismund August zu vermählen, sehr entsprechend findet und diese Ehe aufs wärmste gutheißt 1), und andererseits aus einigen polnischen Quellen. Radziwiłł hatte nämlich schon am 28. März einen Boten nach Krakau gesandt 2), der offenbar dem Könige die Nachricht vom günstigen Stande der Heiratsangelegenheit brachte; daraufhin versammelte dieser am 8. April die in der Hauptstadt anwesenden Senatoren, teilte ihnen mit, daß Ferdinand ihm seine Tochter zur Frau angeboten habe, und beschloß offiziell, trotzdem die Befriedigung hierüber keineswegs allgemein war, den Vorschlag anzunehmen ${ }^{3}$ ). Es wurde zugleich bestimmt, daß zur Finalisierung des Ehevertrages auch noch ein Würdenträger der polnischen Reichshälfte, der Vizekanzler Przerębski, zu Ferdinand abgesendet werden sollte. der auch wirklich Ende des Monats nach Wien fuhr ${ }^{4}$ ), und daß die Hochzeit am 2. Juli stattfinden würde. Wie schon erwähnt, wollte anfangs Ferdinand diesen Termin womöglich noch beschleunigen, da er sich vom Zustandekommen der Ehe außerordentlich viel versprach: nicht nur schloß sie endgültig die Möglichkeit aus, daß Sigismund August auf französischer Seite seine neue Gemahlin und zugleich politische Verbindungen suche, sondern Radziwiłł hatte bei seinen vertraulichen Vorverhandlungen noch ein wichtiges Versprechen abgegeben, von dem wir zufällig aus späteren Briefen Ferdinands erfahren ${ }^{5}$ ); er erklärte. nämlich, daß nach Katharinas Hochzeit jede gegen Österreich gerichtete Unterstützung des ungarischen Thronprätendenten und Neffen des polnischen Königs, Johann Sigismund Zápolya, und seiner Mutter Isabella von Seiten Sigismund Augusts aufhören werde. Wenn auch Fürst. Nikolaus wahrscheinlich zu einer solchen Erklärung keine ausdrückliche Vollmacht hatte, so war sie doch angesichts seines bekannten Einflusses nicht weniger wertvoll und konnte Ferdinand, für den in seinen

1) Fiedler, Beil. VIII.

2) Sein von diesem Tage datierter Paß in den Wiener Polonica; dieser Bote Alex. Princza oder Brinza wurde von Radziwiłł schon vorher zu vertraulichen Missionen: verwendet, vgl. Lachowicz, S. 35.

8) Hosii Epistolae, II nr. 1011, 1012; Jagiellonki polskie, l. c.

4) Hosii Epistolae, II nr. 1029; das neue Sendschreiben für Radziwiłł und Przerȩbski rom 29. April in den Polonica.

5) 21. Jänner 1554 an seine Gesandten in Polen, 3. Februar 1554 an Radziwiłł (Polonica). Bisher waren diesbezüglich nur die Verhandlungen bekannt, die 1553 Erzherzog Ferdinand in Polen führte, als er seine Schwester dahin geleitete (vgl. Jagiellonki V 73-76). Erst E. Zivier hat in seiner Neueren Geschichte Polens I (S. 530 Anm. 1), die während des Druckes dieser Arbeit erschien und daher bei ihrer Abfassung nicht benützt werden konnte, u. a. auch auf diese beiden Schreiber in den Polonica hingewiesen. 
Beziehungen zu Polen jene ungarische Frage bekanntlich die Hauptsache war, mit den erreichten Ergebnissen wohl zufrieden sein.

Noch ehe Radziwiłłs neue Mission, die mit Przerębski durchzuführende offizielle Werbung um Katharina, mit des letzteren Ankunft begonnen hatte, war jenes "negotium Moschicum", dem Ferdinand neben der Vermittlung Radziwiłłs - seinen Erfolg verdankte, aus der Welt geschafft worden. Schon am 24. April konnte nämlich der König einen Auszug aus des Kaisers Antwort dem sie in Wiener Neustadt erwartenden polnischen Gesandten übersenden ${ }^{1}$ ). Sie erhielt Karls feierliche Versicherung, daß er bei seiner Verwendung für den Zaren in Rom keine Ahnung gehabt habe, daß dies dem Könige von Polen schaden könne, und daß er nunmehr selbst dem Papste raten werde, Moskau gegenüber Zưückhaltung zu üben und Sigismunds Wünsche zu berïcksichtigen. Es müssen die Habsburger auch wirklich sogleich dieses Versprechen erfüllt haben, da Julius III. in demselben Breve an Ferdinand ${ }^{2}$ ), in dem er die zu Katharinas Ehe nötige Dispens erteilt, auch auf die Moskau betreffende Bitte antwortet, daB er ohnehin schon mit Rücksicht auf Polen die Vorschläge des Zaren (bekanntlich handelte es sich, wie schon erwähnt, um eine Fälschung, von der dieser gar nichts wußte) abzulehnen beschlossen habe. So konnte am 23. Juni der endgültige Ehevertrag abgeschlossen werden ${ }^{3}$ ); die ersten Hochzeitszeremonien fanden sogleich in Wien statt, wobei Radziwiłł die Person seines Königs vertrat, die eigentliche Feier in Krakau aber mußte wegen Zeitmangels und Unwohlseins Sigismunds vom Anfange auf die Mitte und schlieBlich auf das Ende des Monates Juli verschoben werden $\left.{ }^{4}\right)$.

Als sich während der Verbandlungen Ferdinand I. anfangs Juni in einer uns leider nicht näher bekannten Frage - vielleicht bloß des endgültigen Termins der Hochzeit - mit seinem Schwiegersohne verständigen wollte, sandte er den "pocillator" von Litauen, Starosten von VIII, IX

1) Polonica; das Schreiben selbst und Ferdinands Antwort bei Fiedler, Beil.

2) Fiedler, Beil. $X$. Bekanntlich kam es 1561 wieder zu einem, diesmal von Rom ausgehenden Versuche, zwischen dem Papste und Moskau mit Wissen des Kaisers Beziehungen anzuknüpfen, die auch wieder ähnliche Besorgnisse Sigismund Augusts weckten; vgl. über den mißglückten Versuch des Legaten Canobio, über Polen und Litauen nach Moskau zu gelangen, und die damalige Rolle Radziwitłs bei Pierling: La Russie et le St.-Siège, I 369, sowie Sauermanns Bericht vom 7. September 1561 in den Polonica.

8) Dogiel: Codex dipl. I S. 220/8, nr. 52, 53.

4) Lachowicz, S. 51/2, 53, 56; vgl. Orzechowski, o. c. 
Tykocin und Mohilew, Stanislaus Kieżgajło nach Krakau 1). Dieser, der letzte Sproß eines der vornehmsten und reichsten litauischen Adelsgeschlechter und Neffe Nikolaus Radziwiłłs ${ }^{2}$ ), einst eine wichtige Vertrauensperson bei des Königs geheimer Vermählung mit Barbara, war wahrscheinlich mit seinem Oheim nach Osterreich gereist und es ist nicht unwahrscheinlich, daB der Titel eines Grafen auf Kroże, den ihm Ferdinand in seinem Paßschreiben gibt, ihm eben damals von diesem verliehen worden war. Wieder hatte nämlich das Haus Habsburg die Gelegenheit benützt, um seine litauischen Anhänger durch die stets so beliebten Titelverleihungen für die geleisteten Dienste zu belohnen und sicherer an sich zu fesseln: so erhielt Radziwiłł selbst, der mit der letzten Szydłowiecka vermählt war, den Titel eines Reichsgrafen auf Szydłowiec $^{3}$ ) und am seiben Tage (10.Juli) wurde ein zweiter ihn begleitender Neffe, Georg Ilinicz, ebenfalls der letzte seiner Familie, zum Reichsgrafen auf Mir erboben 4).

Auch bei den Hochzeitsfeierlichkeiton in Krakau, am 31. Juli, sollte Radziwiłłs Ehrgeiz nochmals befriedigt werden. Wenn auch zahlreiche Vertreter des litauischen Hochadels, darunter auch Gegner seiner Familie, anwesend waren ${ }^{5}$ ), so nahm doch er, der die Heirat zustandegebracht, eine besondere Ehrenstellung ein und ritt beim festlichen Einzuge der neuen Königin zur linken ihres Wagens, während den Platz zur rechten ihr Bruder, Erzherzog Ferdinand, einnahm ${ }^{6}$ ). Aber Fürst Nikolaus knüpfte an sein gelungenes Werk noch viel wichtigere Hoffnungen, die mit seiner unvergleichlichen Machtstellung überhaupt und

1) Polonica, 4. Juni 1553.

2) Boniecki: Poczet rodów S. 123 und Herbarz polski X 68. Uther seine Beziehungen zu den Radziwilł vgl. z. B. Jagiellonki polskie, I 329, 337; Lachowicz, S. 2, 8, 17; Baliński: Pisma histor., passim. Allerdings tituliert sich $\mathrm{K}$. schon 1549 Graf auf Kroże (Kolankowski, S. 42 Anm. 1). Kulturgeschichtlich ist interessant, daß er sich 1552 einen Wagen aus Deutschland kommen ließ, der der Königin Bona so gefiel, daß sie sich einen ähnlichen bestellte (Lachowicz, S. 27).

3) Vgl. in den verschiedenen Genealogien der Radziwiłł, sowie bei J. Kieszkowski: Kanclerz Krzysztof Szydłowiecki, S. 662; Kotłubaj: Galerja Nieświeżska, S. 246 (nach einer ungedruckten Familiengeschichte) gibt irrtümlich an, er habe diesen Titel erhalten, als er in Prag auf dem Wege nach Wien einen Sohn des böhmischen Königs Muximilian (Erzherzog Ernst) aus der Taufe hob. Dies letztere ist allerdings richtig (vgl. in den Polonica Cyrus' Bericht vom 19. Juni 1571, sowie das schon oben erwähnte Empfehlungsschreiben an Maximilian vom 25. Februar 1553) nur die Verknüpfung beider Tatsachen unrichtig.

4) Das Originaldiplom im Archiv der Fürsten Radziwiłł zu Nieśwież, Pergamenturkunden nr. 126.

5) Vgl. bei Orzechowski, o. c., und in Stryjkowski's Chronik, Buch 24 Kap. 7.

e) Orzechowski, o. c. (stanti inceptor et confector connubii «). 
seinen kühnen Zukunftsplänen zusammenhingen und die auch gleich nach der Hochzeit durch einen hochinteressanten Bericht des österreichischen Gesandten in Polen, Dr. Johann Lang ${ }^{1}$, zur Kenntnis Ferdinands kamen.

In Litauen hatten die Radziwiłł es endlich erreicht, die tatsächliche Herrschaft über das Großfürstentum in ihre Hände zu bekommen. Die Gunst des Königs hatte ihnen nicht nur einen ungewöhnlichen persönlichen Einfluß auf ihn, sondern auch alle leitenden Würden des Landes verschafft, die sich in rascher Folge auf Nikolaus den Schwarzen und den Roten gehäuft hatten: war doch der erstere schon seit mehreren Jahren nicht bloß Palatin von Wilna und Großkanzler, wie einst sein Oheim und sein Großvater, sondern zugleich Reichsmarschall, der latztere Palatin von Troki und Grobfeldherr, so dab diese beiden Fürsten "von Gottes Gnaden ", wie sie sich zu titulieren liebten, die ersten weltlichen Sitze im Rate, die Leitung der äußeren und inneren Politik, die böchste Heeresgewalt, sowie die Verwaltung und Justiz in den das Zentrum des Reiches bildenden Provinzen vereinten. Dazu kam noch, daß eben in diesen Jahren fast alle übrigen mächtigen Magnatenhäuser Litauens erloschen oder doch schon dem Aussterben nahe waren: wir wissen schon vom Ende der Gasztołd im Jahre 1542, 1554 starb der letzte Kieżgajło, 1556 der. letzte Fürst Holszański, um dieselbe Zeit der letzte Ilinicz u. s. w., und da alle diese Geschlechter in ihren letzten Vertretern mit den Radziwiłł verwandt waren, befand sich deren gewaltige Hausmacht durch häufige Erbschaften in ununterbrochenem Zunehmen 2). Es kann daher nicht Wunder nehmen, wenn, wie Dr. Lang in seinem Berichte betonte und andere gleichzeitige Quellen bestätigen ${ }^{3}$ ), die Meinung verbreitet war, daß Nikolaus der Schwarze für den Fall eines kinderlosen Todes Sigismund Augusts Großfürst von Litanen zu werden hoffte und darauf hinarbeite; es ist möglich, daß er sich gərade deshalb so lebhaft dafür interessierte, ob Königin Katharina eine Nachkommenschaft zu erwarten habe ${ }^{4}$ ).

1) Polonica, 10. August 1553.

2) Vgl. hiezu die Artikel über die genannten Familien und die Radziwił selbst in Boniecki's: Poczet rodów (und teilweise auch Herbarz polski). Nach dem Aussterben der Ilinicz ging auch der ihnen 1553 verliehene Titel eines Reichsgrafen auf Mir auf die Radziwiłł über (z. B. schon 1571 bei Lachowicz, S. 313).

s) Z. B. eine ungedruckte, gleichzeitige Schilderung eines polnischen Adeligen im Archiv der Fürsten Czartoryski zu Krakau MS. 1604, S. 54. St. Hosius schrieb 1557 über ihn: „gerit se pro duce Lituaniae (Hosii Epistolae, II nr. 1718).

4) Niemcewicz: Zbiór pamiętnikow, II $432 / 4$. 
Wenn aber der erst allmählich politischen Einfluß gewinnende niedere Adel Litauens, ja selbst die den Radziwiłl mißgünstigen, aber im Vergleich mit ihnen noch zu schwachen übrigen litauischen Herrengeschlechter, ihrer Ubermacht keinen ernstlichen Widerstand entgegensetzen konnten, so lagen die Dinge in der polnischen Reichshälfte ganz anders. Der polnische Adel, der unter sich keine aristokratische Oligarchie aufkommen ließ, sah nur mit größter Unzufriedenheit, daß Nikolaus der Schwarze, der überdies, wie wir sehen werden, bis zu seinem Tode der endgültigen Vereinigung Litauens mit Polen entgegenarbeitete, den König in seiner Gewalt hatte ${ }^{1}$ ), da $B$ gerade er es nun wieder war, der die neue Königin nach Polen brachte, und duldete, so lange sich der Hof in Polen aufhielt, keine eigenmächtige Einmischung des ersten litauischen Würdenträgers in die Politil des Königreiches. Daher beschloß Radziwiłł, der selbst Polen möglichst bald zu verlassen dachte ${ }^{2}$ ), trotz der Unzufriedenheit des dortigen Adels, das königliche Paar zu bewegen, ebenfalls nach Litauen zu reisen, wo er beide ungestört beeinflussen konnte; erwartete er doch, daß Katharina, die geradezu durch seine Vermittlung Königin geworden war, durch ihre Gunst seine Stellung zu einer noch mächtigeren machen werde, als bisher. Und wirklich hatte diese sofort bemerkt, welchen Einfluß er auf ihren Gatten ausübte, und wollte sich daher seiner Absicht nicht widersetzen, wenn sie auch gar keine Lust hatte, die unbequeme Reise nach dem kalten, unwirtlichen, schütter bewohnten Großfürstentum anzutreten ${ }^{3}$ ); ja sogar Ferdinand selbst, deu sein Gesandter aufgefordert hatte, im Interesse seiner Tochter durch irgend einen Vorwand die Verwirklichung dieses Planes zu verhindern, tat, so viel wir wissen, gar nichts in dieser Hinsicht, nur um sich den leicht verletzbaren Magnaten, der ihm doch so gute Dienste leisten konnte, nieht zu entfremden.

Radziwiłł zeichnete sich nämlich durch ein ungewöhnliches Mißtrauen aus, wo immer es sich um seine allmählich errungene Machtstellung handelte, quälte damit sogar seinen eigenen, ihm so gewogenen König, der ihn immer wieder, so z. B. am Ende jenes wichtigen Jahres $\left.1553^{4}\right)$, in seinen Briefen versichern mußte, dab er nach wie vor die

1) "In potestate sua habet×, wie Dr. Lang ausdrücklich zweimal schreibt; die weiter zitierte Stelle über die Polen lautet: „nec quidquam rerum publicarum regni in aula eum [scil. Radziwiłł] gerere patiuntur".

2) Über seine Abreise Hosii Epistolae, II nr. 1079.

3) Vgl. die Schilderung Litauens in Langs Bericht vom 24. August, ferner äber die Königin auch den Bericht vom 16. August in den Polonica, sowie Hosii Epistolae, II nr. 1079, 1083.

4) Lachowicz, S. 67 und an vielen andern Stellen. 
rerste Stelle in seiner Gunst einnehme. Obwohl ihm daher Katharina keinen Widerstand entgegensetzte, bemerkte er doch einerseits, wie ungern sie sich zur Reise nach Litauen entschlo $B$, und andererseits, daß auch sie an der Seite ihres Gatten eine politische Rolle spielen wollte, und war sofort von Argwohn erfüllt, daß sie ihm die anfangs bewiesene Gunst entziehe und seinen Einfluß, statt zu stärken, beeinträchtigen werde. In seinen Erwartungen getäuscht, zögerte er nicht, in der von ihm selbst vermittelten Ehe Mißstimmungen hervorzurufen, um nur zu verhindern, daß Sigismund August auf irgend jemanden, und wenn es auch seine Gattin wäre, mehr höre, als auf ihn, und da einerseits der König, wie Dr. Lang meinte, gleichsam durch teuflische Zauberkünste an ihn gefesselt war, und andererseits die Königin nicht gewillt war eine rein passive Rolle zu spielen, dürfte Radziwiłł nicht wenig dazu beigetragen haben, daß das gegenseitige Verhältnis der beiden Gatten von Anfang an ein getrübtes war ${ }^{1}$ ).

Trotzdem wäre es ganz unrichtig, hieraus, wie es gewöhnlich geschieht, die Folgerung zu ziehen, Fürst Nikolaus sei überhaupt ein Gegner des Hauses Habsburg geworden. Allerdings wäre es gewiß für die österreichischen Interessen in Polen vorteilhafter gewesen, wenn er gemeinsam mit Katharina für sie gewirkt hätte. Wenn sich dies auch als unmöglich erwies, so beweist doch seine Korrespondenz mit Ferdinand I. nach seiner Rückkehr aus Wien in den Jahren 1553 und $\left.1554^{2}\right)$ ganz unzweifelhaft, daß er den traditionellen Beziehnngen seiner Familie $\mathrm{zu}$ den Habsburgern, die seine Gesandtschaft neu gefestigt hatte, rückhaltslos treu blieb, ja sogar manchmal seit dieser Zeit dem kaiserlichen Hause mehr dienstbar war, als dies den Interessen seines Vaterlandes und seines Königs entsprach.

Am deutlichsten läßt sich dies in der ungarischen Frage, den Beziehungen Sigismund Augusts zu seiner Schwester Isabella Zápolya und ihrem Sohne feststellen. Da der König Radziwiłł auch fernerhin ein unumschränktes Vertrauen schenkte und ihm in seine Politik mehr Einblick gewährte, als irgend einem andern seiner Räte ${ }^{3}$ ), vrubte er wohl, daß trotz der Annäherung an die Habsburger, die Anfang 1553

1) Langs Bericht vom 24. August 1553, Polonica; vgl. Szujski, o. c., S. 370 Anm. 1, sowie Jagiellonki polskie $V$, S. LXXXIII.

2) In den Polonica; besonders zu beachten sein Brief an Ferdinand vom 15. Oktober 1553 und die folgenden, auch Ferdinands Schreiben an ihn vom 3. Februar 1554. Vgl, auch Katalog der Raczyński'schen Bibliothek, 1. c. Über Radziwiłls Beeinflussung durch Ferdinand in der livländischen Frage (1557) vgl. bei E. Zivier, o. c., S. 610 .

s) Vgl. Lachowicz, S. 87. 
so nötig schien, Sigismund Isabellas Bemühungen, ihrem Sohne zunächst Siebenbürgen zu sichern und hierauf seine Ansprïche auf ganz Ungarn aufrechtzuerhalten, nicht zu hindern, sondern eher zu unterstützen dachte oder wenigstens in einer für sie günstigen Weise zwischen ihnen und Österreich vermitteln wollte ${ }^{1}$ ). End da mißbrauchte nun Nikolaus der Schwarze dieses Vertrunen seines Herrn derart, daß er, nicht zufrieden damit, durch seinen Einfluß den österreichischen Interessen zu dienen, durch die Gesandten Ferdinands in Polen diesem die ganze ungarische Politik seines Königs enthüllte ${ }^{2}$ ). Dies erklärt uns auch, warum z. B. Anfang 1554 die österreiehischen Gesandten danach trachteten, daB Sigismund August bei ihren Verhandlungen mit der damals noch in Polen weilenden Isabella und ihrer sie unterstützenden Mutter Bona gerade Nikolaus Radriwił zu seinem Vertreter bestimme, was sie allerdings ,wichtiger Hindernisse * wegen - vielleicht war doch des Königs Argwohn rege geworden — nicht erreichten ${ }^{3}$ ). Allerdings fehlte es auch nicht an Versuchen der Gegenpartei, den mächtigen Palatin von Wilna in dieser schwierigen Frage für sich zu gewinnen; ja als Isabella 1559 starb, schrieb ihr Sohn selbst, „Joannes electus rex orphanus* wie er sich unterzeichnete, sofort an ihn, damit er ibn der Gunst. Sigismund Augusts empfehle und Rat und Hilfe für ihn beim Könige erwirke 4). Und wir hören auch im selben Jahre, sogar schon etwas. früher, von einem merkwürdigen Plane Radziwiłłs, der beweist, daß er trotz aller österreichfreundlichen Gesinnung auch für den jungen Johann. Sigismund eine gewisse Sympathie besa B: er meinte nämlich die beiderseitigen Interessen am besten dadurch befriedigen zu können, daß er den Vorschlag machte, Ferdinand solle Zápolya eine seiner Töchter zur Frau geben und ihn so an sich fesseln 5 ), wozu man allerdings am österreichischen Hofe keineswegs geneigt war.

Radziwiłłs Sympathie für Johann Sigismund Zápolya ist deshalb. von Bedentung und Interesse, weil sie mit zwei Fragen zusammenhängt, die für die damalige innere Entwicklung Polens, aber auch für seine Beziehungen zu den Habsburgern von größter Wichtigkeit waren: es:

1) Siehe z. B. bei Szujski, o. c., 369-374.

2) Von den Beweisdokumenten in den Polonica ist am deutlichsten des Erasmus. Haydenreich Bericht an Ferdinand vom 12. Jänner 1055; es erhellt daraus, daB in dieser Beziehung dieselbe Rolle, wie Radziwiłł in Litauen, in Polen sein Begleiter bei den Heiratsverhandlungen von 1553, Vizekanzler Przerębski spielte.

3) Uchańsciana, V 138, bes. die Zitate in Anm. 3.

4) Niemcewicz: Zbiór pamiętników, I 468/9; vgl. Katalog der Raczyński'šchen Bibliothek, 1. c.

5) Langs Bericht an Ferdinand I. vom 10. März 1559; vgl. bei Szujski, S. 373 Anm. 4. 
sind dies die Reformation, deren Verbreitung im Jagelionenreiche eben damals ihren Höhepunkt erraichte, und die Sukzession, das Problem, wer nach dem Tode Sigismund Augusts, der nun auch in dritter Ehe kinderlos: blieb, seinen verwaisten Thron besteigen würde.

Was die religiöse Frage betrifft, so neigte sich bekanntlich Johann Sigismund, unter dem Siebenbürgen eine Heimstätte weitgehendster Toleranz bildete, den kühnsten Neuerern auf diesem Gebiete, den verschiedenen Sekten der Antitrinitarier zu, was außer anderen Edelleuten Polens und Litauens eben auch Nikolaus Radziwiłł für ihn gewinnen mußte. War doch dieser seit ungefähr zehn Jahren die Hauptstütze, der weltliche Führer der Reformationsbewegung in Litauen und führte ihn sein religiöser Werdegang allmählich zu immer radikaleren Glaubenslehren: vom augsburgischen Bekenntnisse zum Kalvinismus, von diesem schließlich, in langsamem aber stetigem Übergange, zum Antitrinitarismus, in dem er auch starb 1). Dieser Umstand war nun auch für seine Stellung in der Sukzessionsfrage maßgebend. Trotz jener oben erwähnten, vielleicht übertriebenen Gerüchte, daß er selbst wenigstens nach dem litauischen Thron strebe, mußte er sich dessen doch wohl bewußt. sein, daß seine Kandidatur in beiden Reichshälften zugleich vollkommen aussichtslos und eine Loslösung der litauischen von der polnischen kaum möglich sein würde ${ }^{2}$, und sich für eine von jenen Parteien entscheiden, die sich unter dem polnisch-litauischen Adel bildeten, seitdem diese Frage der Thronfolge offen auf der Tagesordnung war. Eine von ihnen, die vielleicht auch der König selbst nicht am wenigsten unterstützte, war eben die seines Neffen Zápolya, und deshalb war Radziwiłł auf jenen Gedanken gekommen, ibn mit einer Habsburgerin zu verheiraten. Seit der Ehe mit Katharina sprach man nämlich in Polen auch von der Möglichkeit ${ }^{3}$, daß das Baus Österreich sich um Sigismund Augusts. Erbe bewerben würde, und wenn auch Ferdinand selbst keine direkten diesbezüglichen Schritte unternahm, so konnte es dem Fürsten Nikolaus. doch zweckmäßig erscheinen, auf diese Weise beide Parteien und zugleich seine beiderseitigen Sympathien zu verbinden. Er mußte aber

1) Vgl. z. B. bei Th. Wotschke: Der Briefwechsel der Schweizer mit den Polen, (Archiv f. Reformationsgesch., Ergänzungsband ШI), nr. 318, 328/9, 332, 339 u. s. w.; ferner die genaue Schilderung seiner religiösen Entwickelung im Vorworte zu Monumenta reformationis Polon. et Lithuan., Serie X, Heft 1 (Wilno 1913).

2) Wer immer König von Polen werden wird, schreibt Lang im zit. Bericht vom 10. März 15599, „non Polonis tantum, verum etiam Lituanis ... imperitabit, eo. quod ita inter se duo isti populi sunt confoederati, ut unus idemque utrorumque sit princeps. Ipsi confraternitatem vocante

s) Vgl. z. B. Lachowicz, S. 119. 
allerdings, als er mit dem österreichischen Gesandten seinen Plan besprach, zugeben, daß Zápolya in Polen nicht mehr allzuviele Anhänger habe, da sie seine geringe Regierungskunst und seine "Turcica plane indoles" abschrecke 1); selbstrerständlich konnte auch die Aussicht, ihn auf dem polnischen Throne zu sehen, die Habsburger nicht geneigt machen, sich mit ihm zu verschwägern. Übrigens scheint auch Radziwiłł, trotz der religiösen Berührungspunkte, Zápolya's Kandidatur nicht mehr ernstlich unterstützt zu haben, was vielleicht auch mit einer bisher wenig beachteten, aber höchst charakteristischen Veränderung in seinen Beziehungen zu den Habsburgern zusammenhängt.

Es verdient nämlich gewiß näher erklärt zu werden, warum $\mathrm{Ni}$ kolaus der Schwarze bei diesen Beziehungen allmählich einem anderen Vertreter des österreichischen Herrscherhauses nähertritt, als in den vorhergehenden Jahren, wo er, wie wir gesehen haben, vor allem mit Ferdinand I. korrespondierte und verhandelte. Ungefähr von 1558 an tritt nun statt dessen die Person seines Sohnes, Erzherzog Maximilians, damals schon Königs von Böhmen, in den Vordergrund. Interessant ist in dieser Hinsicht Radziwiłłs Schreiben vom 3. Mai $1558^{2}$ ), in dem er Maximilian seine Gratulation zur Erlangung der kaiserlichen Würde durch seinen Vater ausspricht. Den Hauptinhalt dieses Briefes bilden längere Ausführungen religiösen Inhalts, in denen der Führer der litauischen Reformierten die Hoffnung ausspricht, daß ,das Evangelium und die Kirche Gottes von der bisherigen Knechtschaft und unerträglichen pharisäischen Unterdrückung befreit, sowie die Zügellosigkeit und Straflosigkeit der Sünde, die der römische Antichrist der Welt versprochen und bei sich käuflich gemacht habe, abgeschafft werde", was auch zum Heile des Reiches gereichen würde. Es ist einleuchtend, daB sich Radziwiłł in einem solchen Tone nicht an den streng katholischen Ferdinand selbst, sondern nur an den mit dem Protestantismus innerlich sympathisierenden, eben in jenen Jahren so stark von Melanchthon beeinflußten ${ }^{3}$ ) Maximilian wenden konnte. Und wirklich fand Radziwiłł bei diesem ein volles Verständnis für seine konfessionellen Überzeugungen: schon am 21. September desselben Jahres schickt ihm der König von Böhmen ein warmes Empfehlungsschreiben für den späteren Führer der Unitarier Lelio Sozino ${ }^{4}$ ), bald darauf dankt hiefür der Palatin von

1) Die Stelle über Zápolya in Lang's zitiertem Berichte ist mit dem Schreiben ,Sauermanns rom 10. Mai 1561 (Polonica) zu vergleichen.

2) Polonica.

s) Die Ergebnisse der neuesten Untersuchungen hierüber bei G. Loesche: Luther, Melanthon und Calvin in Österreich-Ungarn, Tübingen 1909, S. $145 \mathrm{ff}$.

4) Th. Wotschke: Der Briefwechsel der Schweizer mit den Polen, S. 81 Anm. 3; $\checkmark$ gl. dessen Gesch. der Reformation in Polen, S. 196. 
Wilna, hochbefriedigt vom Umgange mit dem geistrollen Szeptiker ${ }^{1}$ ), und nimmt überhaupt in der weiteren Korrespondenz zwischen ihnen die religiöse Frage beinahe den ersten Platz ein. Wenn vielleicht auch Maximilian Radziwiłłs maßlose, gehässige Angriffe gegen den Katholizismus $\left.{ }^{2}\right)$ nicht immer billigen konnte, so duldete er sie doch in dessen Briefen und begegneten sich beide im allerdings nicht mehr erfüllbarem Wunsche, daß die erbitterten Glaubenskämpfe und Zweifel einer vollständigen religiösen Einheit Platz machen mögen ${ }^{3}$ ). Besonders interessant ist Fürst Nikolaus' Schreiben vom 15. August 1564, mit dem er Maximilian die in seiner Druckerei zu Brześć litewski erschienene polnische Bibelübersetzung übersandte, weil er bei dieser Gelegenheit betont, daß dieser über "Völker derselben, Zunge" herrsche, wie sein eigener König 4 ).

Diese Bemerkung kann uns als Hinweis dienen, daß dieser regen Korrespondenz ${ }^{5}$ ) auch noch ein anderes Motiv zugrundelag, als das religiöse. Wenn man nämlich berücksichtigt, daß sich Maximilian schon wenige Monate später ${ }^{6}$ ) desselben Argumentes der böhmisch-polnischen Stammesgemeinschaft bediente, um seine eventuelle Kandidatur für den polnischen Thron zu unterstützen, so liegt die Vermutung nahe, daß für seine Beziehungen zu Radziwiłł auch die zweite der von uns vorher hervorgehobenen Fragen maßgebend war, nämlich die der polnischen Sukzession. Während nämlich, wie schon erwähnt, Ferdinand I., der ja ohnehin nicht damit rechnen konnte, den bedeutend jüngeren Sigismund August zu überleben, zwar für alle Fälle in Polen und Litauen eine starke österreich-freundliche Partei zu bilden bestrebt war, aber der Sukzessionsfrage gegenüber eine mehr abwartende, beobachtende Stellung einnahm, brachte ihr Maximilian, der schon 1559 in Polen selbst bei den Beratungen ernstlich als Kandidat genannt wurde ?), ein

1) 4. Jänner 15̄59, Jagıellonki polskie, V 145.

2) Interessant ist u. a. sein Schreiben vom 17. April 1561 in den Polonica, wo er behauptet, von Leuten, „quibus nomen meum non alia res ulla exosum reddidit quam sacrosanctum Evangelium Jesu Christi«, bei Maximilian verleumdet worden zu sein.

8) Vgl. Maximilians Brief vom 18. Oktober 1564, Jagiellonki polskie, V 150/1.

4) Jagiellonki polskie, V 148/50.

5) Vgl. auch 3. Jänner 1559, Polonica, sowie Katalog der Raczyński'schen Bibliothek, 1. c. Im Briefe Maximilians vom 18. Oktober 1564 ist auch ein Kondolenzschreiben Radziwiłłs anläßlich des Todes Kaiser Ferdinands I. erwähnt.

0) In der Instruktion von 5. Februar 1565, Polonica.

7) In Sauermanns Bericht vom 10. Mai 1561, Polonica, finden sich diese und andere interessante Einzelheiten über die Beratungen in der Sukzessionsfrage während des Reichstages von 1558/9. Über Ferdinands Politik in der poln. Suk- 
viel aktiveres Interesse entgegen, und sobald er nach seines Vaters Tode selbst als Kaiser die polnische Politik der Habsburger in seine Hände bekam, begnügte er sich nicht mehr damit, sich wie dieser von seinen Gesandten in Polen über die Aussichten der einzelnen Kandidaten benachrichtigen zu lassen, sondern empfahl ihnen von allem Anfang an in seinen Instruktionen, für die habsburgische Stimmung zu machen 1 ).

Es ist daher unzweifelhaft, daß er bei seinen Beziehungen zu einzelnen polnischen Magnaten schon zu Ferdinands Lebzeiten jene $\mathrm{Zu}-$ kunftspläne nicht aus dem Auge ließ und waren hiebei gerade die zu -Radziwiłł von größter Wichtigkeit. Nicht nur war es ja durch ihn am ehesten möglich, auf Sigismund August selbst, aus dessen Äußerungen über die Thronfolge die Habsburger niemals recht klug werden konnten, einen Einfluß auszuüben, sondern schien ja auch seine Stellung in -dieser Frage für ganz Litauen entscheidend zu sein. Je häufiger ferner die österreichischen Gesandten über den Gegensatz zwischen Polen und Litauen berichteten ${ }^{2}$ ), bei dem eben Radziwiłł eine Hauptrolle spielte, umso notwendiger mußte es erscheinen, neben den Anhängern in Polen .auch ihn und seine litauische Partei für die Nachfolge eines Habs'burgers nach Sigismund Augusts Tode zu gewinnen. Hiezu war nun gewiß jener intime briefliche Verkehr mit dem Hauptkandidaten Maximilian ein vortreffliches Mittel. Da hiebei die Sukzessionsfrage nicht unmittelbar berührt wurde, ist es nicht leicht zu ergründen, wie sich Fürst Nikolaus selbst hiezu verhielt; wenn man aber berïcksichtigt, wie - eifrig später sein gleichnamiger Vetter, der in allem und jedem seine Politik weiterführte, und sein Sohn Nikolaus Christoph die Wahl eines Habsburgers unterstützten, daß er 1559 die siebenbürgische mit der iösterreichischen Kandidatur zu vereinbaren suchte, daß er sich schon im vorhergehenden Jahre an den späteren Lieblingskandidaten der Litauer, Maximilians Sohn Erzherzog Ernst, mit einem Schreiben wandte ${ }^{3}$ ), kann es wohl kaum einem Zweifel unterliegen, daB er sich mehr und mehr mit dem Gedanken betreundete, nach Sigismund Augusts Tode einen Habsburger auf dem Throne za sehen. Ebenso wie bei vielen .anderen Protestanten verscheuchte wohl auch bei ihm Maximilians

zessionsfrage vgl. in der neuesten Literatur B. Kadelka: Jakőb Heraklides Despota, Kwartalnik histor. XXVI 26 Anm. 1, 29 Anm. 1.

1) Vgl. austührlich bei Szujski, 1. c., 378/9, Wierzbowski im Ateneum 1879 III 408, Uebersberger S. 378.

2) Vgl. die Berichte Sauermanns aus Wilna 26. Februar, 17. April, 10. Mai in den Polonica.

3) 3. Mai 1558, Polonica. 
"Kompromißkatholizismus" die konfessionellen Befürchtungen, die das sonst so glaubenstreue Kaiserhaus geweckt hätte, und seiner aristokratischen Gesinnung, der die auch in Litauen um sich greifende polnische Adelsdemokratie so verhaßt war, konnte gerade diese Dynastie, für die die aristokratische Regierungsform typisch war $\left.{ }^{1}\right)$ und der seine Familie ihren Reichsfürstenstand verdankte, am ehesten entsprechen.

In diesem Zusammenhange gewinnt es besondere Bedeutung, daß der häufige Briefwechsel mit Maximilian nicht den einzigen Beweis bildet, wie die traditionellen Beziehungen der Radziwiłł zum österreichischen Herrscherhause immer enger und häufiger wurden. So schickt der Palatin von Wilna 1560 zwei seiner litauischen Verwandten nach Österreich, und zwar jenen 1553 zum Reichsgrafen erhobenen Ilinicz an den Hof des Erzherzogs Karl von Steiermark und Johann Hlebowicz, "Freiherrn auf Dąbrowno", an den Maximilians 2). Um sie den Habsburgern anzuempfehlen, schrieben nicht nur der polnische König und Nikolaus der Schwarze selbst an diese, sondern auch des letzteren Gattin Elisabeth, eine geborene Szydłowiecka, an Maximilians Gemahlin, die nun auch mit ihr in brieflicher Verbindung bleibt uud z. B. 1564 ihrer „amica carissima“ Elisabeth Radziwiłł für mit einem herzlichen Schreiben äbersendete Handarbeiten dankt ${ }^{3}$ ). Besonders wichtig war es aber, daß schon 1561 Fürst Nikolaus der Rote, der wenige Jahre später an seines Vetters leitende Stelle in Litauen treten sollte, unmittelbaren AnschluB an die Habsburger suchte, indem er durch Ferdinands Gesandten Sauermann um Aufnahme seines Sohnes an den kaiserlichen Hof bat; selbstverständlich beeilte sich der Gesandte, dem Kaiser die Erfüllung dieser Bitte dringendst anzuempfehlen, indem er darauf hinwies, wie außerordentlich einflußreich der Palatin von Troki beim Könige und den litauischen Ständen war und wie vorteilhaft es für den Kaiser sei, sich solche Persönlichkeiten zu verpflichten und zu treuen Anhängern zu machen. Alsbald erfolgte denn auch des Kaisers freundlich zustimmende Antwort 4), so dab, als 1565 Nikolaus der Schwarze starb und der Rote seine hohen Würden erbielt, die österreichische Partei unter dem litauischen Hochadel keinerlei Einbuße erlitt.

Im Anschlusse daran wäre zu erwähnen, daß damals zu dieser Partei neben den allerdings weitaus bedeutendsten Radziwiłł auch jenes zweite litauische Magnatengeschlecht gehörte, das allmählich mächtig

1) Vgl. bei Uebersberger, S. 391.

2) Mehrere Schreiben hierüber in den Polonica: 25. September, 26. September, 12. Dezember 1560, 29. April 1561.

s) Jagiellonki polskie, V 147.

4) Polonica, .9. Juni und 10. Juli 1561. 
genug geworden war, um die Stelle ihrer früheren Rivalen einzunehmen, nämlich die Chodkiewiez. Einem übrigens schon im XV. Jahrhundert: sehr angesehenen Kiew'er Bojarenhause entstammend, waren sie zur Zeit. Sigismund Augusts, obwohl er ihnen anfangs wenig Sympathien entgegenbrachte 1), in drei Vertretern zu hohen Würden emporgestiegen ${ }^{2}$ ). Die zwei bedeutendsten unter ihnen, die Brüder Hieronymus und Gregor, nacheinander Kastellane von Wilna, waren zu jener Zeit die Hauptgegner der Radziwił in Litauenj ${ }^{3}$ ), nichtsdestoweniger aber, ebenso wie. diese, Anhänger der Habsburger. Der erstere hatte von Kaiser Ferdinand ein Reichsgrafendiplom erhalten 4) und sein später so einflußreicher Sohn Johann Hieronymus hatte noch an Karls V. Hofe seine Jugend verbracht und sich in dessen Kriegen mit Frankreich ausgezeichnet ${ }^{5}$ ), während Gregors Sohn 1566 an Hofe Maximilians II. freundliche Aufnahme fand, wofür sein Vater dem Kaiser in einem ergebenen. Schreiben dankt 6).

So sehen wir wieder, daß die Habsburger, wie einst vor 40 Jahren, mit verschiedenen Parteien des litauischen Hochadels in Verbindung standen, was ihnen auch wirklich schon zur Zeit des ersten Interegnums zugutekommen sollte; schon die vorhergehenden Jahre sollten aber beweisen, warum dies trotzdem nicht genügte, um auf die gesamte litauische Reichshälfte einen entscheidenden Einfluß auszuüben.

\section{Die österreichische Politik und die Union von Lublin.}

Wenn sich auch Radziwiłt der Schwarze im allgemeinen bis zu seinem Tode der königlichen Gunst erfreute und noch unmittelbar vorher anläßlich der kaiserlichen Gesandtschaft zu Rate gezogen wurde ${ }^{7}$ ), erlebte er doch noch die bittere Enttäuschung, daß in der wichtigsten

1) Jagiellonki polskie, I 325, 334, 338 .

2) Vgl. die Geschichte dieser Familie bei St. Kossakowski: Monografie histor. geneal. I, Warszawa $1876^{2}$.

s) Hosii Epistolae II nr. 1935 (1558); Ss. rer. Pol. XV 186 (P. Giovannini's Bericht über Polen 1565). Durch Hieronymus Chodkiewicz suchten seinerzeit Sigismund I. und Bona die Ehe ihres Sohnes mit Barbara Radziwiłf zu verhindern: vgl. Jagiellonki I 348, 351.

4) Kossakowski, S. 46 .

s) Karls V. Brief an Sigismund August 18. September 1555 in den Polonica; vgl. auch seine ausführliche Lebensbeschreibung im Privileg Sigismund Augusts 19. Dezember 1568 (Opisanije rukop. otdielenija Wilenskoj Publ. Bibliotieki, III. S. $76 / 9)$. 28. Mai).

8) 13. Juni 1566, Polonica.

7) Lachowicz, S. 280 (des Königs Brief vom 3. Mai 1565; der Fürst starb am. 
innerpolitischen Frage Sigismund August nicht mehr auf ihn hörte, sich in seinen Absichten nicht irre machen ließ $\left.{ }^{1}\right)$. Es handelte sich um den endgültigen $A b s c h l u B$ der Union Litauens mit Polen. Die beiden schon seit 1386 mehr oder weniger eng verbundenen Reiche sollten noch vor des letzten Jagellonen Tode durch einen klaren, ihrer nunmehrigen inneren Entwicklungsstufe und äußeren politischen Lage entsprechenden Vertrag für immer vereint werden ${ }^{2}$ ).

Sigismund August hatte nicht immer mit dem gleichen Eifer nach diesem Ziele gestrebt. So lange die in Litauen erbliche Dynastie der Jagellonen blühte, war mindestens die Personalunion beider Reiche gesichert, da man ja anch in Polen, wie schon erwähnt, nicht daran gedacht hätte, jemand anderen zu wählen. Für den Fall ihres Erlöschens aber konnte es leicht zu einer Spaltung kommen, da die eine gemeinschaftliche Herrscherwahl bestimmende Union von 1501 von Litauen nicht endgültig angenommen war und die letzte vorhergehende, von 1499, eigentlich nur ein loses Bündnis schuf. Außerdem kamen seit dem Anfang der Sechzigerjahre, als des Königs Hoffnung auf Nachkommenschaft immer aussichtsloser wurde, noch zwei Unstände hinzu, die die Erneuerung und Festigung der Union unbedingt nötig machten. Während dies erstens bisher gewöhnlich bloB ein einseitiges Streben Polens war, dem sich die führenden Oligarchen Litauens widersetzten, beginnt nun im Gegensatze zu diesen der gesamte litauische Adel ebenfalls energisch nach einer engeren Vereinigung mit dem Bruderstaate, vor allem nach einem gemeinsamen Reichstage zu verlangen, schließt sich sogar zu diesem Zwecke 1562 zu einer Konföderation zusammen ${ }^{3}$ ); je mehr sich nämlich in Litauen die polnischen Kultur- und Verfassungseinflüsse verbreiteten, je mehr durch die allmählichen Konzessionen der Reichsprivilegien und die, wenn auch langsame, Entwicklung des Parlamentarismus die soziale Stellung des niedern Adels gehoben und sein politisches Verständnis geschult wurde, umso unerträglicher mußte die rücksichtslose, egoistische Magnatenherrschaft, die, wie wir sahen, schon Herberstein entsprechend verurteilt hatte, allgemeine Unzufriedenheit

1) Lachowicz, S. 193.

s) Über die Gesamtgeschichte der polnisch-litavischen Union rgl. die populäre, aber gründliche und quellenmäßige Darstellung bei J. Zerbiłło-Eabuński: Unia Litwy z Polską, Warsz. 1913, sowie vor allem die neue, vorzïgliche Arbeit St. Katrzoba'. Unia Polski z Litwą, Kraków 1915 (aus dem Sammelwerke: Polska i Litwa w dziejowym stosuniku).

s) Archiv der Fürsten Czartoryski in Krakau MS. 1604 pag. 58-74; vgl. meine Bearbeitung dieser für das Verhältnis des litavischen Adels zur Union entscheidenden Quelle im Przegląd histor. XVIII Heft 3. 
und Sehnsucht nach der in Polen herrschenden Freiheit erwecken. Zweitens war Litauen als selbständiger Staat dem rastlosen Vorwärtsdrängen Moskaus nicht mehr gewachsen; zu allen übrigen Gebietsverlusten in diesen Kämpfen kam 1563 der Fall von Połock und die ständige Bedrohung des kaum gewonnenen Livland. Hier konnte nur, wie dies nicht viel später Stefan Báthory's Erfolge bewiesen, ein gemeinsames Vorgehen Polens und Litauens Hilfe bringen.

Daher wurden einerseits des Königs Bemühungen, eine entsprechende Union zustandezubringen, immer energischer und führten zunächst in den Jahren 1564/6 zu durchgreifenden, ihren Abschluß vorbereitenden Reformen in Litauen, welche die Übermacht des Hochadels einschränkten, andererseits begannen auch nach und nach zahlreiche Magnaten die Notwendigkeit der Union einzusehen, so daß ihre Gegner immer mehr isoliert wurden. Es waren dies schon 1562 fast ausschließlich nur mehr die Radziwiłł und ihr unmittelbarer Anhang, die mächtigsten Oligarchen, die eben am meisten zu verlieren hatten ${ }^{1}$ ). Voll Erbitterung über die Unionspläne, von denen er den König nicht mehr abbringen konnte, über den wachsenden Einfluß der großen Massen des niederen Adels, starb Nikolaus Radziwiłł der Schwarze ${ }^{2}$ ), die Leitung der Oppositionspartei seinem Vetter überlassend.

Es läßt sich nun nicht leugnen, daß die kaiserlichen Gesandten in Polen, sogar der kluge Andreas Dudič, der seit 1565 unter ihnen die Hauptrolle spielte, diese.Verbältnisse nicht immer richtig zu beurteilen wußten. Erstens überschätzten sie den polnisch-litauischen Gegensatz, indem sie den Widerstand der allerdings noch immer übermächtigen Radziwiłł und ihrer Partei der Gesamtheit Litauens zuschrieben, zweitens aber auch die Stärke der Moskau zumeigenden Partei unter den Litauern ${ }^{3}$ ), was zur Folge hatte, daß der Kaiser allzusehr mit der Gefahr einer Kandidatur des Zaren auf den polnischen und litauischen Thron rechnete. Diese letztere Partei ließ sich weniger von national-religiösen Motiven ${ }^{4}$ ),

1) Die oben zitierte Adelskonföderation richtet sich vor allem gegen die Radziwiłł und betont eine sie erlänternde gleichzeitige Notiz im selben Manuskript, daß ganz Litauen nach der Union verlangte und nur einige Herren, Nikolaus der Schwarze und der Rote und der ihnen stets zur Seite stehende Eustachius Wołowicz, dagegen waren.

2) Sein politisches Credo, auch in Bezug auf die Union mit Polen, enthalten seine Briefe an Nikolaus den Roten vom 22. Februar und 1. März 1565 im Radziwiłł'schen Archiv zu Nieśwież, Abteilung IV (Familienbriefe).

s) Vgl. neben den vorhin zitierten Berichten Sauermanns von 1561, die des Dudič von 1566 (z. B. 19. August, die interessante Stelle fol. 149v) und 1568 (6. Juni).

4) Die von der russischen Literatur geflissentlich verbreitete Behauptung von der "russischen Irredenta im litauischen Staate ist dahin zu rektifizieren, daß es 
wie Dudič meinte, als von der Hoffnung leiten, daß durch die moskauische Herrschaft die endlosen, aussichtslosen Kriege an der Ostgrenze aufhören und die Macht des Hochadels gebrochen würde. Das Zustandekommen der Union mit Polen, das ja in diesen beiden Richtungen Abhilfe brachte, mußte auch diese Strömung alsbald abschwächen.

Erst auf dem berühmten Reichstage zu Lublin im. Jahre 1569 hatten die österreichischen Gesandten Gelegenheit, einen genaueren Einblick in diese Fragen zu gewinnen. Sie konnten sich nicht nur überzeugen, wie schwach in Litauen die moskauische Partei war ${ }^{1}$ ), sondern es wurde ihnen auch allmählich klar, daß der Widerstand gegen den UnionsabschluB, dessen Zeugen sie waren, nur von einigen $\mathrm{Ma}$ gnaten genährt und geleitet wurde, während alle übrigen Litauer hiezu geneigt waren ${ }^{2}$ ). Daher kann man ihnen, wenn sie auch durch ihren unbegründeten Optimismus die Aussichten der habsburgischen Sukzession im Jagellonenreiche nicht entsprechend zi fördern wußten, auch vom Standpunkt der österreichischen Interessen keineswegs den Vorwurf machen, daß sie hiezu den polnisch-litauischen Konflikt nicht auszunuïtzen verstanden hätten ${ }^{3}$ ). Allerdings standen die hervorragendsten Anhänger der Habsburger in Litauen, die Radziwiłł und - wenn auch nicht so hartnäckig - die Chodkiewicz an der Spitze der Oppositionspartei, welche im wohlverstandenen Klasseninteresse die Union mit Polen so lase als möglich zu gestalten suchte; sie wußten aber selbst daß sie bei der Allgemeinheit des litauischen Adels auf keine Unterstützung rechnen konnten ${ }^{4}$ ), dieser drohte vielmehr im Gegenteil gegen

in Litauen keine russische (im heutigen Sinne des Wortes d. h. großrussische) Bevölkerung gab, sondern Weiß- und Kleinruthenen, die sich überdies külturell von den großrussischen „Moskovitern “ immer mehr entfernten. Die religiöse Gemein. schaft (durch den griechisch-orientalischen Glauben) spielte wohl oft eine Rolle, doch muß betont werden, daß manche der bedeutendsten Heerführer Litauens gegen Moskau orthodoxen Glaubens waren und daß eben damals (1563) der letzte Rest einer politischen Beeinträchtigung des nichtkatholischen Adels in Litauen aufgehoben wurde.

1) Vgl. ihren Bericht vom 9. März 1569, Jagiellonki polskie V 251/2.

2) Ibidem, $\nabla \mathbf{3 1 6 .}$

3) Uebersberger, S. 384. Diese Auffassung ist dadurch zu erklären, daß der Verfasser im Abschnitte über die Union von Lublin den Ausführungen des russischen Historikers I. I. Łappo: Wielikoje kniażestwo litowskoje I, folgt, der in seiner durchaus einseitigen Darstellung die Union als eine vollständig . erzwungene, die Opposition der Litauer als eine allgemeine und grundsätzliche zu schildern trachtet. Ü̈ber einige besonders strittige Punkte vgl. meine Arbeit: Przylączenie Podlasia, Wołynia i Kijowszczyzny do Korony w r. 1569, Kraków 1915, sowie den Aufsatz: Unia lubelska, Kraków 1916.

4) Vgl. z. B. das deutliche Eingeständnis im Briefe Chodkiewicz's an Radziwiłł 6. Juni 1569 , Archeograficzeskij sbornik $k^{*}$ istorij siewierozapadnoj Rusi, Wiłna 1870, VII nr. 25. 
jene Magnatenpartei aufs entschiedenste aufzutreten, falls sie den $\mathrm{Ab}$ schluB der Union nochmals verzögern sollte ${ }^{1}$ ). Bekanntlich kam es: auch schließlich zu einer Verständigung, die in den beiderseitigen denkwürdigen Unionsakten rom 1. Juli 1569 ihren Ausdruck fand; es hatten aber diese Verhandlungen so lange gedauert, daß dem Reichstage keine Zeit blieb, sich mit manchen anderen wichtigen Fragen, so auch der Sukzession, zu beschäftigen. So hatten also die österreichischen Gesandten, von privaten Unterredungen mit dem Könige abgesehen, gar keine Gelegenheit, in dieser Beziehung die Aussichten der Habsburger zu fördern, und hätte ein Anschluß an die an Zahl so geringe und schließlich auch überwundene litauische Opposition in diesem Augenblicke, wo eine so gewaltige Mehrheit mit Sigismund August an der Spitze nach der für beide Staaten so notwendigen Union strebte, ihrer Sache nur Schaden gebracht.

Übrigens dürften jene Führer des litauischen Hochadels in der für sie so kritischen Zeit selbst wenig Lust gehabt haben, sich durch Verhandlungen über die habsburgische Thronkandidatur von der sie momentan in erster Linie beschäftigenden Unionsfrage ablenken zu lassen, und beschränkt sich das, was wir in den stürmischen Monaten vor dem Unionsabschlusse von ihren Beziehungen zum Kaiserhause wissen, auf einen Brief Maximilians vom 5. Februar $156 y^{2}$ ), worin er dem Sohne Nikolaus' des Schwarzen, Nikolaus Christoph Radziwiłł mitteilt, daß er zwei Pferde an ihn gesendet habe. Diese Artigkeit ist zugleich die erste Spur einer Annäherung an den jungen Fürsten, der damals eine noch wenig bedeutende Rolle spielte, aber bald darauf zu größtem Anwehen in Litauen gelangte und zum eifrigsten Anhänger der Habsburger wurde.

Ŭberhaupt wäre es ein Irrtum zu meinen, die litauischen Magnaten hätten dadurch, daß sie bei der Union mit mancher für sie wichtigen Forderung nicht durchdrangen, ihre bisherige Stellung im Großfürstentume eingebüßt. Es hatte sich wohl gezeigt, daß sie die unumschränkte Leitung der litauischen Politik verloren hatten, aber gerade um sie für das Unionswerk $z \mathfrak{u}$ gewinnen, hatte sie der König wieder einmal mit. hohen Würden und Güterverleihungen reich bedacht; so wurde z. B. Füst Nikolaus Christoph eben auf dem Reichstage von Lublin litauischer Hofmarschall ${ }^{3}$ ). Für uns ist hiebei besonders interessant, daß Sigismund Angust, der gesehen hatte, wie die Habsburger durch schön klingende

1) Archiv der Fursten Crartoryki in Krakan Ms. 1609 p. 1623.

2) Katalog der Raczyński'schen Bibliothek, l. c.

8) Vgl. auch die kolossalen Guterverleihungen an J. H. Chodkiewicz im oben. xitiorten Privileg vom 19. Demember 1568. 
Adelstitel auf den Ehrgeiz dieser Herren zu wirken verstanden, in jenen wichtigen Augenblicken ausnahmsweise dasselbe Mittel für seine Zwecke anzuwenden begann, wenn es auch nicht nur in Polen, sondern auch in Litauen ein ganz ungewöhnliches war. So erhob er vor dem Unionsreichstage den Johann Hieronymus Chodkiewicz, dessen Vater allerdings schon ein Reichsgrafendiplom besa $\beta$, nun auch seinerseits, ohne diese kaiserliche Standeserhöhung zu erwähnen, am 10. Juni 1568 zum Graf zn auf Szkłów, Mysz, Bychów und Hłusk ${ }^{1}$ ), und nach dem Reichstage, am 5. November 1569, den Palatin Wasil Tyszkiewicz, der ebenfalls zur Opposition gehört hatte, zum Grafen auf Łohojsk und Berdyczew ${ }^{2}$ ), indem er betont, dab seine Grafenstandsverleihung mit einer kaiserlichen gleichwertig sei.

Nach dem Abschlusse der Union von Lublin war aber wirklich die Frage, wer des letzten Jagellonen Nachfolger werden sollte, für alle, die die Stürme und Gefahren eines unvorbereiteten Interregnums voraussahen, zum wichtigsten Probleme des Staatslebens geworden, das aber leider auch auf den beiden letzten Reichstagen zur Zeit Sigismund Augusts (1570 und 1572) infolge der ron der protestantischen Partei aufgeworfenen konfessionellen Fragen nicht gelöst werden konnte. Umso ausgiebiger entwickelte sich daher in den letzten zweieinhalb Jahren vor dem Aussterben der Dynastie die private Agitation der einzelnen Parteien, bei der bekanntlich der rührige und scharf beobachtende, aber mehr für Intriguen kleineren Maßstabes als für eine großzügige, taktvolle diplomatische Tätigkeit geeignete kaiserliche Resident, Abt Johann Cyrus, eine in seinen zahlreichen Berichten an Maximilian deutlich zum A usdruck kommende Hauptrolle spielte ${ }^{3}$ ).

Begreiflicherweise nahmen an dieser inoffiziellen Vorbereitung zur kommenden Königswahl auch die führenden Magnaten Litauens hervorragenden Anteil; konnte doch nichts ihre durch die Union gefährdete Machtstellung so sehr stützen, als ein Herrscher, der ihren Interessen entsprechen würde und dem gerade sie zum Thron verholfen hätten. Und wirklich beweist ein Brief des Johann Chodkiewicz an Nikolaus Radziwiłł den Roten vom 15. Oktober 1569 4), daB schon damals, kaum zwei Monate nach dem Ende des Lubliner Reichstages, die vor den Polen streng geheimgehaltenen Intriguen der litauischen Herren in der

1) Kossakowski: Monografie hist. geneal. $146 \mathrm{Anm}$. Das Diplom publiziert bei J. Malinowskij: Sbornik matieriałow $\mathrm{k}^{\prime}$ istorii panow rady, S. 78.

2) Ausführl. Auszug aus dem Diplom bei J. Eappo, o. c., S. 717 Anm. 1.

3) Die Charakteristik Cyrus' bei Szujski: Stosunki dyplom., S. 393; W. Zakrzewski: Po ucieczce Henryka, Krakow 1878, S. 96 ; Uebersberger, S. 385/6.

4) Archeograficzeskij Sbornik, VII nr. 28. 
Frage der Königswahl in vollem Gange waren. Er beweist aber dabei auch, daß ein Umstand all ihre Bemühungen ungemein erschweren mußte, nämlich der Mangel an Solidarität und vor allem an gegenseitigem Vertrauen zwischen den einzelnen Familien. So lange es sich um die Union mit Polen handelte, war ein vorübergehendes Einverständnis zwischen den Radziwiłł und Chodkiewicz noch eher möglich gewesen 1), obwohl hiebei letztere in ihrer Opposition keineswegs sa weit gingen wie jene; jetzt aber, wo es sich in geheimem, ränkerollen politischen Spiele um den zukünftigen Einfluß unter einem neuen Herrscher handeln mußte, waren alle kleinlichen Rivalitäten wieder an der Tagesordnung. So z. B. besteht der Hauptinhalt des erwähnten Schreibens in überschwänglichen Versicherungen Chodkiewicz's, daß der Argwohn des Fürsten Nikolaus, er verrate ibre Geheimnisse in der Sukzessionsfrage den Polen, vollkommen unbegründet sei!

Aber der stille Kampf zwischen diesen beiden scheinbar verbündeten Familien, den uns erst Cyrus' Berichte ganz entschleiern werden, sowie ihr gemeinsamer Gegensatz zur polenfreundlichen Partei war nicht der einzige innere Zwist, der die Bedeutung des litauischen Hochadels im entscheidenden Augenblicke schwächen mußte. Vor allem waren es die alten dynastischen Fürstengeschlechter, die eine ausgesprochene Sonderstellung einnahmen. Schon während des Reichstages zu Lublin waren die Mißhelligkeiten zwischen den litauischen Herrengeschlechtern und den stolzen Fürstenhäusern der Słucki und Ostrogski zu Tage getreten ${ }^{2}$ ) und sollten sich während des Interregnums erst recht fühlbar machen. Zwar war mehr oder weniger für alle ein Habsburger der erwünschteste Kandidat, aber unmöglich war es, aus den verschiedenen sich bekämpfenden Familiengruppen eine einheitlich wirkende Partei zu bildẹn.

Von den litauisch-ruthenischen Fürsten war der mächtigste und reichste Konstantin Ostrogski, der allerdings durch die Einverleibung der Palatinate Wolhynien und Kiew, wo er seine Würden und Güter innehatte, in die polnische Reichshälfte, zu einem Senator der Krone Polen geworden war. Er wäre vielleicht am leichtesten für die kaiserlichen Pläne zu gewinnen gewesen, da er gerade in jenen Jahren ohnehin mit Maximilian II. verhandelte, um die in Böhmen gelegenen Raudnitz'er Güter, die er von den Tarnowski geerbt hatte, übernehmen zu können ${ }^{3}$ );

1) Ibid., nr. 21, 22, 23, 25. $119 / 20$.

2) Dniewnik Lublinskawo sejma 1569 goda (ed. Kojałowicz 1869), S. 8,

3) Vgl. die Briefe Sigismund Augusts, 1567/8, in der Biblioteka ordyn. Krasińskich 1872, S. 208, 210; sowie die Briefe des Kaisers und Ostrogskis vom 
wir finden aber in den Berichten des Cyrus keine Nachricht, daß er versucht hätte, sich diesem Fürsten zu nähern, um die alten Beziehungen seiner Familie zum Hause Österreich, deren wir schon einmal gedachten ${ }^{1}$ ), bei dieser Gelegenheit aufzufrischen. Auch von Ostrogskis Verwandten, dem tüchtigen, durch seine Siege über Moskau berühmten litauischen Feldherrn Fürsten Roman Sanguszko, der allerdings schon 1571 starb, weiß er nur zu berichten, wie gerne er auch gegen die Türken zum Schwerte greifen würde ${ }^{2}$ ), was gewiß geeignet war, ihn für die habsburgische Kandidatur, die ja stets den Bruch mit den Osmanen zur Folge zu haben schien, günstig zu stimmen. Ebenso gewann es keine konkrete Bedeutung, dal Fürst Andreas Kurbskij, der seinerzeit von Moskau nach Litauen geflohen war, an den kaiserlichen Gesandten mit dem Plane herantrat, Maximilian II. solle zwischen Polen und Moskau vermitteln, um eine allgemeine Türkenliga zustandezubringen; wurde doch Kurbskij's Absicht, behufs näherer Verständigung zum Kaiser zu fahren, nicht verwirklicht ${ }^{3}$ ). So beschränkten sich denn schließlich des Abtes Cyrus Bemühungen und Informationen, soweit sie die Magnaten der litauischen Reichshälfte betrafen, fast ausschließlich auf jene zwei politisch am meisten tätigen Familien der Radziwiłł und Chodkiewicz.

Aber selbst was diese betraf, war er sich anfangs nicht ganz im klaren, obwohl er sich Anfang 1570 längere Zeit in Wilna aufhielt, um die Absichten der eben dort versammelten litauischen Herren zu erforschen ${ }^{4}$ ). Auch er überschätzte wenigstens in den ersten Monaten seiner diplomatischen Tätigkeit die Stärke der moskauischen Partei in Litauen; teilweise schien $\mathrm{ihm}$ ferner der dortige Adel für die Kandidatur Johann Sigismund Zápolya's eingenommen zu sein, während er die Anhänger der Habsburger eher in Großpolen suchte 5). Erst Mitte 1571 beginnt in seinen Berichten die Überzeugung aufzutauchen, daB man

2. Juni 1570 und 2. Februar 1571 in den Polonica. Ferner Jagiellonki polskie V S. CXIII.

1) Vgl. auch die Fürsprache, welche 1553 Ferdinand I. bei Sigismund August für Ostrogski einlegte, Jagiellonki V S. CXXXVII.

2) Bericht vom 21. März 1571, Polonica ( $₫$ vir heroicus et spirans odium quoddam erga hostes crucis Christi ).

s) Außer den von Szujski in den Ss. rer. pol. I 134/5, 141 angegebenen Stellen sind auch die von Uebersberger, S. 398 Anm. 1, zitierten interessanten Berichte vom 26. November 1569, 8. Jänner und 31. Jänner 1570 in den Polonica zu berücksichtigen.

4) Bericht vom 8. Jänner 1570, Polonica.

5) Ss. rer. Pol. I 134, 137; des Kaisers Brief an Cyrus vom 13. Jänner 1570 in den Polonica. 
gerade von den Litauern die Wahl eines der Söhne des Kaisers am sichersten erwarten könne; wie er zu dieser Anschauung gelangte und warum er hiemit manche irrtümliche Vorstellung verknüpfte, erklärt uns sein hochinteressantes, bisher ganz unberücksichtigtes Schreiben an Maximilian rom 19. Juni 1571 1).

Er berichtet darin von einer bedeutungsvollen Unterredung mit dem litauischen Sekretär Mathias Sawicki, einer wenig bekannten, aber damals außerordentlich einflußreichen Persönlichkeit. Einer ganz unbedeutenden, polnischen Adelsfamilie Podlachiens entstammend, war er am Hofe Nikolaus Radziwiłł des Schwarzen aufgewachsen, in dessen Kanzlei er Verwendung fand und dessen Gunst und Vertrauen er rasch zu gewinnen wußte; als "homo ingeniosus", wie ihn Cyrus mit Recht nennt, benützte er dies, um in seiner heimatlichen Provinz verschiedene Landesämter, sowie die Würde eines litauischen Reichssekretärs zu erlangen, sein Vermögen schnell zu vermehren und in beiden Reichshälften Güter anzukaufen; als Podlachien bei der Union von 1569 an Polen kam, hatte er es äußerst geschickt verstanden, sich beiden Parteien anzupassen und sowohl des Königs, als auch der Radziwiłł Gunst zu bewahren, und sollte der kluge Emporkömmling schon binnen wenigen Jahren als Kastellan von Podlachien sogar Senator werden 2). Wenn auch sein usprünglicher Protektor nicht mehr lebte, war er doch durch seine vertrauten Beziehungen zu dessen Sohne Nikolaus Christoph und überhaupt zu allen Radziwiłł noch immer in die geheimsten Pläne dieses Hauses eingeweiht und wurde jetzt dazu ausersehen, in der Sukzessionsfrage zwischen ihnen und dem Vertreter des Kaisers zu vermitteln.

Die Eröffnungen, die er bei seiner Besprechung mit Cyrus machte, sind ein klarer Beweis, daß jene geheime, die Thronfolge betreffende Aktion der Radziwiłł, die, wie wir sahen, nach 1569 begonnen hatte, wirklich die Wahl eines Habsburgers zum Ziele hatte. Er erklärte nämlich gleich am Anfange, daß die Litauer, worunter natürlich die Partei der Radziwiłł zu verstehen ist, niemand anderen zum Nachfolger Sigismund Augusts haben wollen, als einen Sohn des Kaisers, am liebsten Erzherzog Ernst, den einst Nikolaus der Schwarze aus der Taufe gehoben hatte; seine Wahl würden sie gegebenen Falls gegen Moskau und gegen die anderen Parteien in Polen durchzusetzen wissen.

1) Polonica.

2) In dieser Würde unterzeichnete er am 31. Dezember 1575 das Wahldekret Maximilians (Uchańsciana, II nr. 154). Nähere Angaben über Sawickis Herkunft und seine Rolle auf dem Reichstage zu Lublin in meinem Buche: Przyłazczenie Podlasia, Wołynia i Kijowszczyzny, S. 74/6. 
Sofort deutete er aber auch an, was der Preis für eine so energische Unterstützung der habsburgischen Kandidatur sein sollte; getreu der zweideutigen Rolle, die er als Vertrauensmann der Radziwiłł schon auf dem. Lubliner Reichstage gespielt hatte, erhob nämlich Sawicki, trotz seiner polnischen Herkunft und trotz des vom König reichlich belohnten Eides der Treue, den er damals der Krone Polen geleistet batte, die ungeheuerlichsten Anschuldigungen gegen die Polen, die heftigsten Vorwürfe gegen die kaum abgeschlossene Union, die eine demütigende Knechtung Litauens bedeuten solle. Wir hören zwar noch nichts von jenen genauen, das Verhältnis zu Polen betreffenden Bedingungen, die 1572 von der Partei der Radziwiłł dem Kaiser gestellt wurden, aber es kam schon zum Ausdrucke, daB sie für den Fall der Wahl eines Habsburgers auf eine Abänderung des Unionsvertrages rechnete. Sawicki wurde nicht müde, dem Kaiser, dem er auch die problematische Aussicht, von Litauen aus ganz Moskau zu erobern, in Aussicht stellte, durch Cyrus die Angelegenheit der Wahl seines Sohnes auf den polnischlitauischen Thron angelegentlich ans Herz legen zu lassen, betonte sogar, daß der Erzherzog recht gut tschechisch lernen sollte, um sich mit seinen künftigen Untertanen halbwegs verständigen zu können. In wessen Auftrage er aber dies alles vorbrachte, bewiesen, wenn es noch nötig gewesen wäre, seine Schlußbemerkungen. Erstens gab er deutlich zu verstehen, daß das beste Mittel, sich jene Wahl zu sichern, darin bestehe, das Haus der Radziwiłł - „quae praecipua authoritate in ea natione polleat" - durch "Wohltaten" zu gewinnen, hiezu z. B. den Aufenthalt der drei jüngeren Brüder des Fürsten Nikolaus Christoph an der Universität Leipzig ${ }^{1)}$ zu benützen. Inzwischen aber warnte er Cyrus vor jenem anderen mächtigen litauischen Magnaten, mit dem die Radziwiłł noch vor kurzem scheimbar zusammenwirkten, dessen mit der ihrigen rivalisierende Stellung sie aber im Vorhinein untergraben wollten; vollkommen grundlos, in rücksichtsloser Entstellung der Tatsachen beschuldigte Sawicki den uns wohl bekannten Johann Chodkiewicz, daß er, obwohl ein „homo novus", nach Sigismund Augusts Tode, der nach Voraussagen der Astrologen binnen Jahresfrist eintreten werde, die Herrschaft über das Großfürstentum Litauen anzustreben beabsichtige, daß er aber allgemein verhaßt sei, man seine Tyrannei befürchte, weil er am Blutvergießen Vergnügen finde, daß er die Verwaltung Livlands aufs nachlässigste führe, in Schulden stecke u. s.w.

1) $1570 / 2$ sind dort Georg, Albert und Stanislaus Radziwiłł, Füsten auf Ołyka und Nieświcż, Grafen auf Szydłowiec, immatrikuliert (Metrica nec non liber nationis Pcl. univ. Lipsiensis, Archiwum do dziejów liter. i oświaty w Polsce II). 
Cyrus brauchte nicht viel diplomatische Fähigkeiten, um angesichts: dieser Ausführungen den rücksichtslosen Eigennutz, die gegenseitige Eifersucht der litauischen Magnaten, den Ehrgeiz Sawicki's selbst zur durchblicken, was er auch hierauf in seinem Berichte an Maximilian offen aussprach; ebenso bemerkte er wohl die gehässigen Übertreibungen in den erwähnten Behauptungen über die Union von Lublin und erwiderte daher in richtigem Verständnis ihrer weltgeschichtlichen Bedeutung, daß sein kaiserlicher Herr die Aufrechterhaltung der Eintracht zwischen Polen und Litauen wünsche, die nur so vereint ,vallum munitissimum contra paganos" bilden können. Wenn er sich aber auch. überhaupt Sawicki gegenüber wenigstens anfangs einer vorsichtigen Zurückhaltung befleiBigte, so riet er doch dem Kaiser, dem er diese geheime Unterredung ausführlich mitteilte, die vom Vertrauensmanne der Radziwiłł gemachten Eröffnungen wohl zu berücksichtigen und auszunützen. Ja man kann sogar mit Hilfe von Cyrus' späteren Berichten unzweifelhaft feststellen, da $B$ er selbst sich immer stärker in dieser Richtung beeinflussen ließ: schon am 11. Juli ${ }^{1)}$ wiederholt er in seinem Schreiben an den Kaiser die merkwürdigerweise eingetroffene, ihm - wie wir sahen - von Sawicki mitgeteilte Prophezeiung, daß der König bloß ein Jahr mehr zu leben babe, und stellt es schon als ganz unzweifelhaft hin, daß die Litauer, stets bereit, bei entsprechender Gelegenheit die Union zu lösen, im Falle daß die Polen einen anderen König wählen würden als einen der österreichischen Erzherzoge, sich von ihnen trennen und einen eigenen Herrscher, selbstverständlich einen Habsburger, auf den litauischen Thron erheben würden, wobei sie auf den Anschluß Preußens und Livlands hoffen. Welche Bedeutung aber Maximilian selbst diesen Aussichten und Nachrichten zuschrieb, erhellt aus seinem Antwortschreiben an Cyrus vom 21. Juli 2); er fordert nämlich seinen Gesandten auf, auch fernerhin jenen Mathias Sawicki in seinen Sympathien und seiner Dienstbereitschaft für das Haus Habsburg zu bestärken und ihm in entsprechenden Worten die hohe Gunst, deren sich beim Kaiser die Familie Radziwiłł erfreue, zu schildern. Und auch später noch, in den letaten Monaten Sigismund Augusts, betont Cyrus immer wieder ${ }^{3}$ ), da 3 die Litauer erstens zu den eifrigsten Anhängern der habsburgischen Kandidatur gehören und zweitens die Union von Lublin rückgängig machen wollen.

1) Polonica.

2) Polonica.

s) Z. B. in seinen Berichten über den Reichstag von 1572, 11. April, 14: Mai, Polonica. 
Während sich aber der kaiserliche Gesandte selbst eigentlich nur auf Erkundigungen, Unterredungen wie die mit Sawicki und Berichte an Maximilian beschränkte, entwickelte jemand anderer eine viel konkretere Tätigkeit, um den Habsburgern die Nachfolge nach Sigismund August zu sichern. Es war dies der päpstliche Nuntius Commendone, der eben damals zum zweiten Male im Jagellonenreiche weilte und schon während seiner ersten dortigen Legation, in den Jahren 1563/5, für die Zukunftsaussichten des Hauses Österreich vorgearbeitet hatte. Jetzt, da der entscheidende Zeitpunkt nahte, trachtete er aufs eifrigste, sowohl in der polnischen, wie auch in der litauischen Reichshälfte für das herannahende Interregnum eine starke österreichische Partei zư bilden, und meinte wohl ebenso wie Cyrus, daß in Litauen nur die seit Jahrzehnten dem Hause Habsburg nahestehenden Radziwiłł ibren sicheren Grundstock bilden konnten; besser aber als dieser erkannte er, daß es auch unumgänglich nötig war, dem inneren Hader zwischen den litauischen Herrengeschlechtern ein Ende zu machen, vor allem. zwischen den Radziwiłł und den ja ebenfalls zu Österreich gravitierenden Chodkiewicz ein aufrichtiges Einvernehmen herzustellen und der gegenseitigen Mißgunst, die wir so deutlich in Sawicki's Anschuldigungen zu Tage treten sahen, endlich abzuhelfen.

In diesem Wunsche begegnete er den gleichfalls dahin gerichteten Bestrebungen des jungen Fürsten Nikolaus Christoph Radziwiłl, der ebenfalls, wie seine Privatkorrespondenz deutlich beweist 1), ein gegenseitiges Einverständnis zwischen den litauischen Magnaten für entscheidend wichtig hielt und in diesem Sinne auf seinen Oheim Nikolaus den Roten zu wirken suchte. Da es ebendieselben Briefe auch ganz unzweifelhaft machen, daß er wirklich die Wahl eines Herrschers aus der „domus Austriaca“ für die einzig wünschenswerte hielt ${ }^{2}$, hatte Commendone vollkommen recht, daß er bei. ihm mit seinen Bemühungen den Anfang machte. Und wirklich erklärte sich der Sohn Nikolaus des Schwarzen nicht nur für seine Person zur Unterstützung der östereichischen Kandidatur bereit, sondern meinte auch, daß das Haupt der Familie Chodkiewicz, Graf Johann Hieronymus, ebenfalls leicht zu gewinnen wäre, da er nichts heftiger befürchte, als einen Sieg der Anhänger Moskaus ${ }^{3}$ ). Bekanntlich ${ }^{4}$ ) kam

1) A. Traczewskij: Polskoje biezkorolewie, Moskwa 1863, Beilage 4, 6, 7.

2) Ibidem, Beilage 4 (Brief an Nikolaus den Roten vom 15. Juli 1572).

8) Vgl, ebendort Beilage 9 (Brief Chodkiewicz's vom 31. August 1572). Schon 1570 hatten sich beide Herren einander genähert, vgl. Archeograf. Sbornik VII nr. 29,30 .

4) A. M. Gratiani: De vita J. F. Commendoni cardinalis, Patavii 1685, S. 364 -370 (Buch 4, Kap. 3). 
es alsbald, noch zu Lebzeiten Sigismund Augusts, auf einer geheimnisvollen Zusammenkunft in Wäldchen, wo sich der päpstliche Legat zu ergehen pflegte, nicht nur zu einer Verständigung zwischen Radziwiłł und Chodkiewicz, sondern auch zu einer gemeinsamen Vereinbarung mit Commendone, betreffend die Wahl eines Sohnes Maximilians: ohne auf die Entscheidung der Polen zu warten, sollte er sofort nach des Königs Tode zum Großfürsten von Litauen gewählt werden, was dann, unterstützt durch die Bereitschaft eines größeren Heeres, gewiß zur Folge hätte, daß er nachträglich auch in Polen zum Könige gewählt würde. Es sollte also dasselbe Mittel angewendet werden, dessen sich seinerzeit Sigismund I. zweimal mit vollkommenem Erfolge bedient hatte, zunächst im Jahre 1506, als er sich nach seines Bruders Alexander Tode zuerst in Wilna von den Litauern zum Großfürsten wählen ließ, um seine Wahl zum König von Polen unzweifelhaft zu machen 1), und hierauf 1529, als er es durch die Erhebung seines neunjährigen Sohnes auf den litauischen Großfürstenstuhl durchzusetzen wußte, daß dieser auch in Polen schon damals, zu Lebzeiten seines Vaters gewählt und gekrönt wurde ${ }^{2}$ ).

Trotz dieser Analogien in der Geschichte der Jagellonen, auf die man damals hinwies, muß nachdrücklich betont werden, daß diesmal der scheinbar so ähnliche Plan einen weit bedenklicheren Staatsstreich ${ }^{3}$ ) ankündigte. Handelte es sich doch zu Sigismund I. Zeiten um das angestammte Herrscherhaus, das ohnehin nicht ernstlich zu fürchten brauchte, bei der Königswahl zu unterliegen, sondern nur formell seine dynastische Stellung dem polnischen Wahlrechte gegenüber stärken wollte und in Litauen ohnehin ein erbliches Recht auf den Thron besaß; außerdem aber hatten doch die Litauer, die sich bei jenen Prä. zedenzfällen darauf berufen konnten, daß sie die Union von 1501 nicht angenommen hatten, nunmehr zu Lublin feierlich beschworen, daß sie von nun an stets gemeinsam mit den Polen den gemeinsamen Herrscher wählen würden; es hätte also die Erfüllung des mit Commendone be-

1) L. Finkel: Elekcya Zygmunta I, Kraków 1910.

2) L. Kolankowski: Zygmunt August w. ks. Litwy do r. 1548, I Sukcesor Zygmunta, I.

3) In Polen war man sich auch dessen wohl bewußt; so heißt es in der Instruktion der Wojewodschaft Reußen für den Konvokationsreichstag (14. Dezember 1572, bei Noailles: Henri de Valois et la Pologne en 1572, III Documents, Paris 1867, S. 235) ausdrücklich, daß in den früheren Fällen, „da es sich um Söhne oder Brüder der königlichen Dynastie handelte, dies leicht geduldet wurde, jetzt aber eine alia facies rerum sei, weil wir uns von anderswo einen Herrscher suchen müssen, den sie mit uns gemeinsam haben sollen". Daher meinte man sogar, sich zu einer Konföderation zusammenschließen zu sollen, um jenen Plan zu verhindern. 
sprochenen Planes einen unzweifelhaften Bruch des Unionsvertrages von 1569 bedeutet und das mühevolle Lebenswerk des letzten Jagellonen, dessen Heilighaltung er in seinem Testamente seinen Völkern in so ergreifenden Worten ans Herz legte, wäre in kürzester Zeit zerstört worden. Um aber die Gesamtlage richtig zu verstehen, die Politik der litauischen Magnaten, ihre Ziele und Aussichten beurteilen zu können, sowie zu unterscheiden, ob auf diesem Wege, der dem Kaiser von allem Anfange an bedenklich schien, die Habsburger wirklich den polnischlitauischen Thron gewinnen konnten, müssen folgende zwei Fragen beantwortet werden: wie weit die Radziwiłł und Chodkiewicz in ihrer Aktion gegen den Lubliner Unionsvertrag gehen, ob sie ihn vollständig lösen oder nur in gewissen Punkten abändern wollten, und inwieweit sich die übrigen Litauer mit ihnen solidarisierten, ob das ganze Land ihren Standpunkt teilte.

Commendone's Biograph, sein Sekretär Graziani, dem wir die Schilderung jener geheimen Zusammenkunft verdanken, behauptet, daß die beiden litauischen Magnaten hiebei anfangs den Wunsch äußerten, überhaupt einen selbständigen Herrscher in Litauen zu haben, da ihr Land durch die Verbindung mit Polen nur Schaden gelitten habe; erst. Commendone, der eine Schwächung beider Länder oder gar einen Krieg zwischen ihnen befürchtete, hätte sie dazugebracht, daß sie dies dem Kaiser selbst anheimzustellen beschlossen. Man müßte also meinen, daß ihre eigentliche Absicht dahin gegangen sei, den gewählten Erzherzog ausschlieblich in Litauen zu behalten und nicht einmal eine Personalunion mit Polen zu dulden. Leicht läßt sich aber erweisen, daß Graziani in diesem Punkte, wohl um ein neues Verdienst seines Herrn hervorheben zu können, unbedingt übertrieben hat. In einem der Briefe, die Fürst Nikolaus Christoph gleich nach Sigismund Augusts Tode streng vertraulich an seinen Oheim sehrieb, finden wir z. B. die Ansicht aus-

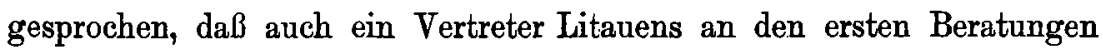
der Polen während des Interregnums teilnehmen solle, um diese zu überzeugen, daß man von litauischer Seite die Union keineswegs zerreißen wolle 1); allerdings betont er fast gleichzeitig, daß man die Gelegenheit benützen müsse, um eine für Litauen günstige Abänderung dieser Union durchzusetzen ${ }^{2}$ ), und meint, daß es ganz gut wäre, wenn die Wahl des neuen Herrschers in beiden Reichshälften getrennt stattfände, weil ja dann eben jener Plan, durch die Wahl eines Habsburgers von Seiten der Litauer auf die Polen einen Druck auszuüben, am besten

1) Traczewakij, Beilage 5 (18. Juli 1572).

8) Tbid., Beilage 4 (15. Juli 1572). 
gelingen könnte. Der radikalste Schritt, an den er denkt, wäre nach seinen eigenen Ausführungen der, die Polen nötigen Falles durch Waffengewalt zur Annahme des von den Litauern gewählten österreichischen Kandidaten zu zwingen 1); so sehr aber dieser Gedanke dem Geiste der Union widerspricht, ebenso deutlich beweist er, daß auch Radziwiłt an keine vollkommene Trennung beider Reiche dachte.

Übrigens stünde dies mit dem vorhin skizzierten Plane, der eben den Gegenstand der Verhandlungen mit Commendone bildete, in unvereinbarem Widerspruche, während die konkreten Forderungen der litauischen Magnaten, die Graziani im weiteren Verlaufe seiner Schilderung angibt, in Übereinstimmung mit jenem Plane deutlich erkennen lassen, um was es sich ihnen in Wirklichkeit handelte. Diese von ihm nur kurz dargestellten Wünsche erscheinen aber auch vor allem deshalb als einzig glaubwürdig, weil sie, in allerdings viel eingehenderer Form, in einem Dokumente vollständige Bestätigung finden, das während der beiden ersten Interregna für die Beziehungen des litanischen Hochadels zur habsburgischen Kandidatur von hervorragender Bedeutung war. Es sind dies die "Articuli, quos proceres Lythuanici sibi ante electionem iureiurando confirmari postulant", die sie schon 1572, jedenfalls gleich nach des Königs Tode (7. Juli), nach Wien sandten ${ }^{2}$ ) und deren Entstehung, wie wir sehen, auf jene ersten Verhandlungen mit Commendone, zu Lebzeiten Sigismund Augusts, zurückgehen muß. Daher verdienen ihre einzelnen Punkte kurz besprochen zu werden.

Die ersten zwei, Aufrechterhaltung der ,electio libera " und aller von den vorhergehenden Großfürsten von Litauen und Königen von Polen verliehenen Freiheiten und Privilegien, sind bloß jene selbstrerständlichen Garantien, welche sowohl die Polen wie die Litauer vor der Wahl jedes neuen Herschers verlangten. Aber schon der dritte fordert in entschiedenen Worten eine "reformatio" der polnisch-litauischen

1) Ibid., Beilage 6 (29. Juli 1572).

2) Polonica, 1572 ohne Datum (fasc. 10, conv. h., fol. 101); vielleicht ist dies "eben jenes Dokument, das - wie Nikolaus Christoph Radziwiłł 29. Juli schrieb - Nikolaus der Rote an den kaiserlichen Gesandten schickte. Es ist höchst bezeichnend, daB, als später die litauischen Magnaten zur Partei Heinrichs von Valois übergingen, sie sich von dem französischen Gesandten eine Deklaration ansstellen ließen (26. April 1573), in der ihnen die Erfüllung genau derselben Wünsche und Bedingungen zugesichert wird (Noailles: Henri de Valois et la Pologne, III 399402); dort finden wir auch einen weiteren Beweis, daB, wie unten im Texte nach gewiesen werden wird, alle diese Forderungen blob ron der Partei der Radziwiłł und Chodkiewicz ausgingen: Monluc und Lansac erklären ja ausdrücklich, daß sie diese Deklaration ausstellen, um die einflubreichsten Würdenträger Litauens, Nikolaus .Radziwiłł und Johann Chodkiewicz, für die französische Kandidatur zu gewinnen! 
Union, nicht ihre Auflösung, wohl aber eine Abänderung der ,Unionsformel* von 1569, die, wie hier behauptet wurde, eine „inhonesta subiecto " Litauens bedeute. Wie übertrieben diese Behauptung war, erhellt am besten daraus, daß ja im Lubliner Vertrage keineswegs Litauen dem polnischen Reiche einverleibt wurde, wie dies eine radikale Partei in Polen öfter verlangt hatte, sondern ein ausgesprochen dualistischer Staat gebildet wurde, dessen eine Hälfte eben auch fernerhin das, Großfürstentum Litauen" mit eigener Regierung, eigenem Heere und Finanzen, eigenem Rechte und eigener Staatssprache bildete. Womit aber die litauischen Magnaten so unzufrieden waren, führten sie im folgenden eingehend aus. Unleidlich schien es ihnen, daß nur mehr ein gemeinsamer polnisch-litauischer Reichstag bestehen sollte, wonach allerdings der litauische Adel - gegen ihren Willen - schon seit Jahren verlangt hatte, und wollten sie die ehemaligen, gesonderten litauischen Reichstage wieder eingeführt haben; auf diesen hatten natürlich der Hochadel, die Ratsherren und erblichen, aristokratischen Mitglieder, die führende Rolle gespielt, während im gemeinsamen, nach polnischem Muster, die Landbotenkammer, die Vertreter der Allgemeinheit des Adels einen entscheidenden Einfluß hatten. Ferner sollten die vier 1569 Polen veinverleibten Palatinate Podlachien, Wolhynien, Bracław und Kiew wieder der litauischen Reichshälfte zufallen, sowie auch das gemeinsame Reichsland Livland ausschließlicher Besitz Litauens werden. Schließlich verlangte man, daß alle Würden und Ämter im Großfürstentum nur mit Einheimischen besetzt werden sollten; zwar war es ja auch ein Hauptgrundsatz der polnischen Verfassung, daß in jedem Gebiete, jeder Provinz des Reiches nur ein dort Ansëssiger ein Amt erhalten konnte, aber den exklusiven litauischen Magnaten genügte dies wicht: nicht jeder, der in Litauen ein Gut besaß, sollte dort ein amtsfähiger „Indigena" sein, sondern nur ein solcher Edelmann, dessen Geschlecht seit vier Generationen daselbst lebte! Die übrigen Wahlbedingungen, wie Gleichberechtigung der Griechisch-Orthodoxen, Aufrechterhaltung des alten Fürstenstandes, waren nicht mehr gegen Polen gerichtet.

Der Standpunkt der Partei der Radziwiłł und Chodkiewicz läßt sich also dahin zusammenfassen, daß der Zusammenhang mit Polen zwar aufrechterhalten, aber alles rückgängig gemacht werden sollte, wodurch zu Lublin die bisherige Magnatenherrschaft in Litauen geschwächt worden war, und die strittigen Territorien, die 1569 Polen zufielen, wieder an Litauen fallen sollten. Die Annahme dieser Bedingungen, die, wie es am Ende hieß, der kaiserliche Gesandte garantieren und der Thronkandidat vor dem Regierungsantritte beschwören mußte, war also der Preis, um den der Kaiser jene mächtigen Geschlechter des Groß- 
fürstentums, mit denen die Habsburger schon seit so langer Zeit. nahe Beziehungen angeknüpft hatten, für die rückhaltslose Unterstützung der österreichischen Kandidatur auf den Thron der Jagellonen gewinnen konnte. Konnte aber diese Unterstützung wirklich den erwünschten Erfolg gewährleisten? Um dies zu entscheiden, muß jene zweite vorhin gestellte Frage beantwortet werden, ob nämlich der Standpunkt der Herren, mit denen Commendone verhandelt hatte, auch der ganz Litauens war. Nur in diesem Falle war ja mit ihrer Hilfe die Wahl eines Habsburgers im Groffürstentume und ein entsprechender Druck auf die polnische Reichshälfte durchführbar.

Wieder kann uns zunächst die Korrespondenz des Fürsten Nikolaus Christoph Aufschluß geben. Vor allem ist daraus zu entnehmen, daß nicht einmal die Verständigung der Familien Radziwiłł und Chodkiewicz eine vollständige war, da ja der Fürst seinen Oheim, den Palatin von Wilna, erst dringend bitten muß, sich um des gemeinsamen. Zieles willen mit Johann Chodkiewicz, dessen guten Willen er betont. ins Eivernehmen zu setzen ${ }^{1}$ ). Ebenso hält er es aber auch für dringend nötig, sich anch mit den anderen, den Radziwiłł bisher feindlichen. Magnatengeschlechtern, vor allem mit dem Fürsten Stucki, auszusöhnen ${ }^{2}$ ); wenn er dies aber auch anfangs für leicht möglich hielt, so. mußte er einige Monate später selbst seinen Oheim warnen, daß ihren Gegnern, den Hlebowicz, sowie den Fürsten Słucki und Ostrogski nicht. zu trauen sei, daß diese sogar im Stande wären, Nikolaus Radziwiłł und Johann Chodkiewicz, als die höchsten und einflußreichsten Würdenträger, gewaltsam aus dem Wege zu räumen ${ }^{3}$ )! Ebenso gut wußte er aber auch, daß natürlich nicht nur unter den einzelnen Magnatengeschlechtern, sondern vor allem auch zwischen diesen und dem übrigen Adel ein gefährlicher und, wie er behauptete, von den Polen genährter Unfriede herrschte 4). All dies erfahren wir von Radziwiłł selbst, der aber gewiß bemüht war, es vor den Vertretern des Kaisers und seiner Interessen verborgen zu halten und die Ziele und Forderungen seiner Partei als die ganz Litauens hinzustellen trachtete. Bald jedoch sollte auch Cyrus, als er Ende 1572 nach Litauen gesandt wurde, in die dortigen Verhältnisse einen - allerdings verspäteten - besseren Einblick gewinnen, als bisher; sein bis jetzt vollkommen übersehener $\mathrm{Be}$ -

\footnotetext{
1) Traczewskij, Bei 4.

2) Ibid., Beil. 6.

9) Ibid., Beil. 7 (31. Jänner 1573).

4) Ibid., Beil. 6 .
} 
richt vom 1. Dezember dieses Jahres ${ }^{1}$ ), den er aus Wilna an Maximilian II. sandte, ist schon deshalb von größtem Interesse, weil er in unparteiischer Darstellung der Tatsachen endlich auch über die Gegenpartei in Litauen gründlichen Aufschluß gewährt.

Klar und deutlich ist es hier ausgesprochen, daß bloß die Radziwiłł und Johann Chodkiewicz, um sich an den Polen dafür zu rächen, daß die Union von Lublin nicht nach ihrem Sinne durchgeführt wurde, diese gewaltsam, sogar um den Preis gefährlicher innerer Wirren, zur Wahl Erzherzog Ernst's zwingen und hiebei den Unionsvertrag brechen wollten. Die vernünftigere Mehrheit aber unter den Litauern („plerique tum prudentiores maxime"), mit dem würdigen und klugen Bischof von Wilna Valerian Protasewicz an der Spitze, war hiemit keineswegs einverstanden und fürchtete, da $\beta$ die genannten Herren "durch ihr verwegenes und unerwünschtes Streben, die Union zu lösen, und durch die Unzuverlässigkeit ihrer Versprechungen" sich alle zum Feinde machen und Litauen ins Verderben stürzen würden. Als Cyrus selbst dem Fürsten Nikolaus Christoph riet, den Polen gegenüber den Weg friedlicher Überredung einzuschlagen, stimmten ihm alle übrigen Litauer bei und Bischof Protasewicz, ein eifriger litauischer Patriot, der stets bei den Unionsverhandlungen die Interessen seines engeren Vaterlandes energisch vertreten hatte, erklärte offen, daß, wenn sogar sein Leben in Gefahr kommen sollte, er niemals von der Lubliner Union, die er zu wahren beschworen hatte, abstehen werde ${ }^{2}$ ). Auch die Absicht Radziwiłts, der behauptete, Litauen habe durch die Angliederung der erwähnten vier Palatinate an Polen für den Kriegsfall 10.000 Reiter eingebüßt, diese Gebiete während des Interregnums zurückzugewinnen, wurde von der Gegenpartei in Litauen selbst keineswegs gebilligt. Wußte man doch, daß, wie es sich teilweise schon 1569 gezeigt hatte ${ }^{3}$ ), die strittigen Länder sich mehr der polnischen Reichshälfte zuneigten und nicht zu erwarten war, daß sie sich Litauen anschließen würden ${ }^{4}$ ). Daher war der Bischof gar nicht damit einverstanden, daß die Radziwiłł kurz vorher, selbstverständlich ohne Erfolg, die Podlachier und Wol-

1) Polonica; die Schilderung der litauischen Verhältnisse in einer dem eigentlichen Berichte hinzugefügten Beilage (fasc. 10, conr. i, fol. 178-181).

2) ... saperte dicit se, etiamsi capitis subeundum sit periculum, nunquam recessurum ab Unione facta Lublini, quam se servaturum iuravita ...

9) Vgl. in meiner vorhin zitierten Arbeit: Przyłączenie Podlasia, Wołynia ..., S. 38, 87, $197 / 8$.

4) „Vix esse, quod Volinhios et Podlaschios putent suis accessuros partibus, etiam Polonis non adversantibus, a quibus minus quam ab his (scil. Lithuanis alienos esse perspectum site. 
hynier zum Abfalle von Polen zu bewegen versucht hatten, und sagte auch dem kaiserlichen Gesandten, daß er unbedingt dagegen sei, die verlorenen Provinzen jetzt zurückzuverlangen, da sie einmal Polen zugesprochen worden waren und ein solcher Schritt nur höchste Verwirrung und den Untergang des Vaterlandes zur Folge haben könnte.

Höchst bemerkenswert ist hiebei, daß auch die zu Polen haltende, den Radziwiłł und ihrem Anhange feindliche Mebrheit Litauens ebenfalls mit der habsburgischen Kandidatur sympathisierte, ihr aber auf legalem Wege zum Erfolge zu verhelfen wünschte. Protasewicz stellte Cyrus dar, daß er eine gemeinsame, einträchtige - also der Union vou Lublin entsprechende - Wahl des Erzherzogs durch beide Völker wünsche, die Litauen gegen Moskau besser sicherstellen würde, als die Intriguen der Magnaten, welche die Polen reizen mußten. Hier schien sich den Plänen des Kaisers eine viel entsprechendere Aussicht zu erschließen und hätten die Bemühungen seiner Gesandten und Agenten einen sichereren Grund gefunden, als bei den geheimen Verhandlungen mit einigen in Litauen selbst angefeindeten Magnaten, die sich eigentlich nur von ihrem persönlichen Ehrgeiz leiten ließen. Mußte doch Cyrus im selben Berichte dem Kaiser mitteilen, daß Johann Chodkiewicz ihm nicht ganz zuverlässig schien, daß es sich ihm hauptsächlich darum handle, von den Habsburgern, wie einst die Radziwiłł, den Fürstentitel zu erhalten und dann durch Vermählung seines Sohnes mit der Tochter des Herzogs von Kurland Gothard Kettler dieses Herzogtum für sein Haus zu gewinnen. Solche Motive waren also für ihn, der einst selbst für die Union mit Polen gearbeitet hatte ${ }^{1}$ ), maßgebend, um sich den Radziwiłł, denen er im Grunde immer abgeneigt blieb, in einem so kritischen Augenblicke anzuschließen.

Cyrus' so inhaltsreiches Schreiben beweist wieder einmal, daß er ein besserer Beobachter als Diplomat war. Es war aber auch überhaupt, wie erwähnt, schon zu spät, seine in Litauen gemachten Erfahrungen zu berücksichtigen. Hatte sich doch der Kaiser sofort nach Sigismund Augusts Tode, den traditionellen Beziehungen zu den Radziwiłł entsprechend, gerade an den Fürsten Nikolaus Christoph gewandt 2), um ihm, unter Berufung auf die oft erwiesene Anhänglichkeit seiner Familie an das Haus Osterreich, die Unterstïtzung der habs-

1) 1562 war er sogar einer der Gesandten, die die vorhin erwähnte Adelskonföderation an den König sandte, um nach der Union mit Polen zu verlangen!

2) Niemcewicz: Zbiór pamiętników, II 73/4, ebenso im zweiten Interregnum ibid. S. 74/5; vgl. den Katalog der Raczyński'schen Bibljothek, 1. c. 
burgischen Kandidatur auzuempfehlen und sich mit ihm durch mündliche Aufträge des Überbringers seines Schreibens in vertrauliche Verbindung zu setzen. Nun war es ihm nicht mehr möglich, über die Radziwiłł hinweg Anschlu $B$ an ihre Gegner zu suchen.

Alle unvorteilhaften Folgen des verhängnisvollen Umstandes, daß, was Litauen betraf, Maximilian seine Hoffnungen auf jene isolierte, eigennützige und nicht immer zuverlässige Magnatengruppe stützen mußte, traten in beiden, bekanntlich so rasch aufeinander folgenden Interregnen deutlich zu Tage. Ohne näher auf die schon oft geschilderte Geschichte dieser Königswahlen einzugehen, sei zum Beweise nur auf die bemerkenswertesten Umstände hingewiesen.

So ist es höchst bezeichnend, da $\beta$ gleich am Anfange, als der erste kaiserliche Agent nach Litauen eilte, Chodkiewicz $\mathrm{ihm}$ in der allgemeinen Versammlung der litauischen Senatoren nur ausweichend antworten konnte und erst bei einer vertraulichen, privaten Unterredung er und Radziwiłł die Wahl Ernst's für sicher erklärten, wenn nur der Kaiser die vorhin von uns besprochenen Bedingungen annehme, seine Anbänger zu belohnen und eventuell gegen die Polen zu unterstützen verspreche ${ }^{1}$ ). So mußten die Bestrebungen Österreichs sofort den Charakter geheimer Intriguen annehmen, der ihnen die Mehrheit des Adels abwendig machen mußte, andererseits aber gar keinen Nutzen bringen konnte, da der Kaiser von allem Anfange an schwankte und zögerte, auf die ihm von der Radziwiłł'schen Partei aufgedrängte Taktik einzugehen ${ }^{2}$ ). Sowohl während des ersten, wie des zweiten Interregnums betonte er in den Aufträgen seiner Diplomaten, daß er die polnischlitauische Union, das alte Einvernehmen beider Reiche, aufrechterhalten möchte, aber doch im schlimmsten Falle den Vorschlag einer Sonderwahl in Litauen keineswegs endgültig zurückweisen wolle ${ }^{3}$ ). So zögerte

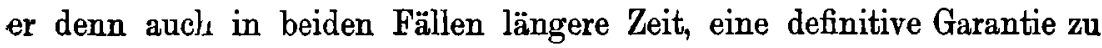
erteilen, daß er jene so offen gegen Polen gerichteten Bedingungen erfüllen werde ${ }^{4}$ ), was natürlich die Radziwiłł in Ungeduld versetzte, und erst am 7. Mai 1575 entschloß er sich, ibnen darauf eine feier-

1) T. Wierzbowski: Zabiegi ces. Maksymiliana II o koronę polską, Ateneum 1879 III 422.

2) Vgl. z. B. W. Zakrzewski: Po ucieczce Henryka, S. 97.

s) T. Wierzbowski, o. c., III 423/5 (1572); Biblioteka ordyn. Krasińskich 1872, S. 273/5 und 278/9 (die Auszüge aus den Polonica von 1575 in den Anmerkungen).

4) T. Wierzbowski, III 428/9, IV 69/70. 
liche Urkunde auszustellen, in der er alle Forderungen, wie wir sie oben besprochen haben, oft wörtlich ihren Text wiederholend, annahm 1).

Diese Unentschlossenheit, die allerdings auch mit des Kaisers Beziehungen zu Moskau zusammenhing ${ }^{2}$ ), worauf hier nicht näher eingegangen werden kann, hatte natürlich zur Folge, daß es auch die Radziwiłł und Chodkiewicz mit ihren Verpflichtungen nicht zu strenge nahmen und schließlich, wie bekannt, bei beiden Wahlen das Haus Habsburg im Stiche ließen. Zuerst war es beide Male Chodkiewicz, der, wie dies Cyrus schon 1572 befürchtet hatte, sich ron der österreichischen Partei lossagte, obwohl ihm wirklich der Fürstentitel, das goldene Vließ und reiche Belohnungen für ihn und seine Verwandten in Aussicht gestellt wurden ${ }^{3}$ ); zu seinem Abfall, der angesichts seines großen Einflusses in Litauen von schwerwiegenden Folgen war, hatten, außer Maximilians II. zögernder Haltung, auch seine Beziehungen zu seinem polnischen Schwager Zborowski und, wie sich nicht leugnen läßt, seine nicht genügend befriedigten Geldforderungen ${ }^{4}$ ) beigetragen. Am längsten harrten, besonders im zweiten Interregnum, die Radziwiłł beim Kaiser aus ${ }^{5}$ ), die ja auch noch bei der dritten Königswahl im Jahre 1587 dank ihrer steten Verbindungen mit den Habsburgern den einzigen Stützpunkt der österreichischen Kandidatur in der litauischen Reichshälfte bilden sollten ${ }^{6}$ ).

Schließlich waren auch immer im entscheidenden Momente die verhängnisvollen Folgen des Mangels an Solidarität zwischen den litauischen Magnatenfamilien deutlich hervorgetreten. 1573 war es der schon erwähnte Fürst Stucki, der die Partei der Chodkiewicz und Radziwiłł in Polen geheimer Wahlintriguen anklagte ${ }^{7}$ ); während des zweiten

1) Diese bisher wenig beachtete (vgl. aber W. Zakrzewski, S. 344 Anm. 1) Urkunde ist bei Eichhorn, o. c., Beil. V, aus dem Archiv der Radziwiłł veröffentlicht worden.

2) Biblioteka ordyn. Krasińskich 1872, S. 279 Anm. (Antwort des Kaisers rom 22. November 1575 aut die Gesandtschaft Georg Radziwiłłs); vgl. die eingehende Darstellung der damaligen österreichisch-moskauischen Beziehungen bei Uebersberger, I $403 \mathrm{ff}$, $438 \mathrm{ff}$.

s) Wierzbowski, o. c., III 438/9.

4) Uchańsciana, V 581; vgl. Bibl, ord. Krasińskich 1872, S. 274 Anm.

5) Acta histor. res gestas Poloniae illustr. XI nr. 22.

-) Vgl. Uebersberger, I 511.

7) Diese schon von Heidenstein exzählte Tatsache muß selbst J. Eappo (I S. 101) zugeben, der sonst immer die Solidarität der litauischen Herren betonen möchte; vgl. auch Traczewskij, S. 344/6 und die Quellen in den Anm. S. 46. 
Interregnums hatte er sich den Radziwiłł genähert, aber nun waren es wieder Chodkiewicz und Hlebowicz, die ihn, um jene nicht zu mächtig werden zu lassen, ihnen abwendig zu machen suchten ${ }^{1}$ ). Sogar als es am 1. November 1574 in Wilna zu einer Konföderation des litauischen Adels gekommen war, die sich verpflichtete, nur Erzherzog Ernst zu wählen ${ }^{2}$ ), waren es vor allem die Radziwiłł und die ihnen nahestehenden Familien Wolowicz, Kiszka, Pac u. s. w., die diesen allerdings nur 26 Unterschriften zählenden Akt zustandegebracht hatten. Das Wahldekret Kaiser Maximilians vom 31. Dezember $1575^{3}$ ), der einzige, aber nicht realisierte Erfolg der habsburgischen Thronbewerbung, bei dem selbst Johann Chodkiewicz schon fehlte, trägt, selbst wenn man den vorhin erwähnten Sawicki mitrechnet, bloß 19 litauische Unterschriften.

Trotzdem also, wie wir sahen, die österreichische Kandidatur in Litauen bei den verschiedensten Parteien beliebt war, wozu nicht wenig der Umstand beitrug, daß sie einen Frieden mit Moskau zu ermöglichen versprach 4), trotzdem selbst die polnischen Anhänger der Habsburger in Litauen die Hauptstütze dieser Kandidatur sahen ${ }^{5}$ ), ja selbst die Sonderwahl eines Erzherzogs auf den litauischen Thron in den Bereich der Möglichkeit gezogen wurde, brachten des Kaisers Bemühungen, durch die habsburgische Partei in Litanen eine günstige Entscheidung zu erreichen, keinen Erfolg. Die Hauptursache davon war, daB diese Bemühungen eben nichts anderes waren, als eine Fortsetzung der schon Jahrzehnte zurückreichenden Bezielungen der Habsburger zu einzelnen Familien des litauischen Hochadels.

So lange wirklich einzelne Magnaten Litauens Politik entschieden, konnten, wie wir in den vorhergehenden Abschnitten sahen, diese Beziehungen für das kaiserliche Haus manchmal von Nutzen sein, obwohl schon damals die gegenseitigen Rivalitäten und ausschließlich selbstsüchtigen, ehrgeizigen Motive jener Herren die Bildung einer einheitlichen österreichischen Partei illusorisch machten. Seitdem aber die Verbindung mit Polen nicht nur einer Oberschicht des litauischen Adels

1) Acta historica $\mathrm{XI} \mathrm{nr}, 6$.

2) Veröffentl. bei Eappo, I 117 Anm. 3, wo aber leider von den 26 Namen nur die ersten 10, darunter 3 Radziwiłł, angegeben sind.

s) Uchańsciana, II nr. 154, vgl. auch I nr. 197.

4) Vgl. u. a. die bezeichnenden Stellen in Nik. Chr. Radziwiłł's Brief an Joh. Zamoyski rom 6. September 1574 (Archiwum Jana Zamoyskiego, I nr. 53 S. 71) und in Bischof Krasiński's Wahlrede 1575 (Bibl. ord. Krasińskich 1872, S. 290). Dudič).

5) W. Zakrzewski, S. 298 Anm. 2 (aus einem Schreiben P. Myszkowski's an 
westeuropäische Kultureinflüsse vermittelte, sondern ihn in seiner Gesamtheit za einem freiheitlichen, regen politischen Leben geweckt hatte, war jene in sich selbst uneinige Gruppe von Oligarchen, welche diesen historischen Prozeß rückgängig machen wollte, nicht mehr von der entscheidenden Bedeutung wie einst. Diese Wendung am Ausgange der Jagellonenzeit hatte zur Folge, daß es den Habsburgern keinen Nutzen brachte, schon mit den Ahnen der nunmehrigen Oppositionspartei Beziehungen angeknüpft zu haben. 